$$
\begin{aligned}
& \text { University of Szeged } \\
& \text { Faculty of Pharmacy }
\end{aligned}
$$

Graduate School of Pharmaceutical Sciences

Department of Pharmacognosy

\author{
Ph.D. Thesis
}

\title{
Isolation of bioactive phenolic compounds from the root bark of Morus nigra
}

\section{Zoofishan Zoofishan}

Supervisor

Attila Hunyadi, Ph.D.

Szeged, Hungary

2020 


\section{LIST OF PUBLICATIONS*}

The thesis is based on the following publications:

I. Zoofishan, Z., Kúsz, N., Csorba, A., Tóth, G., Hajagos-Tóth, J., Kothencz, A. Gáspár, R., Hunyadi, A. (2019). Antispasmodic Activity of Prenylated Phenolic Compounds from the Root Bark of Morus nigra.

Molecules, 24(13), 2497.

IF $3.267(\mathrm{Q} 1)$

II. Heger V., Benesova B., Viskupicova J., Majekova M., Zoofishan Z. , Hunyadi A., Horakova L. (2020). Phenolic compounds from Morus nigra regulate viability and apoptosis of pancreatic $\beta$-cells possibly via sarcoplasmic/endoplasmic reticulum (SERCA) activity.

ACS Medicinal Chemistry Letters, 11(5), 1006-1013.

IF $3.975(\mathrm{Q} 1)$

Other publication closely related to the thesis

III. Zoofishan, Z., Hohmann, J., \& Hunyadi, A. (2018). Phenolic antioxidants of Morus nigra roots, and antitumor potential of morusin.

Phytochemistry Reviews, 17(5), 1031-1045.

IF $4.400(\mathrm{Q} 1)$

${ }^{*}:$ Latin numerals of the corresponding publications related to this thesis will be referenced in this dissertation. 


\section{TABLE OF CONTENTS}

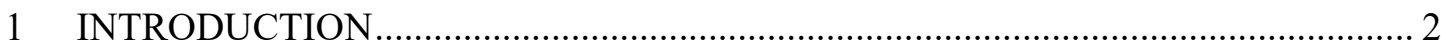

2 LITERATURE OVERVIEW …………………………………………………..... 3

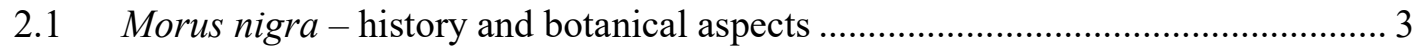

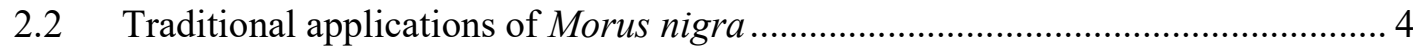

2.3 Chemical overview of the Morus nigra roots .................................................. 5

2.4 Pharmacology of phenolic compounds present in Morus nigra root bark............. 9

2.4.1 Antioxidant activity of Morus nigra root bark ............................................ 9

2.4.2 Anti-inflammatory activity of Morus nigra root bark ................................ 11

2.4.3 Antidiabetic effects of phenolic compounds from Morus nigra root bark.... 11

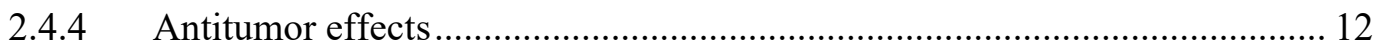

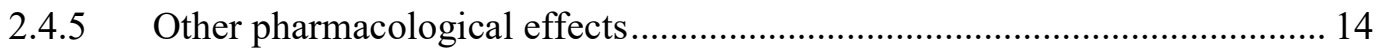

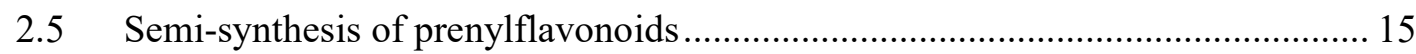

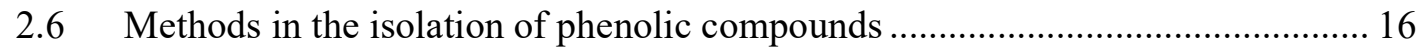

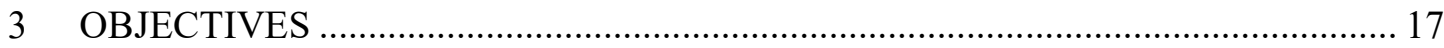

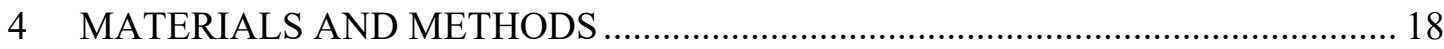

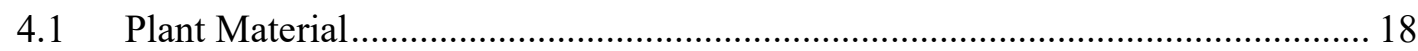

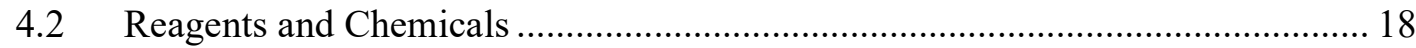

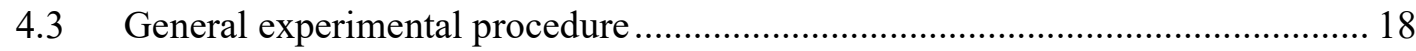

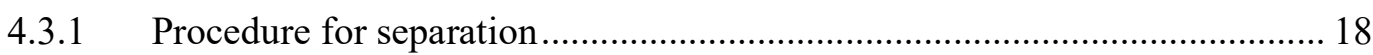

4.3.2 Procedure for structural elucidation ........................................................... 19

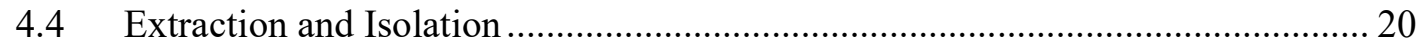

4.4.1 Extraction and pre-purification of the crude extract.................................... 20

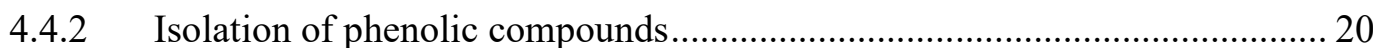

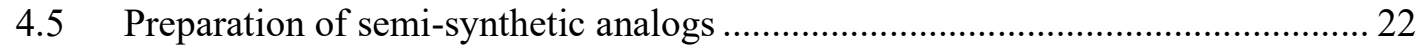

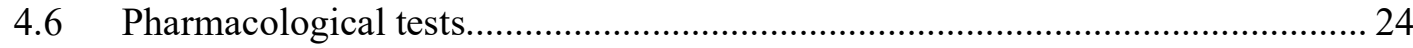

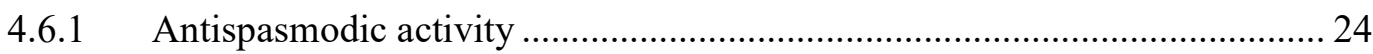

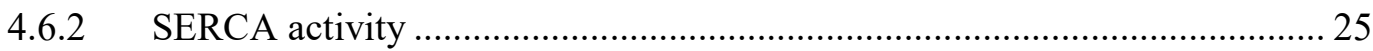

4.6.3 Anti-proliferative activity of synthesized morusin metabolites ................... 26 
4.6.4 Efflux pump inhibition activity of the oxidized metabolite of morusin ........ 26

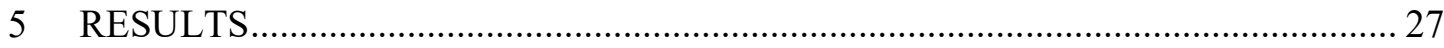

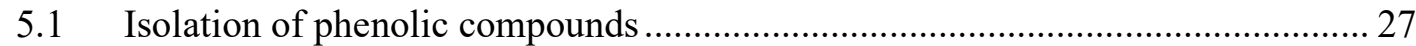

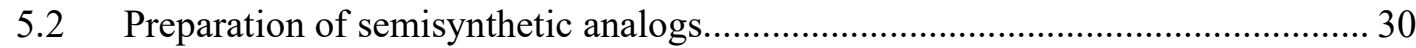

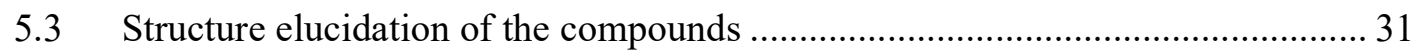

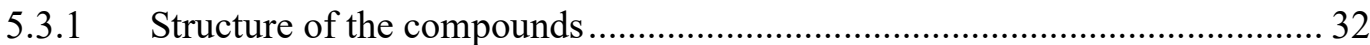

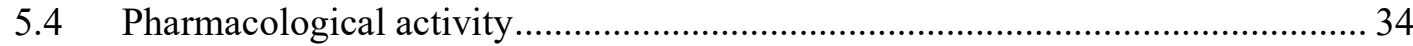

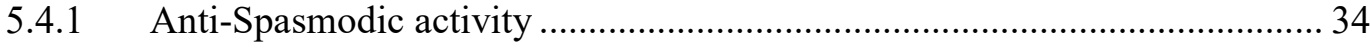

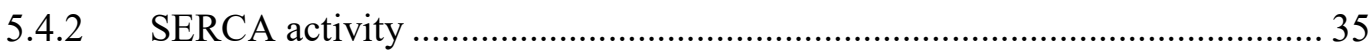

5.4.3 Antitumor activity on human breast cancer cells ........................................ 36

5.4.4 Antitumor and efflux pump inhibitory activity on an MDR cancer cell model 37

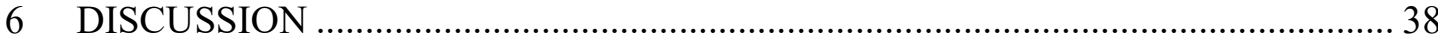

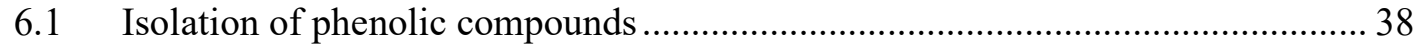

6.2 Preparation of Semi-synthetic derivatives ......................................................... 40

6.3 Structure elucidation of the compounds obtained.............................................. 41

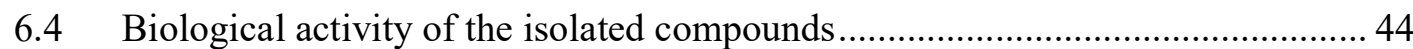

6.4.1 Antispasmodic activity of the isolated compounds ................................. 44

6.4.2 SERCA activity of the isolated phenolic compounds .................................. 45

6.4.3 Anti-tumor activity of semi-synthetic morusin analogs .............................. 46

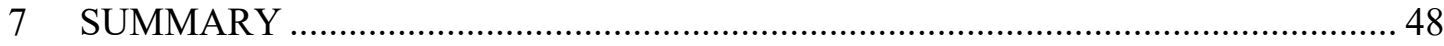

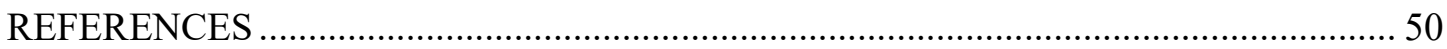

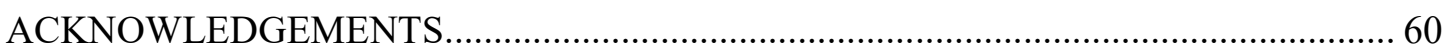

APPENDIX 


\begin{tabular}{|c|c|}
\hline \multicolumn{2}{|c|}{ ABBREVIATIONS } \\
\hline $\mathrm{ACN}$ & Acetonitrile \\
\hline $\mathrm{CC}$ & Column chromatography \\
\hline $\mathrm{CDCl}_{3}$ & Chloroform \\
\hline $\mathrm{CH}_{2} \mathrm{CL}_{2}$ & Dichloromethane \\
\hline${ }^{13} \mathrm{C}$ NMR & Carbon Nuclear magnetic resonance \\
\hline COSY & Correlation spectroscopy \\
\hline DMSO & Dimethyl sulfoxide \\
\hline DPPH & 1,1-Diphenyl-2-picrylhydrazyl \\
\hline EtOAc & Ethyl acetate \\
\hline $\mathrm{EtOH}$ & Ethanol \\
\hline${ }^{1} \mathrm{H}$ & Proton Nuclear magnetic resonance \\
\hline HMBC & Heteronuclear multiple-bond correlation spectroscopy \\
\hline HSQC & Heteronuclear single-quantum coherence spectroscopy \\
\hline $\mathrm{MeOH}$ & Methanol \\
\hline MP & Mobile Phase \\
\hline NP-FC & Normal phase flash chromatography \\
\hline NMR & Nuclear magnetic resonance \\
\hline NO & Nitric Oxide \\
\hline OS & Oxidative stress \\
\hline $\mathrm{Pd} / \mathrm{C}$ & Palladium on carbon \\
\hline RNS & Reactive nitrogen species \\
\hline ROS & Reactive oxygen species \\
\hline RP-FC & Reverse phase flash chromatography \\
\hline r.t. & Room temperature \\
\hline SAR & Structure-activity relationship \\
\hline SERCA & Sarco/endoplasmic reticulum $\mathrm{Ca}^{2+}$ - ATPase \\
\hline SP & Stationary Phase \\
\hline TCM & Traditional Chinese Medicine \\
\hline TLC & Thin layer chromatography \\
\hline
\end{tabular}




\section{INTRODUCTION}

In modern medicine, herbal drugs and natural products are important raw materials for the pharmaceutical industry, and isolated pure compounds serve as leads in drug discovery and development. The evolving recognition of a significant number of natural, nature inspired compounds among approved drugs demonstrates well the importance of natural products research, therefore it is considered that this area of research should be expanded significantly [1]. Among natural products, phenolic compounds have attracted a particularly high attention over the last decades due to their antioxidant potential [2]. Several studies suggest that the antioxidant property of various classes of phenolic compounds might be beneficial in the prevention and/or treatment of diseases whose pathomechanism and/or progression is closely connected to oxidative stress [3-6].

Prenylated phenolics are an outstanding subclass of naturally occurring phenolic compounds with relatively narrow distribution among plant species according to phytochemical literature [7, 8]. The prenyl, isoprenyl or 3-methyl-2-buten-1-yl is a terpenoid side chain present at one or more specific positions of the phenolic skeleton, connected via carbon or oxygen, or both. A major advantage of carbon-carbon type prenyl substitution is that such a bond is non-hydrolyzable and generally stable, and therefore it leads to a stable increase in the lipophilicity as compared to the non-substituted compound [8]. Accordingly, the combination of prenyl group(s) with a phenolic backbone leads to an interesting combination of physicochemical properties, and compounds that join the properties of terpenoids and phenolic compounds. This frequently leads to interesting bioactivity [9-12] profiles. Chemical diversity of such compounds is also greatly increased by the possibility of forming adducts through enzymatic Diels-Alder type reactions between the prenyl groups of the aromatic backbone and other olefins e.g. that present in chalcones [13]. Subsequent natural oxidation and cyclization reactions of such Diels-Alder adducts can result in highly complex structures. This attracted a significant attention from synthetic chemistry, and many related semi-synthetic analogs have been prepared to serve as lead compounds for possible drug discovery initiatives [14, 15].

The majority of prenylated phenolics have been isolated from the Moraceae plant family, with few arising from other genera [8]. Morus, a genus from the Moraceae family, has provided several traditional medicines in Asian countries. Because of the ancient tradition of sericulture, i.e. silk farming, Morus alba is the dominant and best studied Morus species. 
However, a survey of the pertinent literature indicates that $M$. nigra (black mulberry) is an at least similarly rich source of phenolic compounds as M. alba (white) but is much less studied even though it had also been naturalized in Europe centuries ago.

\section{LITERATURE OVERVIEW}

\subsection{Morus nigra - history and botanical aspects}

The Morus genus, belonging to the Moraceae family, comprises twenty-four species with one subspecies, and has ca. one hundred known varieties to date $[16,17]$. Well known as the "black mulberry tree", Morus nigra L. has long been valued for its fruit, which has also been claimed as a "super fruit" that has various health benefits and promotes longevity [18]. Morus nigra is a wildly growing rustic plant that is also present in many gardens and, similarly to other Morus species, and M. alba in particular, it was also used for sericulture $[19,20]$. The plant has a long and remarkable history. Likely introduced to Europe originally from Persia, its cultivation on the Continent appears to date back thousands of years [21]. The ancient Greeks dedicated the fruit to Minerva, the goddess of wisdom recognizing its medicinal value. Black mulberry was abundant in Italy during the Roman era; it was also depicted in the paintings from Pompeii (Georgics ii verse 121). The fruits pips have been found from the House of the Vestals and the House of Hercules' Wedding in Pompeii [22], and the Desiccated pips have been recovered from the Roman quarry settlement of Mons Claudianus in the eastern desert of Egypt [23] suggesting its cultivation in ancient Egypt. Mulberry has also been acknowledged in the Bible (I Maccabees 6:34; Luke 17:5-6). Black mulberry leaves were considered as the feed for Italian silkworms until 1434 A.D. when Morus alba was introduced from the Levantine lands [24]. During the "silk revolution" in 1608, the practice of sericulture was introduced to Britain by promoting mulberry cultivation [25]. Although its medicinal use was an ancient practice, it was the growing silk industry that brought this plant into the spotlight, resulting in the worldwide spreading of mulberry trees to satisfy industrial needs for mulberry leaves [26]. Despite black mulberry is, in fact, more nutritive than M. alba, the white mulberry [27], its importance has been surpassed because of its weaker success in feeding silkworms. The nutritive richness of black mulberry, however, still makes it an excellent animal feed that also enhances the milk yield of dairy animals [28]. 
As far as morphological characteristics are concerned, mulberry is a slow-growing perennial deciduous moderate-size tree or shrub with vigorous branches forming crown producing a shady canopy. The plant has a deep taproot, lateral or horizontal roots that remain in the first 24 inches of soil with root hairs. The stem is erect, strongly covered with green, grey to pink or brown bark, depending upon the species, climate, and origin. The shoot of a mulberry tree may reach up to 6 to 9 meters in height. $M$. nigra often produces leaves of different shapes, and these multilobed leaves can appear on the same branches. The leaves are alternate, simple, serrate or dentate, ovate to broadly ovate, and two to seven inches long. High temperatures, strong light and long days favor maleness in mulberries, with their opposites, as well as high humidity, favoring the production of female flowers. The inflorescence in the mulberry plant is considered as a catkin and the plant is either monoecious or dioecious. The flowers are small, greenish, crowded in clusters, and hanging in the form of, male and female catkins. The pollinated female catkin forms a thick collective fruit. The fruit is blackberry-shaped typically black but sometimes dark blue with a sweet taste. Despite popular belief, the color of the fruit alone does not determine the mulberry species; instead, the leaves and wood characteristics should be considered for exact identification [20]. The longevity of plants is due to their ability to withstand harsh conditions such as tolerance of droughts, infertile and rocky soil, resistance to cold giving it a life expectancy of more than 500 years [25].

\subsection{Traditional applications of Morus nigra}

Black mulberry is valued not only for its nutritional qualities and flavor but also for its use in traditional medicine. The long medicinal history of $M$. nigra includes its therapeutic use in practically every era of traditional medicine, under different names, and with various, frequently different uses in each system [29]. For example, preparations from the plant had been used by the ancient Egyptians for corroding ulcers, dispersing inflamed tumors and healing of wounds. The juice of bark was used as an antidote to the venom of deadly snakes [30]. During medieval times in the eastern Mediterranean, M. nigra had been popular for the treatment of renal stones and urinary disorders [26, 31]. Drugs of M. nigra are well-known ingredients for many preparations in the Ayurveda, one of the oldest holistic healing systems dating ca. 600 B.C. $[32,33]$. Many of these formulations are still in use in different systems of medicine, for example, "Tut-i-aswad" in Unani medicine for cancer, 
contains fruits of black mulberry [34], or Rub-e-toot siyah, an ayurvedic remedy for a sore throat or laryngitis [35]. The roots of Morus plants were recorded in the Chinese pharmacopeia in 500 B.C. collectively known as Sang-Bai-Pi often used for treating lung heat, cough, edema, and oliguria [36]. During the $16^{\text {th }}$ century, the tincture of M. nigra roots was used to gain relief from toothache [37]. Bark and leaves of black mulberry are known folk remedy used for lowering and controlling blood sugar and is widely used in tea blends for diabetes [38]. They also can treat conjunctivitis, lower limb swelling, keratitis, hypertension and skin rashes [16, 37, 39-41]. The bark is used to expel tapeworms, and as a diuretic agent $[42,43]$. The root bark is anthelmintic and it is used to treat bronchitis [44]. The decoction of the root bark is bitter but it is believed to help in "detoxing the belly" [45]. The plant has been used in traditional medicine to treat gastrointestinal ailments [46]. This wide range of traditional uses indicates well the pharmacological versatility of $M$. nigra and the chemical complexity of its secondary metabolite composition behind.

The root bark of $M$. nigra also plays an important economic role through its various uses providing livelihood to people. The pruned and dead roots are suitable for firewood. The root barks and leaves yield a yellow dye, used mainly for heightening the sheen on silk. In Japan, a textile fiber is extracted from the bark. It is also used to prepare 'artificial cotton' paper and clothes $[19,47]$.

\subsection{Chemical overview of the Morus nigra roots}

Bioactive constituents of Sang-Bai-Pi, the root bark of various Morus plants, have been studied extensively in the last few years, and this indicates well the very high current scientific interest in these plants. The most characteristic compounds of Morus species are phenolics including flavonoids, stilbenes, 2-arylbenzofurans, and a variety of Diels-Alder adducts $[48,49]$, and, according to many comparative studies, $M$. nigra appears to be the richest of all in this regard [16, 50-52]. As an example, a comparison with M. alba revealed that $M$. nigra has a higher content of reduced ascorbic acid, titratable acidity, iron, total flavonoids and total monomeric anthocyanins [53].

In particular, the root bark of $M$. nigra contains a remarkable variety of prenylflavonoids isolated in the last several years with a chemical diversity due to their variability in their substitution pattern, and many of these substituents open possibilities to further cyclization as summarized in Figure 1 [52, 54-60]. Structurally, the prenyl side chain on 
flavonoids predominantly occurs as $C$-prenylated, at positions 6 and/or 8 , as well as $3^{\prime}$ and/or 5', whereas a few studies also reported occurrence of $O$-prenylation [7]. Three geranylflavonoids, each containing the geranyl group connected to $\mathrm{C}-5^{\prime}$ on the B-ring, have also been reported from the roots, one flavone and two flavanones [60]. Such a longer side chain may facilitate transport of a phenolic substance into and through the cell membranes and sometimes may also contribute to the biological activity. Most of the reports suggest that the position and the nature of these side chains lead to some relevant SAR conclusions concerning a broad spectrum of biological activities [61, 62].

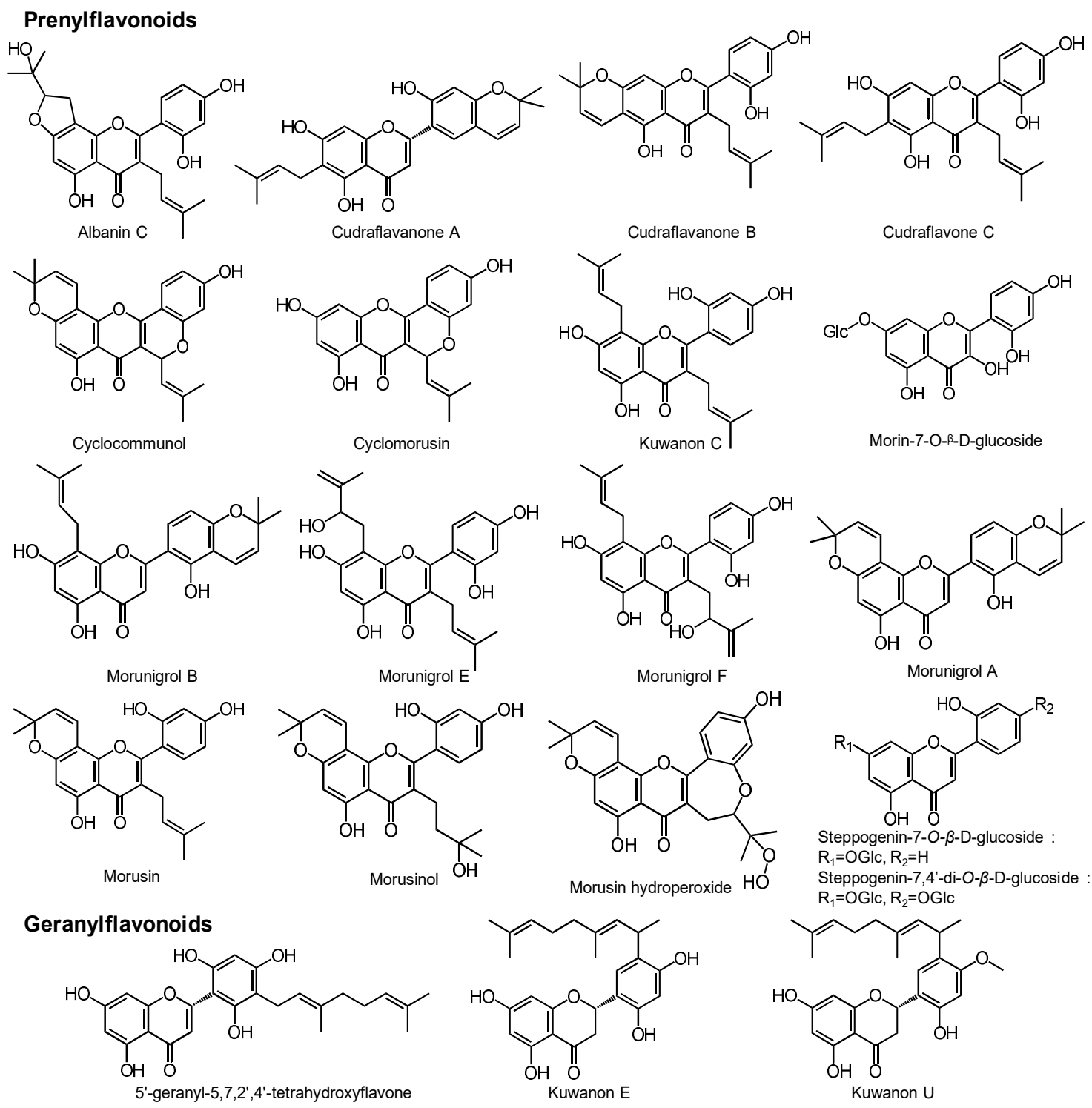

Figure 1. Prenyl and geranylflavonoids from Morus nigra roots 
Chalcones were isolated as minor compounds from the roots and an immense variety of Diels-Alder, often formed by the [4+2]-Cycloaddition of a conjugated diene and a dienophile to form a six-membered derivative are known to occur in the M. nigra, roots as summarized in Figure 2 [60]. The structural complexity of these compounds results in promising bioactivities [63].

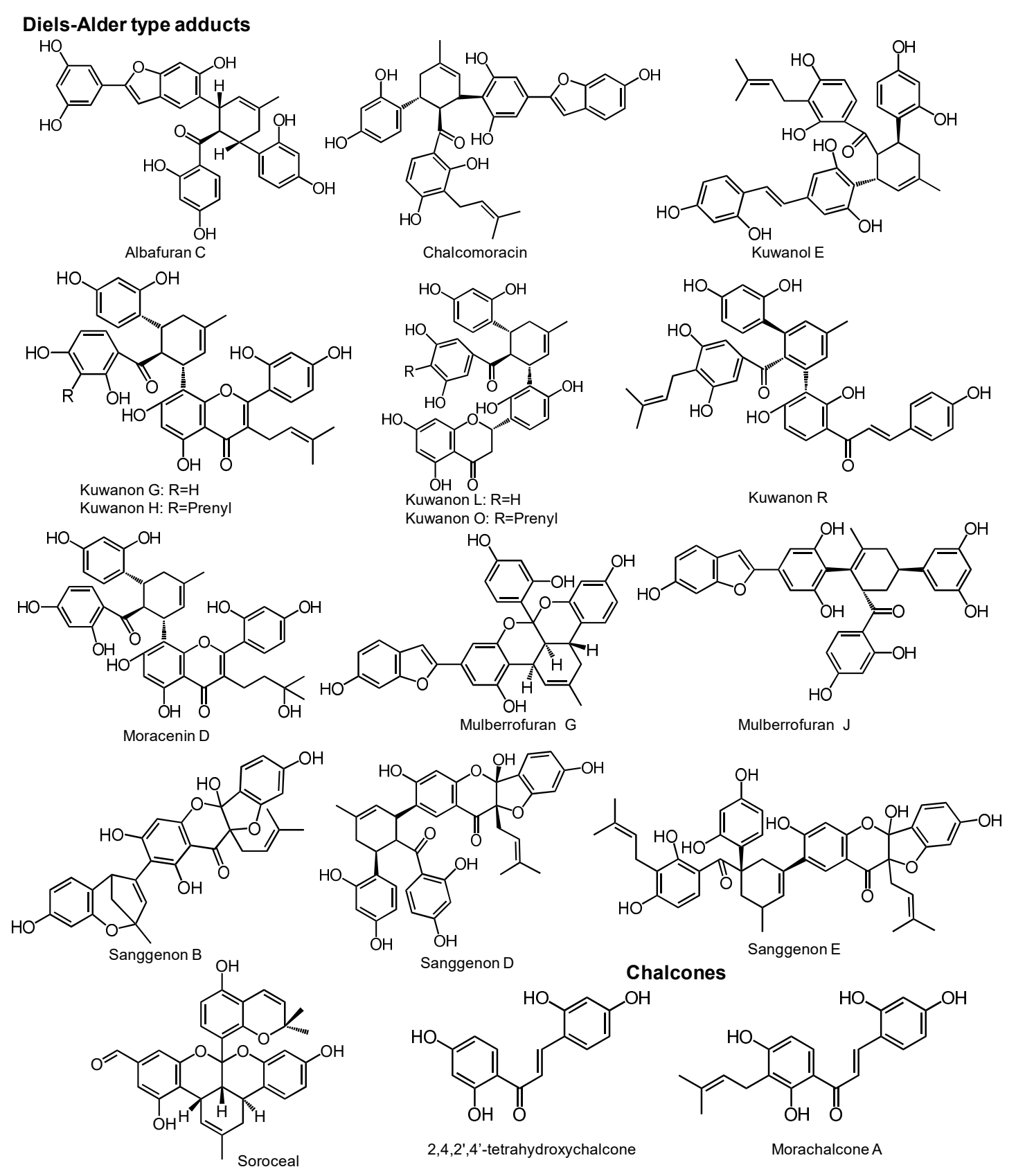

Figure 2. Diels-Alder type adducts and Chalcones from the roots of Morus nigra. 
M. nigra has been widely acknowledged as a rich source of bioactive benzofuran derivatives and stilbenes, among which the 2-arylbenzofurans are commonly substituted by prenyl and geranyl groups. [64]. Various bioactivities (e.g. antifungal, antibacterial, etc.) associated with benzofuran derivatives make these compounds attractive subjects for medicinal chemistry studies $[65,66]$. Similarly to prenylflavonoids, benzofurans can also inhibit nitric oxide synthase, thus indirectly inhibiting the release of a major inflammatory mediator, nitric oxide $[57,59,60]$.

\section{Arylbenzofurans}<smiles>[R]c1c(O)cc(-c2cc3c([R])c([R])c([R])c([R])c3o2)c([R])c1[R]</smiles>
Albafuran A: $\mathrm{R}_{1}=\mathrm{H}, \mathrm{R}_{2}=\mathrm{H}, \mathrm{R}_{3}=\mathrm{OH}, \mathrm{R}_{4}=\mathrm{H}, \mathrm{R}_{5}=\mathrm{H}, \mathrm{R}_{6}=\mathrm{OH}, \mathrm{R}_{7}=$ geranyl
Albafuran B: $\mathrm{R}_{1}=\mathrm{H}, \mathrm{R}_{2}=\mathrm{H}, \mathrm{R}_{3}=\mathrm{OH}, \mathrm{R}_{4}=\mathrm{H}, \mathrm{R}_{5}=$ geranyl, $\mathrm{R}_{6}=\mathrm{OH}, \mathrm{R}_{7}=\mathrm{H}$
Moracin C: $\mathrm{R}_{1}=\mathrm{H}, \mathrm{R}_{2}=\mathrm{H}, \mathrm{R}_{3}=\mathrm{OH}, \mathrm{R}_{4}=\mathrm{H}, \mathrm{R}_{5}=$ prenyl, $\mathrm{R}_{6}=\mathrm{OH}, \mathrm{R}_{7}=\mathrm{H}$
Moracin M: $\mathrm{R}_{1}=\mathrm{H}, \mathrm{R}_{2}=\mathrm{H}, \mathrm{R}_{3}=\mathrm{OH}, \mathrm{R}_{4}=\mathrm{H}, \mathrm{R}_{5}=\mathrm{H}, \mathrm{R}_{6}=\mathrm{OH}, \mathrm{R}_{7}=\mathrm{H}$
Moracin N: $\mathrm{R}_{1}=\mathrm{H}, \mathrm{R}_{2}=$ prenyl, $\mathrm{R}_{3}=\mathrm{OH}, \mathrm{R}_{4}=\mathrm{H}, \mathrm{R}_{5}=\mathrm{H}, \mathrm{R}_{6}=\mathrm{OH}, \mathrm{R}_{7}=\mathrm{H}$
Mulberrofuran B: $\mathrm{R}_{1}=\mathrm{H}, \mathrm{R}_{2}=\mathrm{H}, \mathrm{R}_{3}=\mathrm{OMe}, \mathrm{R}_{4}=$ geranyl, $\mathrm{R}_{5}=\mathrm{H}, \mathrm{R}_{6}=\mathrm{OH}, \mathrm{R}_{7}=\mathrm{H}$
Mulberrofuran L: $\mathrm{R}_{1}=\mathrm{H}, \mathrm{R}_{2}=\mathrm{H}, \mathrm{R}_{3}=\mathrm{OH}, \mathrm{R}_{4}=$ geranyl, $\mathrm{R}_{5}=\mathrm{H}, \mathrm{R}_{6}=\mathrm{OH}, \mathrm{R}_{7}=\mathrm{H}$<smiles>Oc1cc(O)cc(-c2cc3c4c(ccc3o2)OC4(c2cc(O)cc(O)c2)c2ccc(O)cc2O)c1</smiles><smiles>CC(C)(O)C1Cc2cc3cc(-c4cc(O)cc(O)c4)oc3cc2O1</smiles><smiles>Oc1cc(O)cc(/C=C/c2ccc(O)cc2O)c1</smiles><smiles>C=C(C)CCC/C(C)=C/Cc1c(O)cc(O)cc1-c1cc2ccc(O)cc2o1</smiles>

Morunigrol D<smiles>[R]c1cc(O)cc(/C=C/c2ccc([R])cc2[R9])c1</smiles>

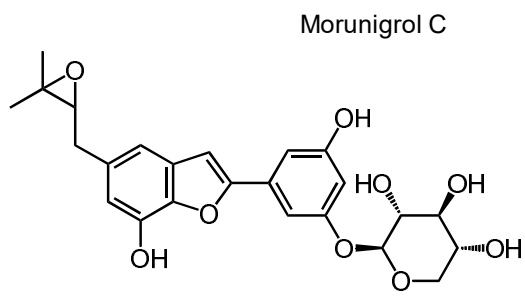

Moracinoside M

Mulberroside $\mathrm{A}: \mathrm{R}_{1}=\mathrm{OH}, \mathrm{R}_{2}=\mathrm{OGlc}, \mathrm{R}_{3}=\mathrm{Oglc}$

Oxyresveratrol: $\mathrm{R}_{1}=\mathrm{OH}, \mathrm{R}_{2}=\mathrm{OH}, \mathrm{R}_{3}=\mathrm{OH}$

Oxyresveratrol-2-O- $\beta$-D-glucopyranoside: $\mathrm{R}_{1}=\mathrm{OGlc}, \mathrm{R}_{2}=\mathrm{OH}, \mathrm{R}_{3}=\mathrm{OH}$

Oxyresveratrol-3-O- $\beta$-D-glucopyranoside: $\mathrm{R}_{1}=\mathrm{OH}, \mathrm{R}_{2}=\mathrm{OH}, \mathrm{R}_{3}=\mathrm{OGlc}$

Figure 3. 2-Arylbenzofurans and stilbenes from the roots of Morus nigra.

Coumarin glycosides are also known to be present in the roots of Morus nigra. Among these, mulberroside B is a $C$-glycoside at C-6, while the others are $O$-glycosides containing one or two sugar components connected to the coumarin skeleton. In each of the latter ones, the coumarin bears an $O-\beta$-D-glucoside at $\mathrm{C}-7$, which can be further glycosylated with a 6-deoxymannose or an apiose. 
<smiles>O=c1ccc2c(O)cc(OC3OC(CO)C(O)[C@H](O)C3O)cc2o1</smiles>

Mulberroside B<smiles>[Y4]O[Na]</smiles><smiles>O=c1ccc2c(O)c(C3OC(CO)C(O)C(O)[C@H]3O)c(O)cc2o1</smiles>

5,7-dihydroxycoumarin-7- $\beta$-Dglucopyranoside

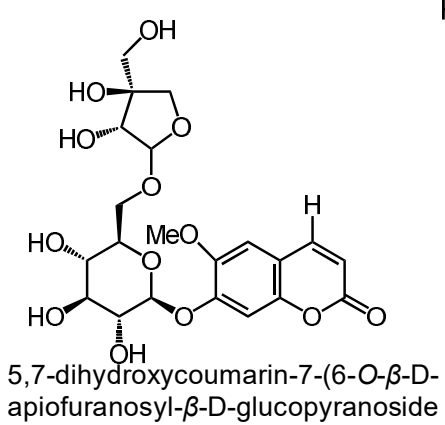<smiles>CC1OC(OCC2OC(Oc3ccc4ccc(=O)oc4c3)C(O)C(O)C2O)C(O)[C@@H](O)C1O</smiles>

7-[[6-O-(6-deoxy-a-Lmannopyranosyl)$\beta$-D-glucopyranosyl]oxyl]-2H-1benzopyran-2

Figure 4. Coumarins from the roots of Morus nigra.

\subsection{Pharmacology of phenolic compounds present in Morus nigra root bark}

Since the roots of Morus nigra are very rich in phenolic compounds, several biological effects might reasonably be expected to significantly contribute at least to some of the health benefits of the drug [67].

\subsubsection{Antioxidant activity of Morus nigra root bark}

Numerous publications reported in vitro antioxidant studies of root bark and its constituents. Strong free radical scavenging effect was reported on various extracts of black mulberry fruits, leaves or roots $[37,68]$ and/or phenolic constituents in a number of in vitro experimental models, and the inhibition of xanthine oxidase or lipid peroxidation was also reported $[50,69,70]$. Among individual compounds, morusin, a major constituent of M. nigra roots, was reported to inhibit superoxide formation from rat neutrophils stimulated with phorbol myristate acetate (PMA) [71]. The benzofurans moracin $\mathrm{C}$ and $\mathrm{N}$ were reported to scavenge superoxide anion radicals and inhibit lipid peroxidation [72]. In a study aiming to assess the antioxidant activity of four arylbenzofuran derivatives, moracin $\mathrm{C}, \mathrm{P}$, and $\mathrm{M}$, and mulberroside $\mathrm{C}$, two compounds, moracin $\mathrm{C}$ and $\mathrm{M}$ were found particularly effective in the inhibition of malondialdehyde production during microsomal lipid peroxidation induced by ferrous cysteine [73]. The stilbene oxyresveratrol exerted considerable superoxide scavenging effects [74]. Among many other compounds in a series of studies, albanol B, moracin $\mathrm{M}$, and mulberrofuran $\mathrm{G}$ were found particularly effective in 
the two most common in vitro test for free radical scavenging, namely the 2,2'-azinobis-3ethylbenzothiazoline-6-sulfonic acid (ABTS) and 1,1-diphenyl-2-picrylhydrazyl (DPPH) assays $[75,76]$, while for example the prenylflavonoids morusin and kuwanon $\mathrm{C}$ showed moderate DPPH radical scavenging activity [77]. Reports on the in vivo antioxidant activity of $M$. nigra are only available for the fruits and leaves, whose compositions certainly show overlaps with that of the roots. Oral administration of crude, $95 \%$ ethanol extract of $M$. nigra fruits to mice resulted in decreasing malondialdehyde (MDA) content in the serum and liver, accompanied by an increase of superoxide dismutase (SOD), catalase (CAT) and glutathione peroxidase (GSH-PX) activity[78]. In another study, the leaves of Morus nigra were tested for their antidiabetic and antioxidant activity on streptozotocin-induced diabetic rats, focusing on the maternal-fetal outcome. The aqueous extract was used, and while it was unable to control blood glucose levels, it demonstrated a potent in vivo antioxidant activity: increased SOD activity, decreased MDA levels were found, and the offsprings from diabetic dams showed a reduced incidence of skeletal and visceral anomalies upon treatment [79]. Concerning the in vivo antioxidant activity of isolated pure compounds, a number of studies have been published on the stilbene mulberroside A, a diglycoside of oxyresveratrol, obtained from Morus bombycis but also reported from Morus nigra roots. Antioxidant properties of this compound have been reported in connection with its antidiabetic and liver protective activity. Oral treatment of STZ-induced diabetic rats with $200-800 \mathrm{mg} / \mathrm{kg}$ of mulberroside A led to an improvement in several diabetic markers including a slight decrease in blood glucose, significant decrease in serum aspartate aminotransferase (AST), alanine aminotransferase (ALT), and blood urea nitrogen, and significant increase in plasma insulin levels. In addition to this, mulberroside A effectively decreased lipid peroxidation, so that no significant difference was found in this regard between the diabetic control animals and those treated with the smallest dose, $200 \mathrm{mg} / \mathrm{kg}$ [80]. Mulbrroside A also displayed a dose-dependent superoxide scavenging activity $\left(\mathrm{IC}_{50}=430 \mu \mathrm{g} / \mathrm{mL}\right)$ in vitro, the oral administration of $100-600 \mathrm{mg} / \mathrm{kg}$ of mulberroside A $30 \mathrm{~min}$ before inducing hepatotoxicity with $\mathrm{CCl}_{4}$ to rats exerted a similarly strong protective activity as silymarin, and significantly decrease AST and ALT levels[81]. Hepatoprotective activity exerted through an antioxidant action was also confirmed by the inhibition of in vitro lipid peroxidation on rat liver homogenate in the presence of $\mathrm{Fe}^{2+} /$ ascorbic acid and by the prevention of serious histopathological changes caused by the $\mathrm{CCl}_{4}$ treatment $[81,82]$. 


\subsubsection{Anti-inflammatory activity of Morus nigra root bark}

Anti-inflammatory effects of $M$. nigra root bark were reported along with the isolation of two of its constituents, morunigrol D and norartocarpetin, both of which showed potent anti-inflammatory activity by inhibiting the release of $\beta$-glucuronidase from rat polymorphonuclear leucocytes [83]. In a dose of $100-300 \mathrm{mg} / \mathrm{kg}$, the methylene chloride extract of $M$. nigra showed promising results in animal models by reducing carragenaninduced paw edema, and significantly inhibited the formation of granulomatous tissue [40].

Many compounds reported as anti-inflammatory in the literature have also been isolated from M. nigra roots. Morusin, oxydihydromorusin (morusinol), kuwanon C, mulberrofuran A, kuwanon $\mathrm{G}$, kuwanon $\mathrm{H}$, sanggenon $\mathrm{D}$, and mulberrofurans $\mathrm{G}$ and $\mathrm{J}$ showed considerable inhibition on arachidonate metabolism in rat platelets [84, 85]. Morusin, kuwanon C, and sanggenons B, D and E inhibited cyclooxygenase activity [4, 86, 87]. Oxyresveratrol inhibited the LPS-stimulated increase of inducible nitric oxide synthase (iNOS) expression [88]. Nitric oxide production was inhibited by moracins $\mathrm{C}, \mathrm{O}$ and $\mathrm{P}$, albafuran A, mulberrofurans $\mathrm{J}$, kuwanons $\mathrm{C}$ and $\mathrm{E}$, sanggenon $\mathrm{F}$, and morusin $[89,90]$. Kuwanon $J$ and $R$ inhibited NF- $\kappa B$ activity [91]. Cudraflavone $B$ inhibited the gene expression and secretion of tumor necrosis factor alpha (TNF- $\alpha$ ) by blocking the translocation of NF- $\mathrm{KB}[92,93]$. Kuwanons $\mathrm{E}$ and $\mathrm{G}$, and norartocarpanone significantly inhibited IL-6 production in lung epithelial cells (A549) and NO production in lung macrophages (MH-S) [94]. Moracin C, mulberrofuran Y, kuwanons C and E, oxydihydromorusin, and sanggenons $\mathrm{E}$ and $\mathrm{H}$ inhibited the secretion of TNF- $\alpha$ and IL-1 $\beta$, and NF- $\kappa$ B nuclear translocation in LPS-stimulated macrophages [59].

\subsubsection{Antidiabetic effects of phenolic compounds from Morus nigra root bark}

The aqueous extract of $M$. nigra leaves reduced MDA, Cholesterol, triglycerides and VLDL levels along with decreased placental index and weight. The fetuses of diabetic rats treated with $M$. nigra extract showed the frequency of skeletal and visceral anomalies as compared to the diabetic group [79]. The ethanol extract of $M$. nigra leaves reduced fasting and postprandial glycemia, improved oral glucose tolerance, increased insulin production, reduced lipolysis and proteolysis in diabetic rats, diminished lipid peroxidation, inhibited low-density lipoprotein (LDL) atherogenic modification and lipid peroxides formation, and increased the expression of adipogenic marker proteins, such as peroxisome proliferatoractivated receptors $\gamma($ PPAR $\gamma$ ) and GLUT4 (glucose transporter 4) [95-97]. 
Much of anti-hyperglycemic activities attributed to some functional components such as morusin, cyclomorusin, neocyclomorusin, kuwanon $\mathrm{E}$, moracin $\mathrm{M}$, steppogenin-4'-O- $\beta-\mathrm{D}-$ glucoside, mullberroside A [80]. Inhibitors for protein tyrosine phosphatase 1B (PTP1B) include mulberrofuran C, kuwanon L [75], albafuran A, kuwanon J, kuwanon R, [98]. Anti-hyperlipidemic compounds include mulberrofuran G, albanol B, morusin, sanggenon F [90], mulberroside A and oxyresveratrol [99].

\subsubsection{Antitumor effects}

The dimethyl sulfoxide extract of $M$. nigra fruits was investigated for its action on prostate cancer cells. The fruit extract showed potential cytotoxic activity through G1 phase cell cycle arrest of the in PC-3 cells at the along with the induction of apoptosis via increased caspase and reduced mitochondrial membrane potential [100]. The anticancer activity of $n$ hexane and aqueous methanol extract of M. nigra leaves were tested against the HeLa cancer cell line, and both extracts decreased viability of cancer cells in a dose-dependent manner [101].

Regarding individual cytotoxic compounds reported from the roots, morusin, a major constituent isolated from the root bark, has recently been thoroughly studied for its antitumor effects on cancer cell lines of various origins, including e.g. pancreas, cervical and colorectal [102-104]. Morusin induced apoptosis in HT-29 colorectal carcinoma cells through caspase 8 subsequently leading to the activation of caspase 9 and 3, and it was suggested to decrease phosphorylation of PDK1, PI3K, and Akt, leading to the

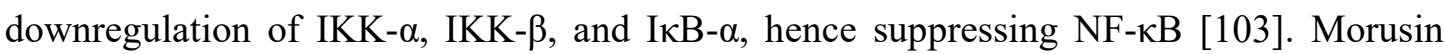
also demonstrated anti-invasive activity on SK-Hep1 cells in non-cytotoxic concentrations, and two key mechanisms were suggested to this: the suppression of the signal transducer and activator of transcription 3 (STAT3; an oncogene with an important role in cancer cell survival and proliferation), and the inhibitory effect on $\mathrm{NF}-\mathrm{\kappa B}$ signaling. The in vitro results were also confirmed in nude mice, whose lung metastasis upon intravenous injection with SK-Hep1 cells was reduced when pre-treated with morusin, and western blots of the lung tissues also gave consistent results with those observed in vitro [105]. STAT3 inhibition by morusin was also reported in various pancreatic carcinoma cell lines. Interestingly, morusin treatment led to an accumulation of different phases in the cell cycle depending on the tested pancreatic cell line, and induced both early and late apoptosis [102]. Considerable selectivity in the in vitro cytotoxic activity of morusin was observed in a variety of breast cancer cell lines as compared to immortalized normal breast MCF10A 
cells. When studying apoptosis-related proteins regulated by STAT3, suppression of the anti-apoptotic protein survivin and overexpression of the pro-apoptotic protein B-cell lymphoma 2-associated-x protein (Bax) was observed. The rate of apoptosis, however, was found lower than expected from the corresponding cytotoxicity results, suggesting that the effect of morusin also involves necrosis and/or autophagy [106]. This appears to be consistent with parallel results: morusin was found to indeed induce autophagy through activating AMPK and inhibiting mTOR, which increased cell survival. Co-treatment with the autophagy inhibitor 3-methyladenine, however, greatly increased the rate of apoptotic cells [107]

Several in vivo studies confirmed the above observations on the antitumor potential of morusin. It had a marked antitumor effect on $\mathrm{H}_{22}$ hepatocarcinoma-transplanted mice and, as a possible mechanism, the activity of morusin on the expression of $\mathrm{p} 53$, Survivin, CyclinB1, and particularly on that of caspase-3 and NF- $\kappa$ B was identified [108], coherently with previous reports. Morusin was most recently reported as an anti-angiogenetic agent: it was found to inhibit the proliferation, migration and tube formation of human umbilical vein endothelial cells (HUVECs) in vitro, and this was also confirmed by the in vivo inhibition of hepatocellular HepG2 xenografts' tumor growth and angiogenesis. Both constitutive and interleukin-6 (IL-6)-induced phosphorylation of STAT3 was inhibited by morusin, and VEGF, MMP2, MMP9, and VEGFR2 were down-regulated both in vitro and in vivo [109]. Interestingly, low-dose morusin treatment forced breast cancer cells and xenograft tissue to differentiate into adipose like cells accumulating lipid droplets and over-expressing transcription factors $\mathrm{C} / \mathrm{EBP} \beta$ and $\operatorname{PPAR} \gamma$, as well as adipogenic proteins adipsin D, and perilipin [110]. Most recently, morusin was found to inhibit gastric cancer cell proliferation and tumor growth by down-regulating the oncogene protein c-Myc both in vitro and in vivo, and it was also found that cells engineered to over-express c-Myc can bypass the G1 phase cell cycle arrest induced by this compound [111].

Morusin showed promising results when tested against cancer stem cells (CSCs) that seem to play a major role in the frequent failure of chemotherapy: due to their chemo-resistance, self-renewal and tumor-initiating capacity, the surviving CSCs can induce tumor relapse. Accordingly, it is insufficient to achieve tumor regression, but special attention is needed to also eradicate the rare CSC population [112]. When testing morusin against cervical CSCs, obtained through a non-adhesive culturing of HeLa cells, it was found to dosedependently suppress their proliferation, tumor sphere formation, and migration, and it was 
inducing high rates of apoptosis at as low as $2-4 \mu \mathrm{M}$ concentration [113]. In a most recent study by the same group, morusin was investigated for its potential against glioblastoma stem cells (GSCs). Glioblastoma multiforme is one of the most aggressive types of cancer with a very poor prognosis, and GSCs are believed to play a central role in this. Morusin was able to target GSCs with a ca. 2-fold selective in vitro cytotoxicity over that exerted on parental glioblastoma cells and ca. 10-fold over that on normal liver cells, and it could significantly inhibit the growth of in vivo glioblastoma xenografts initiated by GSCs [114]. Coherently with the above-mentioned results of [110] on breast cancer cells, GSCs could also be differentiated to adipocytes by lower, non-cytotoxic, $0.5-2.0 \mu \mathrm{g} / \mathrm{mL}$ doses of morusin, with a significant decrease of stemness marker proteins CD133, nestin, Oct4, and Sox2, and with a significant increase of PPAR $\gamma$, adipsin $\mathrm{D}$, adipocyte lipid-binding protein (ap2), and perilipin [114]. On the other hand, slightly higher, 3-5 $\mu \mathrm{g} / \mathrm{mL}$ doses of morusin already induced apoptosis in GSCs.

Several other compounds with different antitumor mechanisms have also been reported from black mulberry roots. Kuwanons $\mathrm{G}$ and $\mathrm{H}$ were found to be specific antagonists for gastrin-releasing peptide (GRP)-preferring receptor [115]. Oxyresveratrol and kuwanon Y were shown to inhibit protein kinase C (PKC) [116]. Sanggenon C inhibited tumor cellular proteasomal activity and cell viability [117]. Mulberrofurans $\mathrm{G}$ and $\mathrm{H}$, moracins $\mathrm{O}, \mathrm{P}$ and $\mathrm{Q}$, albafuran $\mathrm{A}$, and kuwanon $\mathrm{J}$ were found to inhibit the accumulation of hypoxiainducible factor-1 (HIF-1) [118]. Mulberrofuran G induced apoptotic cell death via parallel activation of the cell death receptor pathway and the mitochondrial pathway [119]. Cudraflavone B, kuwanon E, and kuwanon $\mathrm{U}$ exerted antiproliferative and antiinflammatory activities [93].

\subsubsection{Other pharmacological effects}

Several other biological effects have also been demonstrated by the compounds present in M. nigra roots. For example, cyclomorusin [120], morusin, and kuwanon C [121], have anti-platelet effects. Morusin has an anti-nociceptive effect [54]. Mulberroside A showed liver protective and P-glycoprotein inhibitory effects [81, 122]. Sanggenons D and morusin are positive GABA-A receptor modulators [123]. Kuwanons C, E, and U, 5' -geranyl-4'methoxy-5,7,2'-trihydroxyflavone and morusin exhibited cholinesterase inhibitory effects [124]. Cudraflavone B and oxyresveratrol have hepatoprotective effects [74]. Moracins C and $\mathrm{M}$, oxyresveratrol, morusin, kuwanons $\mathrm{E}$ and $\mathrm{U}$, mulberrofuran $\mathrm{G}$, and mulberroside $\mathrm{A}$ $[104,125,126]$ have neuroprotective effects. In addition, kuwanon C, sanggenon D [127], 
5'-geranyl-5,7,2',4'-tetrahydroxyflavone, steppogenin-7-O- $\beta$-D-glucopyranoside, 2,4,2',4'tetrahydroxychalcone, moracin $\mathrm{N}$, kuwanon $\mathrm{H}$, mulberrofuran $\mathrm{G}$, morachalcone $\mathrm{A}$, oxyresveratrol-2- $O$ - $\beta$-D-glucopyranoside, oxyresveratrol-3'- $O-\beta$-D-glucopyranoside, mulberroside A, oxyresveratrol-3-O- $\beta$-glucopyranoside, oxyresveratrol, and moracenin D exhibited tyrosinase inhibitory activities $[60,128-130]$.

\subsection{Semi-synthesis of prenylflavonoids}

Semi-synthesis is a useful strategy to obtain structural analogs with enhanced bioactivity and/or pharmacokinetic properties as compared to the natural compound, and its relevance in lead optimization is well shown by the fact that ca. 5-times more approved drugs are semi-synthetic (ca. 21\%) than purely natural (ca. 4\%) [1]. Further, semi-synthesis is also a useful tool in the study of structure-activity relationships. During this Ph.D. work, morusin was isolated as a major constituent from $M$. nigra root bark. This compound demonstrated a wide range of pharmacological activities [54, 71], and particularly its anti-cancer properties attracted much attention. As detailed above, morusin inhibits angiogenesis and tumor progression, triggers apoptosis, cell cycle arrest and autophagy in various cancer cell lines and in tumor xenografts. To allow scale-up preparation of this promising compound, its total synthesis was developed and reported [131]. However, there are only a few publications on the structural modification of morusin [132-134]. This gave us a good starting point to engage in the semi-synthesis of this versatile bioactive compound, to prepare new derivatives with altered / improved pharmacological properties. Chemical modifications by oxidation and hydrogenation were selected; the literature background to these is briefly summarized below.

Oxidation. Oxidative transformation of morusin may result in diverse compounds whose bioactivity has previously not been studied. The oxidative cyclization of morusin using manganese dioxide was reported by Nomura et. al. [132]. They identified morusin hydroperoxide as the major product, whereas the same product was also obtained through photo-sensitized oxidation of morusin [133]. Geo et al. reported the palladium-catalyzed oxidative cyclization of Kuwanon F, and the reaction resulted in the formation of cyclomorusin as the major product [134]. Hypervalent iodine chemistry has long been of interest in the oxidation of phenols [135], but the use of such reagents has not been reported for oxidizing morusin. 
Hydrogenation. Awouafack et al. reported the hydrogenation of prenylated flavonoids khonklonginol A and lupinifolinol isolated from the roots of Eriosema chinense [136]. The catalytic hydrogenation of cyclomorusin using $\mathrm{Pd} / \mathrm{C}$ was reported by Guo et al. resulting in the formation of dihydrocyclomorusin as the major product [134]. The hydrogenation of morusin has not been reported before.

\subsection{Methods in the isolation of phenolic compounds}

A very large number of articles describe the preparative separation of phenolic compounds in literature. As it is generally true for natural product isolation, optimization of workload needs a well-designed strategy. Scale of the work may be limited by the availability of plant material and research facilities (i.e. laboratory or industrial scale). On the other hand, processing a larger amount of plant material may result in numerous phenolic compounds in amounts high enough for bioactivity studies, and, at the same time, it may lead to the discovery of minor components that may otherwise remain untraceable. After extraction with an appropriately selected solvent, both conventional (liquid-liquid extraction) and modern methods (solid-phase extraction) are used for pre-purification [137, 138]. In the processing of larger amounts of sample, the purification is typically achieved by repeated chromatographic steps using a different combination of solvent and stationary phases. Final purification is generally carried out by HPLC [139]. When purifying smaller amounts of crude extracts, consecutive steps of NP and RP-HPLC separations may also be sufficient. Setting up an acidic pH may be necessary for the successful separation of more polar phenolic compounds. Since phenolic compounds are frequently glycosylated, it is not unusual to apply an acidic hydrolysis as a pre-treatment to release the aglycones [140]. Of the liquid-liquid partition-based chromatographic methods; countercurrent chromatography (CCC) is quite effective in the separations of a complex mixture of phenolic compounds with different polarities. Concerning detection, UV detectors are widely employed since phenolic compounds are usually UV-active and their UV-Vis spectrum is frequently characteristic, and therefore it is also useful in providing some structural information. The use of MS detectors is now common also in assisting preparative chromatography, because of the typically good ionization yield that these compounds provide when using electrospray $[141,142]$ 


\section{OBJECTIVES}

As evident from the above literature overview, Morus nigra is a particularly rich source of phenolic compounds whose structural diversity and versatile pharmacology makes them of high value when searching for new bioactive compounds. Further, semi-synthetic modifications of such compounds provide ample opportunities to obtain new compounds with improved physicochemical and biological properties.

Thus, the following objectives were set up for this Ph.D. work.

Isolation of phenolic compounds from Morus nigra root bark. It was our aim to use a strategic combination of different separation techniques to isolate and purify biologically active compounds from the root bark of $M$. nigra. This includes the identification of phenolic compounds already known from other Morus species, thereby extending the available knowledge on the plant part.

Preparation of semi-synthetic derivatives. To increase the chemical diversity of the compounds obtained, we aimed to perform a set of structural modifications on selected compounds. It was our aim to perform oxidation by using different oxidizing agents, and hydrogenation

Biological evaluation of the isolated and synthesized compounds. The biological studies on the isolated compounds were planned in scientific cooperation. It was our objective to study selected compounds for antispasmodic activity, effect on the sarco/endoplasmic reticulum $\mathrm{Ca}^{2+}$-ATPase (SERCA), and/or for their antitumor potential.

Evaluation of structure-activity relationships. In connection with the bioactivity testing, it was our aim to evaluate the possible role of different structural elements in the bioactivity of the compounds. 


\section{MATERIALS AND METHODS}

\subsection{Plant Material}

The roots of Morus nigra (black mulberry) were collected in December, 2013, from a farm nearby Ásotthalom, Hungary. After air-drying, a voucher specimen was deposited in the Institute of Pharmacognosy, University of Szeged, Szeged, Hungary.

\subsection{Reagents and Chemicals}

Organic solvents used for TLC, FC, and CC (analytical grade) were purchased from Sigma-Aldrich (Budapest, Hungary), and HPLC solvents were purchased from Avantor Performance Materials (Poland). Papaverine was purchased from Takeda Pharma Ltd. (Budapest, Hungary). Morin hydrate was purchased from Sigma-Aldrich (Budapest, Hungary). Chemicals namely PIDA, PIFA, Pd/c, PhenoFluor Mix were purchased from Sigma-Aldrich (Budapest, Hungary).

\subsection{General experimental procedure}

\subsubsection{Procedure for separation}

Polyamide gel (CC 6) 0.05-0.16mm mesh (MP Biomedicals, Eschwege, Germany) or silica gel 60 (Merck, Darmstadt, Germany) was used as stationary phase for column chromatography undertaken in a glass column of MN-polyamide CC 6 [Column 1] 500g $(162 \mathrm{~cm} \times 5.5 \mathrm{~cm})$. The solvent system applied for the Polyamide gel column was mixtures of ethyl acetate and methanol in different concentrations. Column chromatography on Silica gel 60 was afforded with the different proportions of $n$ hexane and ethyl acetate. Flash chromatography (FC) was performed on a CombiFlash $\mathrm{Rf}+$ Lumen instrument equipped with an integrated evaporative light scattering detector (ELSD) from Teledyne Isco, Lincoln, USA. NP-FC was performed on silica gel 60 as a stationary phase with a solvent system of $n$-hexane-ethyl acetate, or on polyamide gel with methanol-water as mobile phase. Columns used were 80g HP Silica RediSep Gold [Column 2] and 13g MN-polyamide CC 6 [Column 3]. Concerning mobile phase compositions specified in the thesis, always $\mathrm{v} / \mathrm{v}$ ratios are given.

Analytical TLC was used for the monitoring of every chromatographic step up until the HPLC. In NP-TLC, DC-Alufolien Kieselgel 60F 254 (Merck, Darmstadt, Germany) was used with the following solvent systems: 1. toluene-ethyl acetate-formic acid $(5: 4: 1) ; 2$. $n$-hexane-ethyl acetate $(1: 1) ; 3$. toluene-ethanol (9:1). In RP-TLC, Whatman $\mathrm{KC}_{18} \mathrm{~F}$ sheets (Whatman, Clifton, NJ, USA) were used with the following solvent 
systems: 4. methanol-water (6:4); 5. acetonitrile-water (5:5). Phenolic compounds were detected under UV Light (Camag UV-Lamp, Camag, Muttenz, Switzerland) at $254 \mathrm{~nm}$ (dark spots), after spraying with a vanillin-sulfuric acid reagent in UV light at $366 \mathrm{~nm}$ (Fluorescent spots) and in daylight usually yellow-colored spot.

Semi-preparative and preparative scale RP-HPLC was used for the final purification of the phenolic compounds on the following instruments: (i) a Jasco PU2080 HPLC pump and a Jasco UV2075 detector connected to Jasco Borwin v1.50 chromatographic software, (Analytical HPLC)(ii) Jasco PU2080 HPLC pump and a Jasco UV2075 detector connected to Hercule 2000 chromatographic interface (Semi-Preparative) (iii) a Waters 600 pump and Waters 2998 dual absorbance photodiode array detector connected via Waters Empower software. (iv) Armen Spot Prep equipped with a dualwavelength UV detector connected via Armen Glider Prep software. Columns used: Kinetex ${ }^{\circledR}$ XB C18 [Column 4] ( Torrance, CA, USA, $5 \mu \mathrm{m}, 250$ x 4.6mm,analytical), Gemini C18 [Column 5] ( Torrance, CA, USA,5 $\mu \mathrm{m}, 250 \times 10 \mathrm{~mm}$,semi-preprative), Kinetex ${ }^{\circledR}$ XB C18 [Column 6] (Torrance, CA, USA,5 $\mu \mathrm{m}, 250 \times 21.2 \mathrm{~mm}$, preparative), Kinetex ${ }^{\circledR}$ Biphenyl [Column 7] (Torrance, CA, USA,5 $\mu \mathrm{m}, 250 \times 21.2$ mm preparative).

The flow rate was usually $1 \mathrm{ml} / \mathrm{min}$ in case of analytical RP-HPLC, $3 \mathrm{ml} / \mathrm{min}$ for semipreparative RP-HPLC and $16 \mathrm{ml} / \mathrm{min}$ for preparative RP-HPLC.

\subsubsection{Procedure for structural elucidation}

${ }^{1} \mathrm{H}$ and ${ }^{13} \mathrm{C}$ NMR spectra were recorded in $\mathrm{CD}_{3} \mathrm{OD}$ on a Bruker Avance DRX 500 spectrometer for compounds 3, 4, 6 and 7, and on a Bruker Avance NEO instrument for compounds $\mathbf{1}, 2$ and 5 at $500 \mathrm{MHz}\left({ }^{1} \mathrm{H}\right)$ and $125 \mathrm{MHz}\left({ }^{13} \mathrm{C}\right)$. The peaks of the residual nondeuterated solvent $\left(\delta_{\mathrm{H}} 3.31, \delta_{\mathrm{C}} 49.0\right)$ were chosen as reference. Chemical shifts $(\delta)$ are given in parts per million (ppm) and coupling constants $(\mathrm{J})$ values are expressed in $\mathrm{Hz}$. Two-dimensional data (COSY, NOSY, HMBC, and HMQC) were acquired and processed with MestReNova v6.0.2-5475 and TopSpin 3.5p17 software. Mass spectra were recorded on an API 2000 triple quadrupole tandem mass spectrometer (AB SCIEX, Foster City, CA, USA) 


\subsection{Extraction and Isolation}

\subsubsection{Extraction and pre-purification of the crude extract}

The scheme for the extraction of Morus nigra root bark is shown in Figure 5. The air-dried root bark (590g) of M. nigra was ground to a coarse powder and percolated with $\mathrm{MeOH}$ $(4 \mathrm{~L} \times 3)$ at room temperature. After evaporation of methanol under vacuum at $40^{\circ} \mathrm{C}$, the residue $(92.7 \mathrm{~g})$ was diluted with $18 \%$ aqueous $\mathrm{MeOH}(850 \mathrm{ml})$. Following this, the crude extract was subjected to solvent-solvent distribution, the residue was first extracted five times with n-hexane $(5 \times 500 \mathrm{~mL})$ and then extracted again five times with ethyl acetate $(5 \mathrm{x} 500 \mathrm{~mL})$ to produce $n$-hexane $(7.3 \mathrm{~g})$, ethyl acetate $(54.1 \mathrm{~g})$ and water $(36.7 \mathrm{~g})$ fractions. The ethyl acetate fraction $(54.1 \mathrm{~g})$ was dissolved in methanol $(100 \mathrm{ml})$ and adsorbed on polyamide gel $(100 \mathrm{~g})$, using a rotary evaporator. This was added to the top of a previously packed column of polyamide [Column 1] suspended in ethyl acetate. After the column has been extensively washed with ethyl acetate, the phenolic compounds were eluted with a stepwise gradient of ethyl acetate-methanol (98\%) $(95: 5,9: 1,85: 15,8: 2$ and 7:3), and $300 \mathrm{ml}$ fractions were collected. The progress of elution was monitored using NP-TLC, using solvent systems 1 and 2. Altogether 258 fractions were afforded through classical column chromatography, and these were combined based on their TLC fingerprints, resulting in 56 complex fractions.

\subsubsection{Isolation of phenolic compounds}

Fraction $5(1.7 \mathrm{~g})$ of [Column 1], eluted with ethyl acetate-methanol (98:2) was dissolved in $15 \mathrm{ml}$ of methanol. The solution was mixed with $30 \mathrm{~g}$ of silica and taken to dryness by rotary evaporation. The sample was subsequently added to the top of a flash [Column 2] . Twenty-four fractions of $100 \mathrm{~mL}$ were collected, eluting with a stepwise gradient of $n$ hexane - ethyl acetate $(9: 1,8: 2,7: 3,1: 1)$ five fractions of each solvent. The tenth fraction, eluted with $n$-hexane - ethyl acetate (8:2), was evaporated to dryness, and the residue (2.1g) was purified by using RP-HPLC gradually eluted with acetonitrile - water (7:3) applying on [Column 6] to yield compound 1 (1.98g). Fractions 17-18, eluted with $n$ hexane - ethyl acetate (7:3) were combined and evaporated, and the dry residue (200mg) was purified with acetonitrile: water (7:3) by using preparative RP-HPLC over [Column 5] to obtain compound $2(85 \mathrm{mg})$.

Fraction 13 (1.2g) from [Column 1], eluted with ethyl acetate - methanol (96:4) was evaporated to dryness. The dried residue $(1.27 \mathrm{~g})$ was dissolved in $5 \mathrm{ml}$ of methanol. The solution was mixed with $9 \mathrm{~g}$ of Celite $(0.02-0.1 \mathrm{~mm})$ and taken to dryness by the rotary 
evaporator. The sample adsorbed onto Celite and packed on to the top of the flash [Column3]. Elution was carried out with a water - methanol gradient $(92: 8,6: 4,1: 1$, and 4:6), and the column was subsequently washed with methanol. Altogether nine fractions were collected from the flash [Column 3]. The fractions eluted with water - methanol (6:4) were combined and evaporated to dryness. The dry residue $(0.3 \mathrm{~g})$ was dissolved in $5 \mathrm{ml}$ of methanol and purified with the help of preparative RP-HPLC with an isocratic elution of acetonitrile - water $(7: 3)$ utilizing [Column 6 ] resulting in compound $\underline{\mathbf{3}}(60 \mathrm{mg})$. The Fractions eluted from flash [Column 3] with water - methanol (1:1) were combined and the dry residue of $0.27 \mathrm{~g}$ was obtained. This residue was purified by semi-preparative RPHPLC [Column 5] by using an isocratic elution of acetonitrile - water (1:1). The fraction (75mg) was further separated on a [Column 7] with the help of preparative HPLC by using an isocratic solvent system of methanol - water (53:47). This separation allowed us to obtain compounds $4(30 \mathrm{mg})$ and $\mathbf{5}(30 \mathrm{mg})$. The fractions eluted from flash [Column 3] at water - methanol (4:6) were combined and dried under pressure. The residue was separated by using [Column 5]. The isocratic elution of acetonitrile - water (1:1) afforded compound 9 (40mg).

Fraction 14 (0.3g) from [Column 1], eluted with ethyl acetate - methanol (95:5) was dried under the Rota evaporator. The dried residue was diluted with $5 \mathrm{ml}$ ethyl acetate. The solution was adsorbed over silica and went through reverse phase flash chromatography utilizing [Column 3] with an eluent comprises of water - methanol (94:6, 9:1, 6:4). Fraction $3(0.07 \mathrm{~g})$ eluted with water - methanol (6:4) was purified by RP-HPLC on [Column 6]. The eluent used was an isocratic solution of acetonitrile - water (7:3). The resultant sample was dried under nitrogen and referred to as compound 3 (30mg).

Fraction 37 (1.1g) from [Column 1], eluted with ethyl acetate - methanol (8:2) was evaporated with the help of rotary evaporation. The dried residue $(1.25 \mathrm{~g})$ was dissolved in $5 \mathrm{ml}$ methanol and adsorbed on polyamide; the elution was carried out with a stepwise gradient of water - methanol $(98: 2,9: 1,6: 4,1: 1$ and 2:8) on flash chromatography [Column 3]. Twenty-five sub-fractions of $100 \mathrm{ml}$ were collected. The flash fractions $(0.2 \mathrm{~g})$ eluted with water - methanol $(2: 8$,$) were collected and separated with preparative HPLC$ using [Column 6]. The isocratic solvent system of acetonitrile - water (1:1) was used throughout the HPLC separation. Compound $6(80 \mathrm{mg})$ was obtained through this process whereas the residue was further purified with RP-HPLC with similar [Column 6], eluted with acetonitrile - water (4:6) to afford compound $\mathbf{8}(25 \mathrm{mg})$. 
Fraction $42(1.02 \mathrm{~g})$ from [Column 1], eluted with ethyl acetate - methanol (7:3) was evaporated to dryness under vacuum. The residue was adsorbed onto polyamide with the help of rotary evaporation. The adsorbed sample was packed on top of the polyamide flash [Column 3]. Gradient elution was carried out with water - methanol (96:4, 9:1, 8:2, 6:4, $3: 7$, and $2: 8$ ) and $25 \mathrm{ml}$ subfractions were collected that were combined based on TLC visualization resulting in 15 larger fractions of $100 \mathrm{ml}$ each. The flash fraction 13-15 (0.2g) eluted with water - methanol (2:8) were combined and evaporated to dryness. The dry residue was subjected to purification through preparative HPLC on [Column 6]. The eluent used for the purification of the major compound of this fraction was acetonitrile - water (1:1) to afford compound $7(51 \mathrm{mg})$. The flash fractions $8-9(0.14 \mathrm{~g})$ eluted with water methanol (3:7) were combined and evaporated under reduced pressure. The residue was diluted by mixing with $5 \mathrm{ml}$ of methanol. The RP-HPLC was utilized for the purification of major compounds present in the following fraction. The purification was done through [Column 7] using methanol - water (7:3) to afford compound $\mathbf{1 0}(40 \mathrm{mg})$.

Fraction $24(0.5 \mathrm{~g})$ from [Column 1], eluted with ethyl acetate - methanol (9:1) was reduced under pressure. The residue was mixed with $5 \mathrm{ml}$ of methanol and was subjected to purification by RP-HPLC with [Column 5]. The mobile phase used in purification was the isocratic solution of acetonitrile - water (3:7). One major compound was possible to purify from this fraction naming it as compound $\mathbf{1 1}(14 \mathrm{mg})$.

The relative purity of each isolated compound was examined by analytical HPLC using [Column 4] with a flow rate of $1.0 \mathrm{ml} / \mathrm{min}, 20 \mu 1$ of the sample was injected each time. The elution conditions used in this test were like those presented above.

\subsection{Preparation of semi-synthetic analogs}

Morusin was the major compound isolated from the M. nigra roots, therefore it was further subjected to semi-synthetic modifications.

\section{Oxidation of Morusin}

Hypervalent iodine oxidation. A. To a stirred solution of morusin (5mg) in acetonitrile - water (9:1) 5ml, 1 equivalent of PIFA [bis(trifluoroacetoxy)iodo]benzene $(5.1 \mathrm{mg})$ was added. The reaction mixture was stirred at $60^{\circ} \mathrm{C}$ temperature for over five hours and the reaction was worked up by SPE over silica using $(2 \times 10 \mathrm{ml})$ ethyl acetate. The residue was evaporated under reduced pressure to give $12 \mathrm{mg}$ of dry residue. 
B. To a stirred solution of morusin (20mg) and PIDA (diacetoxyiodo)benzene (20.4mg) in anhydrous acetonitrile $(10 \mathrm{ml})$. The reaction mixture was stirred at $60 \%$ temperature for over seven hours and then extracted over silica using $(2 \times 15 \mathrm{ml})$ ethyl acetate. The residue was reduced under a rota evaporator to give $(35 \mathrm{mg})$ of the fraction. The purification was done with the help of RP-HPLC (ii) using a C18 column with an isocratic elution of acetonitrile - water $(7: 3 \mathrm{v} / \mathrm{v})$ to afford compound 12

\section{PCC oxidation.}

Morusin $(5 \mathrm{mg}$ ) was dissolved in dichloromethane $5 \mathrm{ml}$, and 1 equivalent of pyridinium chlorochromate $(2.5 \mathrm{mg})$ was added. The reaction mixture was stirred at room temperature for over eight hours and the reaction was worked up by extracted over silica using $(2$ x 5 $\mathrm{ml})$ ethyl acetate. The residue was reduced under a rotary evaporator to give $(6 \mathrm{mg})$ of the fraction.

\section{Copper-catalyzed oxidation.}

Morusin $\left(5 \mathrm{mg}\right.$ ) dissolved in $5 \mathrm{ml}$ of acetonitrile - water (9:1), was added to $\mathrm{CuSO}_{4}$ $(1.8 \mathrm{mg})$. The reaction mixture was stirred at $60^{\circ} \mathrm{C}$ temperature for over five hours. The reaction was worked up by extracted over silica using $(2 \times 5 \mathrm{ml})$ ethyl acetate. The residue was reduced under a rotary evaporator to give $(7 \mathrm{mg})$ of the fraction.

\section{Synthesis of hydrogenated morusin}

$50.0 \mathrm{mg}$ of morusin (1) was dissolved in anhydrous ethyl acetate $10 \mathrm{ml}, 10 \mathrm{mg}$ of $\mathrm{Pd} / \mathrm{C}$ (Palladium on activated charcoal 75990-10G) was added, and the solution was stirred under a hydrogen atmosphere for 4 hours. Later, the catalyst was removed through washing with $(5 \times 20 \mathrm{ml})$ ethyl acetate. The residue was dried under a rotary evaporator and checked on HPLC; the chromatogram showed the presence of two major compounds. The purification was processed through RP-HPLC using a C18 column with an isocratic elution of acetonitrile - water (7:3) to afford compounds 13 and 14.

\section{NMR spectroscopy of the compounds obtained}

One- $\left({ }^{1} \mathrm{H},{ }^{13} \mathrm{C}, \mathrm{APT}\right)$ and two-dimensional (HSQC, HMBC, $\left.{ }^{1} \mathrm{H},{ }^{1} \mathrm{H}-\mathrm{COSY}, \mathrm{NOESY}\right) \mathrm{NMR}$ spectroscopic methods were used in the structural elucidation process. NMR spectra were recorded at room temperature in methanol- $d_{4}$ on Bruker Avance DRX 500 NEO spectrometer, however, for compound 5 the $600 / 150 \mathrm{MHz}$ spectra were taken in dimethylsulfoxide- $d_{6}$ on a Bruker Avance III $600 \mathrm{MHz}$ spectrometer equipped with Prodigy cryo-probe head. Chemical shifts $(\delta)$ are given on the $\delta$-scaled and referenced to 
the solvents (methanol- $d_{4}: \delta_{\mathrm{H}}=3.31$ and $\delta_{\mathrm{C}}=49.1 \mathrm{ppm}$, and dimethylsulfoxide- $d_{6}: \delta_{\mathrm{H}}=$ 2.50 and $\left.\delta_{\mathrm{C}}=39.5 \mathrm{ppm}\right)$ and coupling constants $(J)$ values are expressed in Hz. Pulse programs of all experiments $\left[{ }^{1} \mathrm{H},{ }^{13} \mathrm{C}\right.$, APT, gs-HSQC, edited gs-HSQC, gs-HMBC (optimized for $7 \mathrm{~Hz}$ ), band-selective gs-HMBC and NOESY (mixing time $=300 \mathrm{~ms}$ )] were taken from the Bruker software library. The NMR signals of the products were assigned by a comprehensive one- and two-dimensional NMR methods using widely accepted strategies [143, 144]. Most ${ }^{1} \mathrm{H}$ assignments were accomplished using general knowledge of chemical shift dispersion with the aid of the proton-proton coupling pattern $\left({ }^{1} \mathrm{H}\right.$ NMR spectra).

\subsection{Pharmacological tests}

Pharmacological investigations were performed in research cooperation with research groups of the following principal investigators. Antispasmodic activity: Róbert Gáspár (Department of Pharmacology and Pharmacotherapy, University of Szeged, Hungary); SERCA activity: Lubica Horakova (Institute of Experimental Pharmacology and Toxicology, Centre of Experimental Medicine of the Slovak Academy of Sciences, Comenius University, Bratislava, Slovakia); in vitro antitumor activity on human gynecological cancer cell lines: István Zupkó (Department of Pharmacodynamics and Biopharmacy, Faculty of Pharmacy, University of Szeged); efflux pump inhibitory activity and in vitro antitumor activity on a susceptible / multi-drug resistant mouse lymphoma cell line pair: Gabriella Spengler (Department of Medical Microbiology and Immunobiology, University of Szeged, Szeged, Hungary).

\subsubsection{Antispasmodic activity}

Animal experimentations were carried out with the approval of the National Scientific Ethical Committee. The guidelines of European Communities Council Directives and the Hungarian Act for the Protection of Animals in Research were followed.

Sprague-Dawley rats were maintained at the normal room temperature. The animals were fed with a standard rodent pellet diet with tap water. Eight male rats were applied for isolated organ bath studies. After starving for $16 \mathrm{~h}$ before the experiment, rats were terminated by $\mathrm{CO}_{2}$ inhalation. The dissected samples of distal ileum were mounted vertically in an organ bath containing Tyrode buffer. The bath was heated and carbogen was bubbled through it. The regular contractions were recorded for $5 \mathrm{~min}$ and then $25 \mathrm{mM}$ $\mathrm{KCl}$ was used. The AUC of $\mathrm{KCl}$ evoked contractions was compared with the AUC of 
regular contractions. For trachea tissues, after removing blood vessels these were cut transversally into 4-5 mm-wide rings. Rings were placed in $37{ }^{\circ} \mathrm{C}$ Krebs buffer. The tracheal rings were mounted with their longitudinal axis vertically by hooks and equilibrated for $1 \mathrm{~h}$. Papaverine was applied as a positive control in the same concentration range as the isolated compounds. The buffer solution was renewed every $15 \mathrm{~min}$.

A 3-point assay $\left(10^{-8}, 10^{-7}\right.$ and $\left.10^{-6} \mathrm{M}\right)$ was performed to determine the active compounds. Further, the selected compounds which showed significant activity (the maximum ileum contraction inhibition was higher than $30 \%$, and the tracheal tone reduction was higher than $100 \mathrm{mg})$ underwent an 8-point assay $\left(10^{-8.5}-10^{-5} \mathrm{M}\right)$ with cumulative concentrationresponse curves. The concentrations eliciting the half of the maximum effect $\left(\mathrm{EC}_{50}\right)$ and the maximum effects $\left(\mathrm{E}_{\max }\right)$ were calculated and statistically evaluated (I).

\subsubsection{SERCA activity}

SERCA activity of SR from fast-twitch skeletal muscle of a New Zealand female rabbit was measured spectrophotometrically by NADH-coupled enzyme assay by modification of the method outlined in the literature [145]. Labeling of SERCA1 and SR vesicles incubated with phenolic compounds were tested as indicated in the paper (II)

Pancreatic beta-cell line (INS-1E insulinoma) was cultured in RPMI 1640. Cells were incubated with individual compounds for $24 \mathrm{~h}$ and then submitted to lysis in an ice-cold lysis buffer. Protein separation SDS PAGE and identification of SERCA2b and $\beta$-actin using primary and secondary antibodies were performed. The bands were visualized using luminol (sc-2048, Santa Cruz, USA) as a chemiluminescent probe and analyzed by Amersham Imager 600 (GE Health Care Europe GmbH, Freiburg, Germany).

MTT reduction assay was used as an indicator of cell damage and performed according to a standard protocol (Munoz-Alonzo et al., 2007). The cells were pre-incubated for $24 \mathrm{~h}$ with or without different concentrations of individual phenolic compounds. MTT reagent was added, and incubated for $4 \mathrm{~h}$, after adding solubilization buffer (10\% SDS in $0.01 \mathrm{M} \mathrm{HCl})$ the mixture was stood for 15-17 $\mathrm{h}$ to solubilize leading to the formation of formazan. The absorbance was recorded at $570 \mathrm{~nm}$ with a microplate reader. After $24 \mathrm{~h}$ of incubation, the apoptotic changes were detected using the FITC Annexin V/propidium iodide kit by flow cytometry. Insulin secretion was monitored through the Mercodia Rat Insulin ELISA kit.

Docking study was performed using the modeling program (Molecular Operating Environment) [146]. Spartan software was used to build and optimize the structure of compounds. The detailed study of albanol A docked in SERCA1 was performed. Statistics 
were performed using one-way ANOVA by the Bonferroni test[147]. Values are mean \pm SD of at least three independent experiments, where each sample was measured in duplicates or triplicates. The step-by-step procedure is mentioned in the article (II).

\subsubsection{Anti-proliferative activity of synthesized morusin metabolites}

The antiproliferative properties of the prepared compounds were determined on the human breast cancer cell lines including estrogen receptor-positive (MCF-7) and triple-negative breast cancer (MDA-MB-231). The cells were purchased from the European Collection of Cell Cultures (ECCAC, Salisbury, UK). Both cell lines Cultivated in Eagle's Minimum Essential Medium supplemented with $10 \%$ fetal bovine serum, $1 \%$ non-essential amino acids and $1 \%$ an antibiotic-antimycotic mixture and incubated under a humidified atmosphere at $37^{\circ} \mathrm{C}$ with $5 \% \mathrm{CO}_{2}$. Antiproliferative activity was evaluated by MTT assay $[148,149]$. Cells were plated and diluted. After an overnight standing, the cells-compound mixture containing ten different concentrations $(0.1$ to $100 \mu \mathrm{M})$ was incubated under cell culture conditions. Subsequently, the MTT solution was added and incubated for another $4 \mathrm{hrs}$. DMSO was added through shaking for $60 \mathrm{~min}$ at $37^{\circ} \mathrm{C}$. Finally, the absorbance rates were measured at $545 \mathrm{~nm}$ wavelength by using a microplate reader. Concentrations inducing 50\% inhibition of cell growth (IC50) values were determined by using GraphPad Prism 5.01 (GraphPad Software, San Diego, CA, USA) for two independent experiments. The tested compounds dissolved in DMSO did not show any substantial effect on cell proliferation.

\subsubsection{Efflux pump inhibition activity of the oxidized metabolite of morusin}

Functional efflux pump inhibition by morusin, its oxidized metabolite-mixtures, and the isolated neocyclomorusin was evaluated using rhodamine 123, a fluorescent dye, whose retention inside the cells was evaluated by flow cytometry. Briefly, 2 × $10^{6}$ cells $/ \mathrm{mL}$ were treated with 2 and $20 \mu \mathrm{M}$ of each compound. After 10 min incubation, rhodamine 123 (Sigma-Aldrich) was added to a final concentration of $5.2 \mu \mathrm{M}$ and the samples were incubated at $37^{\circ} \mathrm{C}$ in a water bath for $20 \mathrm{~min}$. Samples were centrifuged (Heraeus Labofuge 400, Thermo Fisher Scientific, Waltham, MA, USA) (2000 rpm, 2 min) and washed twice with phosphate buffer saline (PBS, Sigma). The final samples were re-suspended in $0.5 \mathrm{~mL}$ PBS and its fluorescence measured with a Partec CyFlow flow cytometer (Partec, Münster, Germany). Tariquidar was kindly provided by Dr. Milica Pesic from the Institute for Biological Research Sinisa Stankovic, Belgrade, Serbia, and it was used at $20 \mathrm{nM}$ as positive control. 


\section{RESULTS}

\subsection{Isolation of phenolic compounds}

The methanol extract of Morus nigra root bark was found to contain a wide variety of constituents. Solvent- solvent partition between $n$-hexane, ethyl acetate and water (1:1 $\mathrm{v} / \mathrm{v}$ ), respectively, allowed the purification of phenolic compounds from both the highly lipophilic ( $n$-hexane layer) and the highly polar (aqueous layer) contaminants. Further, the extract was fractionated by using large-scale classical column chromatography on polyamide. With a stepwise gradient elution (ethyl acetate methanol; 98:2, 96:4, 95:5, 9:1, 85:15, 8:5, 8:2, 7:5, 1:1 v/v), the phenolic compounds could be successfully eluted from the SP. The column matrix was eluted with pure methanol to wash the column thoroughly. Based on TLC, fifty-six fractions mostly containing phenolic compounds could be separated. After preliminary purification, an extensive chromatographic purification was performed using a strategic combination of methods of various selectivity; the outline of the procedure is shown in Fig. 5.

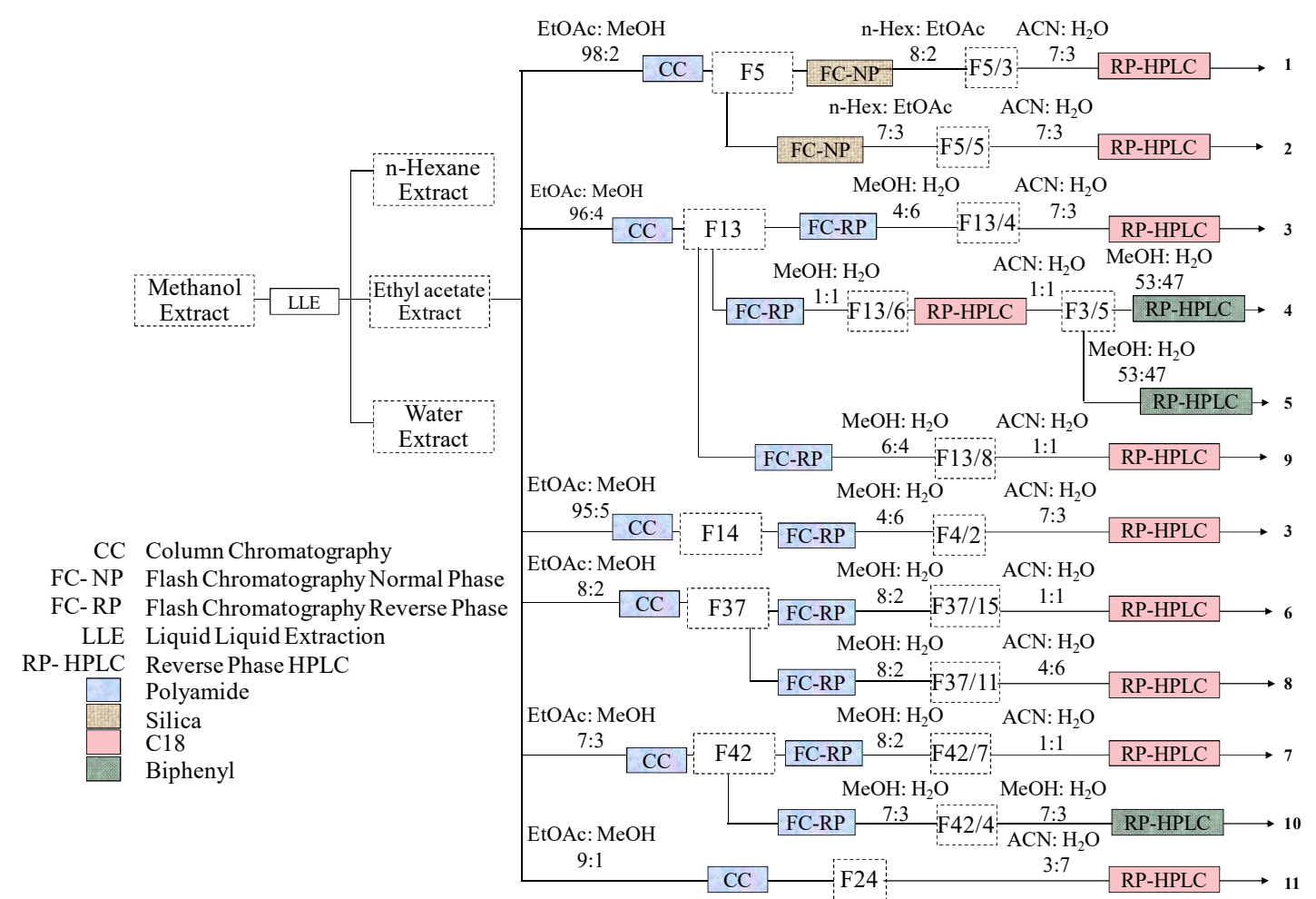

Figure 5. The chromatographic procedure followed for the isolation of phenolic compounds.

The isolated compounds were as follows: morusin (1), kuwanon U (2), kuwanon E (3), moracin P (4), moracin O (5), albanol A (6), albanol B (7), oxyresviratol (8), kuwanon $\mathrm{C}(\mathbf{9})$, mulberofuran $\mathrm{C}(\mathbf{1 0})$, moracin $\mathrm{M}(\mathbf{1 1})$. 
For the purification of major compounds (compound 1), the NP flash chromatographic method was used on silica. At this point of separation, a high amount of Morusin (1) could be isolated using $n$-hexane - ethyl acetate $(8: 2, \mathrm{v} / \mathrm{v})$ at a fair, ca. $94 \%$ purity. A further RP-HPLC purification step was performed using acetonitrile - water $(7: 3, \mathrm{v} / \mathrm{v})$ to reach 97\% purity. Fig. 6 shows the RP-HPLC fingerprint of the pre-purified extract (before its separation on column 1), the flash chromatogram of column fraction F5, and HPLC chromatogram of the isolated pure compound.

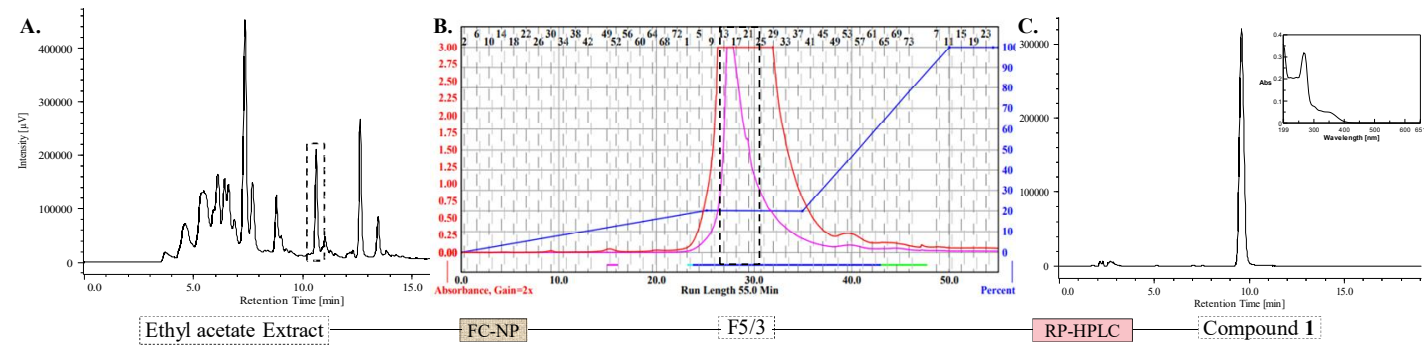

Figure 6. A. RP-HPLC chromatogram of the extract, B. flash chromatogram of first major fraction (F5), and C. the isolated morusin (1).

The purification of minor compound (compound 10), was facilitated by the Reverse phase flash chromatographic over polyamide using water - methanol (3:7). The flash fraction was further separated and purified using reverse phase HPLC with methanolwater $(7: 3)$ on a biphenyl column. The compound was obtained at fair ca. $96 \%$ purity. Fig. 7 shows the multistep performed for the isolation of minor compound $\mathbf{1 0}$.
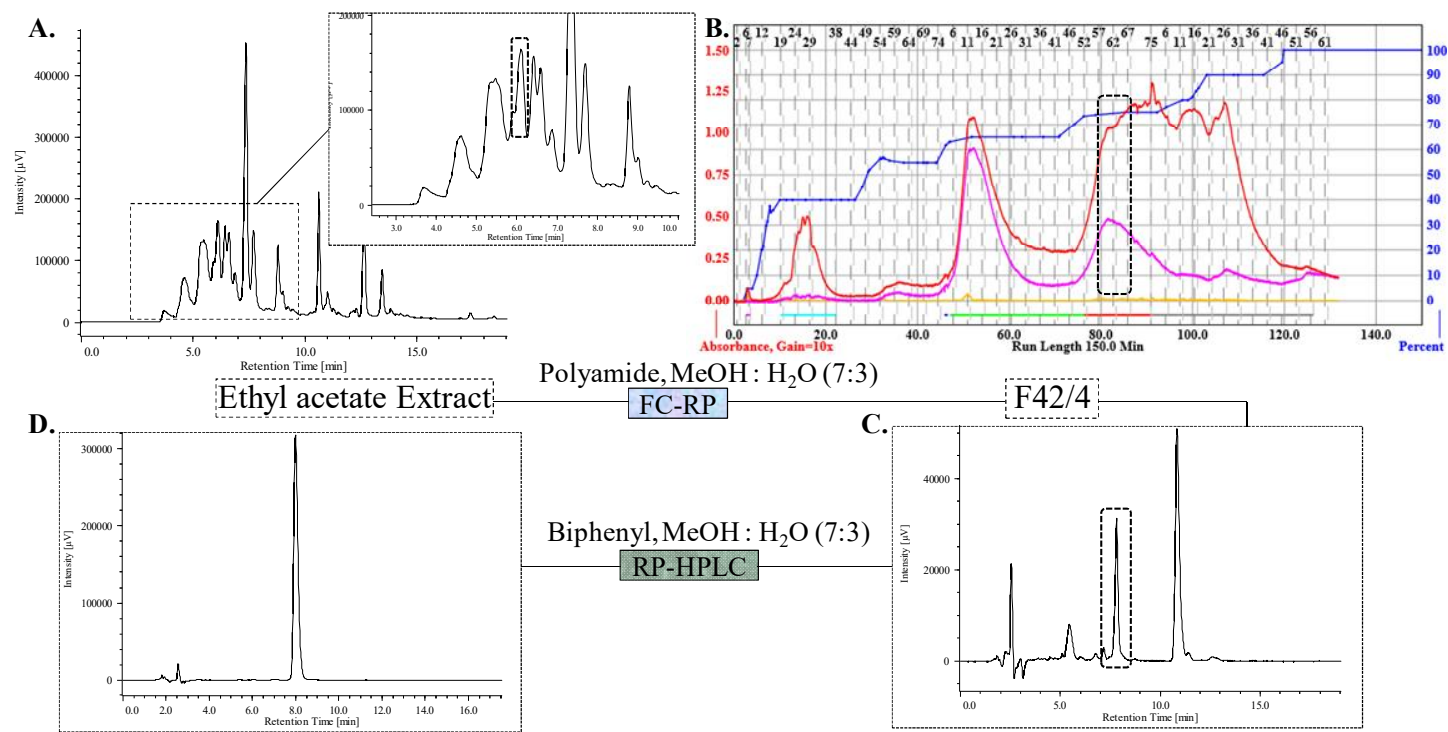

Figure 7. Overview of the stepwise purification of compound 10. A. RP-HPLC fingerprint of the ethyl acetate layer of the extract, B. flash chromatogram of fraction F42, C. HPLC fingerprint of the collected flash fraction (F42/4), D. chromatogram of the isolated mulberrofuran $\mathrm{C}(\mathbf{1 0})$. 
In the separation of our multicomponent samples, a consecutive use of chromatographic techniques with different selectivity was necessary. This involved the use of several different stationary phases with appropriately chosen solvent systems. When performing preparative HPLC separations, it was frequently needed to follow a two-step workflow to avoid longer elution times of some contaminants (isocratic elution) or the need of time- and solvent-consuming re-equilibration of the column in between consecutive injections (gradient elution).

The example of flash fraction 13/6 may illustrate well the importance of selectivity during the separation (Fig. 8 and Table 1). This fraction gave the illusion of a pure compound when analyzing it on a biphenyl HPLC column with an isocratic elution of acetonitrile - water (3:7, v/v) (Fig. 8A), even though it was a mixture of compounds 4 and 5 (Moracin $\mathrm{P}$ and $\mathrm{O}$ ).

A.

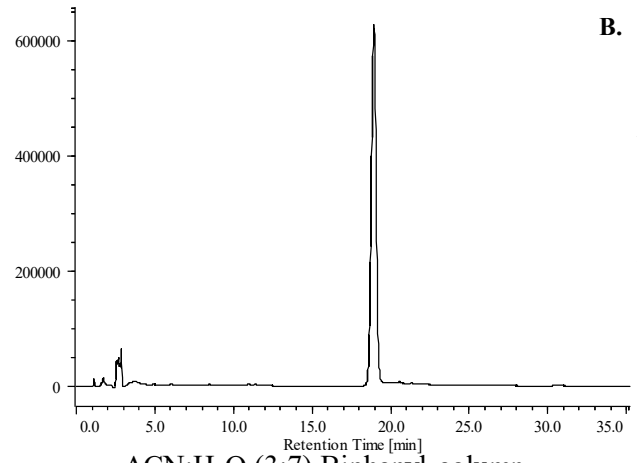

C.

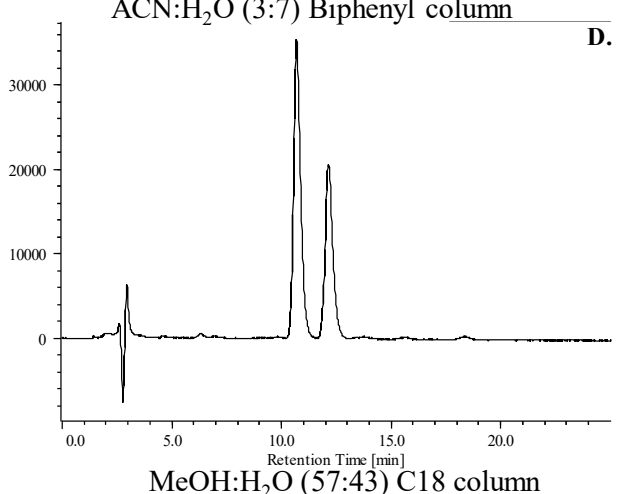

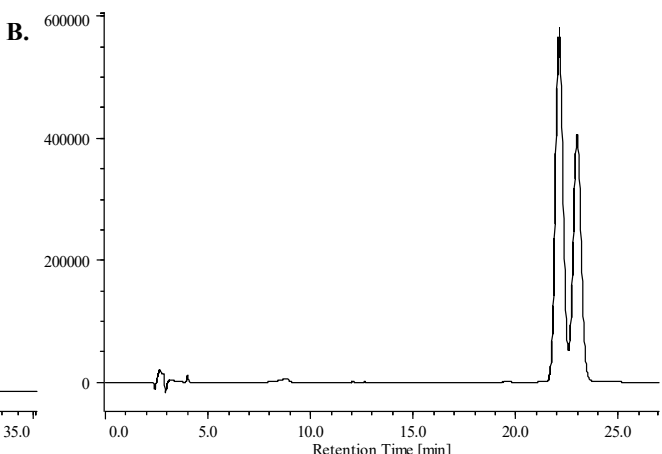

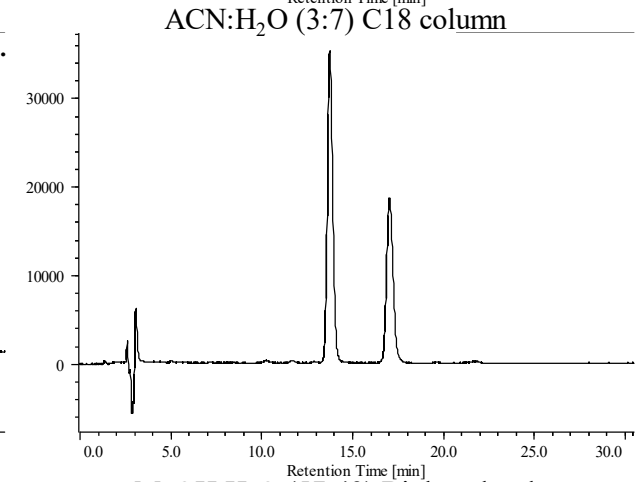

$\mathrm{MeOH}: \mathrm{H}_{2} \mathrm{O}$ (57:43) Biphenyl column

Figure 8. HPLC separation of Moracin P (4) and O (5) in different chromatographic conditions. A. Acetonitrile - water $(3: 7, \mathrm{v} / \mathrm{v})$ on biphenyl column. B. Acetonitrile water (3:7, v/v) on C18 column. C. Methanol - water (53:47, v/v) on C18 column. D. Methanol - water (53:47, v/v) on biphenyl column.

For the separation of these two compounds different separation conditions were optimized. The mixture showed the presence of two compounds when a C18 HPLC 
column was used with the isocratic elution of acetonitrile - water (3:7) (Fig 8B). Changing the eluent to an isocratic $\mathrm{MeOH}$ - water (57:43) solvent system greatly improved resolution (Rs) within a shorter elution time on the C18 column (Fig. 8C), whereas the separation was further improved when using the same $\mathrm{MeOH}$-based solvent system with the above-mentioned biphenyl column (Fig 8D). Therefore, this system was used for the successful preparative separation of compounds $\mathbf{4}$ and $\mathbf{5}$.

Table 1. Efficiency of different HPLC conditions in the separation of compounds $\mathbf{4}$ and $\mathbf{5}$. $t_{R}$ : retention time, $\alpha$ : selectivity factor, $R_{s}$ : resolution.

\begin{tabular}{|l|c|c|c|c|}
\hline \multicolumn{1}{|c|}{ Column / Solvent } & $\begin{array}{c}\mathrm{t}_{\mathrm{R}}(\min ) \\
\text { Compound 4 }\end{array}$ & $\begin{array}{c}\mathrm{t}_{\mathrm{R}}(\min ) \\
\text { Compound 5 }\end{array}$ & $\alpha$ & $\mathrm{R}_{\mathrm{s}}$ \\
\hline Biphenyl / $\mathrm{ACN}-\mathrm{H}_{2} \mathrm{O}(3: 7)$ & 18.893 & 18.893 & - & - \\
\hline $\mathrm{C} 18 / \mathrm{ACN}-\mathrm{H}_{2} \mathrm{O}(3: 7)$ & 22.053 & 22.933 & 1.041 & 0.718 \\
\hline $\mathrm{C} 18 / \mathrm{MeOH}-\mathrm{H}_{2} \mathrm{O}(53: 47)$ & 10.667 & 12.120 & 1.150 & 1.123 \\
\hline Biphenyl / $\mathrm{MeOH}-\mathrm{H}_{2} \mathrm{O}(53: 47)$ & 13.717 & 17 & 1.252 & 2.481 \\
\hline
\end{tabular}

\subsection{Preparation of semisynthetic analogs}

\section{Oxidation of morusin}

To obtain potentially bioactive, oxidized morusin derivatives, different oxidizing agents were used including $\mathrm{CuSO}_{4}$, potassium permanganate, and the hypervalent iodine reagents [bis(trifluoroacetoxy)iodo]benzene (PIFA) and (diacetoxyiodo)benzene (PIDA). Each mixture was subjected to bioactivity screening concerning their cytotoxic / antiproliferative activity on several cancer cell lines, and their effect on the ABCB1-mediated efflux in MDR cancer cells (results are not presented here). Among hypervalent iodine reagents, PIFA was found to be more aggressive while PIDA produced less complex mixtures, and even though the major product(s) could generally be observed by TLC, some mixtures were highly complex with several side products. Moreover, a significant amount of unchanged morusin also remained. Bioactivity screening results turned our attention to one compound present in all oxidized mixture with an increased efflux pump inhibitory activity as compared with morusin. This compound was successfully obtained with PIDA as an oxidizing agent and purification via RP-HPLC, and it was identified by ${ }^{1} \mathrm{H}$ and ${ }^{13} \mathrm{C}$ NMR spectroscopy as neocyclomorusin (12). The reaction led to the formation of one major 
product, compound $\mathbf{1 2}$ was obtained in an acceptable, 25\% yield. Fig. 9 shows the RPHPLC chromatograms of morusin and neocyclomorusin (12) obtained.

Since the ring closure of morusin to neocyclomorusin involves the formation of a new chiral center, compound $\mathbf{1 2}$ was also evaluated by chiral HPLC that confirmed it as a racemic mixture (Fig. 9C). After optimizing the chromatographic conditions for the chiral separation (Amylose-1 column, 80\% Cyclohexane in 20\% isopropanol over $30 \mathrm{~min}, 1$ $\mathrm{mL} / \mathrm{min}$ ), semi-preparative separation of the enantiomers 12a and 12b was also performed and $2 \mathrm{mg}$ of each enantiomer was obtained. However, since the enantiopure compounds showed similar bioactivity (see Section 5.4.4, Table 5), we did not proceed with further studies to assign their absolute configuration.

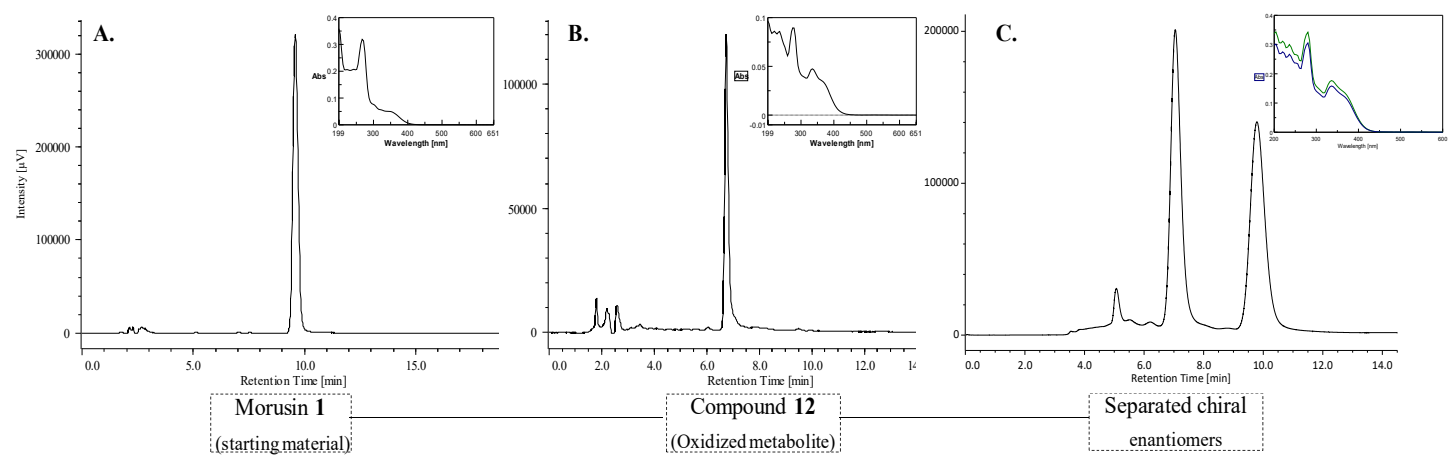

Figure 9. HPLC chromatogram of a major oxidative metabolite of morusin. A. pure morusin B. neocyclomorusin.C. chiral separation of the enantiomers.

\section{Reduction of morusin}

Catalytic hydrogenation of morusin was straightforward by using $\mathrm{Pd} / \mathrm{C}$ and hydrogen gas atmosphere $\left(\mathrm{H}_{2}\right.$ balloon), and the reaction resulted in isolated yields of $20 \%$ and $40 \%$ for the mono and dihydrogenated products respectively.

\subsection{Structure elucidation of the compounds}

Eleven phenolic compounds were isolated and characterized by a direct comparison of their physical and spectroscopic characteristics with those published in the literature. The structure elucidation of compounds 1-3 and 6-12 was straightforward through comparing their HRESIMS and ${ }^{1} \mathrm{H}$ and ${ }^{13} \mathrm{C}$ NMR data with published literature values, and they were identified as morusin (yellow solid; 1) [150], kuwanon U (yellow solid; 2) [151], kuwanon E (yellow solid; 3) [152], albanol A (yellow solid; 6) [153], albanol B (dark brown solid; 7) [153], oxyresviratrol (dark brown solid; 8) [154], Kuwanon C (yellow 
solid; 9) [155], mulberrofuran C (white solid; 10) [156], moracin M (red solid; 11) [157], and neocyclomorusin (yellow solid; 12) [158].

Contradictory data have been published concerning the NMR chemical shifts of moracins $\mathrm{P}$ (4), and O (5), which may lead to a mistaken identification of these compounds. Therefore, compounds 4 and 5 were thoroughly studied and discussed here (see also Section 6.3).

Moracin P (4): brown solid; [159]; m.p. 252-254 ${ }^{\circ} \mathrm{C} ;{ }^{1} \mathrm{H}-\mathrm{NMR}\left(\mathrm{CD}_{3} \mathrm{OD}, 500 \mathrm{MHz}\right) \delta 7.23$ (1H, s, H-4), 6.89 (1H, s, H-3), 6.86 (1H, s, H-7), 6.75 (2H, d, J = 2.1 Hz, H-2' ,6' ), 6.24 $\left(1 \mathrm{H}\right.$, br t, $\left.\mathrm{J}=2.0 \mathrm{~Hz}, \mathrm{H}-4^{\prime}\right), 3.79\left(1 \mathrm{H}, \mathrm{dd}, \mathrm{J}=7.6\right.$ and $\left.5.2 \mathrm{~Hz}, \mathrm{H}-2^{\prime \prime}\right), 3.12(1 \mathrm{H}, \mathrm{dd}, \mathrm{J}=16.5$ and $\left.5.2 \mathrm{~Hz} \mathrm{H}-1^{\prime \prime} \mathrm{a}\right), 2.83\left(1 \mathrm{H}, \mathrm{dd}, \mathrm{J}=16.5\right.$ and $\left.7.6 \mathrm{~Hz} \mathrm{H}-1^{\prime \prime} \mathrm{b}\right), 1.36\left(3 \mathrm{H}, \mathrm{s}, \mathrm{H}-5^{\prime \prime}\right), 1.28(3 \mathrm{H}$, s, H-4"); ${ }^{13} \mathrm{C}-\mathrm{NMR}\left(\mathrm{CD}_{3} \mathrm{OD}, 125 \mathrm{MHz}\right) \delta 160.1$ (C-3' ,5' ), 156.7 (C-2), 156.0 (C-7a), 152.7 (C-6), 133.8 (C-1' ), 124.3 (C-3a), 121.9 (C-4), 117.8 (C-5), 104.1 (C-2' ,6' ), 103.7 (C-4' ), 101.9 (C-3), 99.8 (C-7), 78.3 (C-3"), 70.7 (C-2"), 32.5 (C-1"), 26.1 (C-5"), 21.2 $\left(\mathrm{C}-3^{\prime \prime}\right)$.

Moracin O (5): brown solid; [159] m.p. 235-236 ${ }^{\circ} \mathrm{C} ;{ }^{1} \mathrm{H}-\mathrm{NMR}\left(\mathrm{CD}_{3} \mathrm{OD}, 500 \mathrm{MHz}\right) \delta 7.29$ (1H, s, H-4), 6.89 (1H, s, H-3), 6.85 (1H, s, H-7), $6.74\left(2 \mathrm{H}, \mathrm{d}, \mathrm{J}=2.1 \mathrm{~Hz}, \mathrm{H}-2^{\prime}\right.$, 6' ) 6.23 $\left(1 \mathrm{H}\right.$, br t, J = 2.1 Hz, H-4' ), $4.64\left(1 \mathrm{H}, \mathrm{t}, \mathrm{J}=8.6 \mathrm{~Hz}, \mathrm{H}-2^{\prime \prime}\right), 3.22\left(2 \mathrm{H}, \mathrm{m}, \mathrm{H} 2-1^{\prime \prime}\right), 1.28$ (3H, s, H-4"), 1.24 (3H, s, H-5'); ${ }^{13} \mathrm{C}-\mathrm{NMR}\left(\mathrm{CD}_{3} \mathrm{OD}, 125 \mathrm{MHz}\right) \delta 160.1$ (C-3' ,5' ), 160.0 (C-6), 156.5 (C-7a), 156.3 (C-2), 133.9 (C-1' ), 125.2 (C-5), 124.1 (C-3a), 117.1 (C-4), 103.9 (C$2^{\prime}, 6^{\prime}$ ), 103.5 (C-4' ), 102.5 (C-3), 93.3 (C-7), 91.5 (C-2"), 72.6 (C-3"), 31.3 (C-1"), 25.4 $\left(\mathrm{C}-4^{\prime \prime}\right), 25.5$ (C-5"). ${ }^{1} \mathrm{H}-\mathrm{NMR}\left(\mathrm{DMSO}_{6}, 600 \mathrm{MHz}\right) \delta 9.43\left(2 \mathrm{H}, \mathrm{s}, \mathrm{HO}-3^{\prime}, 5^{\prime}\right), 7.34(1 \mathrm{H}$, s, H-4), 7.07 (1H, s, H-3), 6.97 (1H, s, H-7), 6.66 (2H, d, J = 2.1 Hz, H-2' ,6' ), 6.19 (1H, t, $\left.\mathrm{J}=2.1 \mathrm{~Hz}, \mathrm{H}-4^{\prime}\right), 4.63\left(1 \mathrm{H}, \mathrm{s}, \mathrm{HO}-3^{\prime \prime}\right), 4.60\left(1 \mathrm{H}, \mathrm{dd}, \mathrm{J}=9.3\right.$ and $\left.8.3 \mathrm{~Hz}, \mathrm{H}-2^{\prime \prime}\right), 3.20(1 \mathrm{H}$, dd, $\mathrm{J}=15.7$ and $\left.8.3 \mathrm{~Hz}, \mathrm{H}_{\mathrm{a}}-1^{\prime \prime}\right), 3.15\left(1 \mathrm{H}, \mathrm{dd}, \mathrm{J}=15.7\right.$ and $\left.9.3 \mathrm{~Hz}, \mathrm{H}_{\mathrm{b}}-1^{\prime \prime}\right), 1.144(3 \mathrm{H}, \mathrm{s}, \mathrm{H}-$ $\left.5^{\prime \prime}\right), 1.137$ (3H, s, H-4"'); ${ }^{13} \mathrm{C}-\mathrm{NMR}$ (DMSO-D $\left.6,150 \mathrm{MHz}\right) \delta 158.8$ (C-3' ,5' ), 158.3 (C-6), 154.2 (C-7a), 154.1 (C-2), 131.7 (C-1' ), 124.2 (C-5), 121.8 (C-3a), 116.1 (C-4), 102.5 (C4' ), 102.1 (C-2' ,6' ), 101.7 (C-3), 92.2 (C-7), 90.0 (C-2"), 70.1 (C-3"), 29.5 (C-1"), 26.1 $\left(\mathrm{C}-4^{\prime \prime}\right), 24.8\left(\mathrm{C}-5^{\prime \prime}\right)$.

\subsubsection{Structure of the compounds}

In this study, eleven phenolic compounds were isolated from the root bark of M. nigra, including four prenylated flavone (1-3 and 9), three arylbenzofurans $(\mathbf{4}, 5$ and $\mathbf{1 1})$, a stilbene (8), and three more complex Diels-Alder adducts of prenylated phenolic 
fragments $(6,7$ and 10). Structures of these compounds, together with those obtained by semi-synthesis from morusin (1), are shown in Fig. 10.

A.<smiles>CC(C)=CCc1c(-c2ccc(O)cc2O)oc2c3c(cc(O)c2c1=O)OC(C)(C)C=C3</smiles>

Morusin (1)<smiles>COc1cc(O)c(C2CC(=O)c3c(O)cc(O)cc3O2)cc1C(C)/C=C(\C)CCC=C(C)C</smiles>

Kuwanon U (2)<smiles>CC(C)=CCC/C(C)=C/C(C)c1cc(C2CC(=O)c3c(O)cc(O)cc3O2)c(O)cc1O</smiles>

Kuwanon E (3)<smiles>CC1(C)Oc2cc3oc(-c4cc(O)cc(O)c4)cc3cc2CC1O</smiles>

Moracin P (4)<smiles>CC(C)(O)C1Cc2cc3cc(-c4cc(O)cc(O)c4)oc3cc2O1</smiles>

Moracin O (5)<smiles>Cc1cc2c3c(c1)-c1c(O)cc(-c4cc5ccc(O)cc5o4)cc1OC3(c1ccc(O)cc1O)Oc1cc(O)ccc1-2</smiles>

Albanol B (7)<smiles>Oc1cc(O)cc(C=Cc2ccc(O)cc2O)c1</smiles>

Oxyresveratrol (8)<smiles>CC1=CC(c2c(O)cc(-c3cc4ccc(O)cc4o3)cc2O)C(C(=O)c2ccc(O)cc2O)C(c2cc(O)cc(O)c2)C1</smiles>

Mulberrofuran $C(\mathbf{1 0})$<smiles>COc1cc(O)cc(-c2cc3cc(O)ccc3o2)c1</smiles>

Kuwanon C (9)<smiles>CC(C)=CCc1c(-c2ccc(O)cc2O)oc2c(CC=C(C)C)c(O)cc(O)c2c1=O</smiles>

B.<smiles>CC1(C)C=Cc2c(cc(O)c3c(=O)c4c(oc23)-c2ccc(O)cc2OC(C(C)(C)O)C4)O1</smiles>

Neocyclomorusin (12)<smiles>CC(C)CCc1c(-c2ccc(O)cc2O)oc2c3c(cc(O)c2c1=O)OC(C)(C)C=C3</smiles>

Dihydromorusin (13)<smiles>CC(C)CCc1c(-c2ccc(O)cc2O)oc2c3c(cc(O)c2c1=O)OC(C)(C)CC3</smiles>

Tetrahydromorusin (14)

Figure 10. Structures of the compounds prepared in this study. A. Compounds 1-11 were isolated from the root bark of Morus nigra. B. Compounds 12-14 were semisynthesized from morusin (1). The racemic neocyclomorusin (12) was separated to the enantiopure 12a and 12b by preparative chiral HPLC, but due to the same bioactivities exerted by them (see section 5.4.4), their absolute configuration was not assigned. 


\subsection{Pharmacological activity}

\subsubsection{Anti-Spasmodic activity}

In collaboration with the group of Dr. Róbert Gáspár (Department of Pharmacology and Pharmacotherapy, Interdisciplinary Excellence Centre, University of Szeged), compounds 1-7 were subjected to an ex vivo bioassay to assess their antispasmodic potential on isolated rat ileum and trachea. First, a primary screening was performed through a 3-points assay. In this preliminary bioassay, morusin (1), kuwanon E (3), moracin P (4), and albanol A (6) had only non-significant relaxing activity (or no action) on the rat ileal contractions. Additionally, except for albanol A (6), these compounds elicited a very moderate tracheal tone reducing effects that were also much lower than that of papaverine. However, a remarkable activity was found for kuwanon U (2), moracin O (5) and albanol B (7) on both experimental models, therefore these compounds were further studied for their efficacy The subsequent 8-points assay revealed that compounds $\mathbf{2 , 5}$, and $\mathbf{7}$ are equipotent with papaverine in the inhibition of ileal contractions (Table 2). Further, each of these compounds showed a tendency for higher $\mathrm{E}_{\max }$ value on ileal contraction than that of papaverine, and in the case of moracin O (5), this was statistically significant. Regarding the compounds' activity on the tracheal tone, similar results were obtained. The three studied compounds exerted their $50 \%$ activity at the same, low nanomolar concentration range as papaverine. Furthermore, moracin $\mathrm{O}(\mathbf{5})$ exerted a significantly stronger maximum decrease in the tracheal tone as compared to papaverine.

Table 2. Smooth muscle relaxant activity of compounds 2, 5, and 7 on isolated rat ileum and trachea.

$\mathrm{EC}_{50}$ and $\mathrm{E}_{\max }$ values on the ileal contractions and tracheal tone are presented. Papaverine was used as a positive control of both experimental models. *: $p<0.05$ as compared to the effect of papaverine using one-way ANOVA followed by Tukey's post-hoc test.

\begin{tabular}{|l|c|c|c|c|}
\hline \multirow{2}{*}{ Compound } & \multicolumn{2}{|c|}{ Ileal contractions } & \multicolumn{2}{c|}{ Tracheal tone } \\
\cline { 2 - 5 } & $\begin{array}{c}\mathrm{EC}_{50} \pm \mathrm{SEM} \\
(\mu \mathrm{M})\end{array}$ & $\begin{array}{c}\mathrm{E}_{\max } \pm \mathrm{SEM} \\
(\%)\end{array}$ & $\begin{array}{c}\mathrm{EC}_{50} \pm \mathrm{SEM} \\
(\mu \mathrm{M})\end{array}$ & $\begin{array}{c}\mathrm{E}_{\max } \\
(\mathrm{mg} \pm \mathrm{SEM})\end{array}$ \\
\hline kuwanon U (2) & $0.13 \pm 0.04$ & $70.5 \pm 6.1$ & $0.033 \pm 0.05$ & $247.8 \pm 9.9$ \\
\hline moracin O (5) & $1.1 \pm 0.43$ & $85.3 \pm 4.4^{*}$ & $0.062 \pm 0.01$ & $309.5 \pm 17.7^{*}$ \\
\hline albanol B (7) & $1.3 \pm 0.98$ & $83.2 \pm 3.9$ & $0.100 \pm 0.05$ & $254.9 \pm 19.3$ \\
\hline papaverine & $0.44 \pm 0.15$ & $63.6 \pm 6.3$ & $0.074 \pm 0.03$ & $233.7 \pm 15.4$ \\
\hline
\end{tabular}

To the best of our knowledge, this is the first report of the smooth muscle relaxant activity of compounds $\mathbf{2}, \mathbf{5}$, and $\mathbf{7}$. The bioactivity of these compounds is of high potential 
therapeutic interest: kuwanon U (2) and albanol B (7) are equipotent with the opium alkaloid antispasmodic drug papaverine, and moracin $\mathrm{O}(\mathbf{5})$ exerted an even stronger effect than that.

\subsubsection{SERCA activity}

Compounds 1-7 were also tested for their activity on skeletal muscle sarco/endoplasmic reticulum $\mathrm{Ca}^{2+}$-ATPase 1 (SERCA1). Among the tested compounds, albanol A (6) and $\mathrm{B}$ (7) were identified as the most potent inhibitors of SERCA1 activity, whereas Moracin P (4) and O (5) were inactive. Binding of compounds 1-7 to SERCA1 (PDB ID: 3w5c), and the binding energies showed a good correlation to the compounds' activity as SERCA1 inhibitors. Further, based on similarities in SERCA isoforms, the compounds' effect was also tested on the viability of INS-1E rat insulinoma cells, a common model of pancreatic beta cells that express SERCA2b; the results are shown in Table 3.

Table 3. Interaction of phenolic compounds with SERCA1 and their effect on the viability of INS-1E beta-cells.

Results of E score function and $\log \mathrm{P}$ were obtained from the MOE software, SERCA1 activity was measure by the NADH-coupled enzyme assay, and viability of INS-1E betacells was assessed by the MTT assay.

\begin{tabular}{|l|c|c|c|c|c|c|}
\hline \multicolumn{1}{|c|}{ Compound } & $\begin{array}{c}\text { MOE-E } \\
\text { Score }\end{array}$ & \multirow{2}{*}{ Log P } & \multicolumn{2}{c|}{ Serca ATPase Activity } & \multicolumn{2}{c|}{ Beta Cell Viability } \\
\cline { 4 - 7 } & & $\mathrm{IC}_{50}(\mu \mathrm{M})$ & $\mathrm{R} \mathrm{Square}$ & $\mathrm{IC}_{50}(\mu \mathrm{M})$ & R Square \\
\hline Albanol A (6) & -12.62 & 5.79 & 18.88 & 0.95 & 18.22 & 0.93 \\
\hline Albanol B (7) & -10.85 & 5.77 & 24.56 & 0.96 & 18.17 & 0.85 \\
\hline Kuwanon E (3) & -10.03 & 5.24 & 29.43 & 0.97 & 28.65 & 0.96 \\
\hline Kuwanon U (2) & -9.43 & 5.64 & 35.62 & 0.91 & 64.82 & 0.95 \\
\hline Morusin (1) & -8.84 & 5.23 & 43.57 & 0.97 & 28.65 & 0.91 \\
\hline Moracin P (4) & -6.45 & 2.49 & - & - & 108.6 & 0.94 \\
\hline Moracin O (5) & -5.21 & 2.83 & - & - & 111.4 & 0.96 \\
\hline
\end{tabular}

SERCA1 binding site to the compounds was also analyzed experimentally using the fluorescence marker (FITC) to measure alterations in the cytosolic region, and using intrinsic tryptophan fluorescence to analyze alterations in the transmembrane region of the protein. Kuwanon E, U, Morusin, moracin $\mathrm{P}$, and $\mathrm{O}$ showed binding in or near the ATP binding site as suggested by significantly decreased FITC fluorescence. Interaction in the transmembrane region was also observed for these compounds except for Moracin $\mathrm{P}$ and $\mathrm{O}$, whereas no conformational change in either region of SERCA1 was seen with albanol A and B. These latter two compounds were also the strongest inhibitors with intensive 
binding energy to SERCA1, therefore their binding mode was studied by in silico docking more in detail. Briefly, it was found that albanol A immerses in the luminal gate at the $\mathrm{Ca}^{2+}$ release site in the ER lumen. Kuwanon U, as a compound representing the ability to induce conformational changes in both the cytosolic and transmembrane regions of SERCA1, was also analyzed in greater detail by molecular docking. This study confirmed the binding of kuwanon $\mathrm{U}$ in both regions, and suggested the assumption that its SERCA1 inhibition is due to the occupation of residues Phe487 and Gln202 in the cytosolic region which may prevent ATP binding.

The compounds were also tested for their potential to alter expression of SERCA2b in INS$1 \mathrm{E}$ cells, to induce apoptosis, and to alter basal and/or glucose-induced insulin release in INS-1E cells. Briefly, the compounds' activity on SERCA2b expression showed an inverse correlation with their SERCA1 inhibitory activity, i.e. albanol A and B significantly increased the expression of SERCA2b. Interestingly, moracin P (4) was also similarly active in this regard as albanol B (7). Further, a 24-hours incubation of the cells with albanols $(6,7)$, kuwanons $(2,3)$ and moracins $(4,5)$ at concentrations corresponding to the $\mathrm{IC}_{50}$ values led to a significant, ca. $30-35 \%$ increase in the rate of early apoptotic cells, while in case of morusin the change in early apoptotic cells was not significant and late apoptotic cells showed an over $40 \%$ increase instead. None of the compounds interfered with the basal insulin release, but all of them decreased the glucose-stimulated insulin release, and albanol A (6) and B (7) were the most potent in this regard.

\subsubsection{Antitumor activity on human breast cancer cells}

The in vitro anticancer activity of morusin (1) and its semi-synthetic derivatives (12-14) was evaluated against two human breast cancer cell lines: MCF-7 (estrogen receptor positive; ER+) and MDA-MB-231 (triple-negative; TNBC) by MTT assay after a $72 \mathrm{~h}$ treatment, results are shown in Table 4.

According to our results, the oxidative ring closure between the B-ring of morusin and the 3-prenyl group results in a complete loss of the antiproliferative activity against the two tested breast cancer cell lines. In contrast with this, saturation of the olefins in one or both prenyl functions leads to an increased activity, and particularly in the case of tetrahydromorusin (14) this increase is nearly two-fold on both cell lines. It is also 
noteworthy, that cell line specificity of morusin (i.e. ca. 1.5-times stronger effect on MCF-7 than on MDA-MB-231) did not change upon hydrogenation.

Table 4. Antiproliferative activities of morusin (1) and its oxidized (12) and reduced (1314) derivatives against human breast cancer cell lines. C.I.: $95 \%$ confidence interval, $n=6$ from two biological replicates $(\mathrm{n}=3$ each).

\begin{tabular}{|c|c|c|}
\hline \multirow{2}{*}{} & \multicolumn{2}{|c|}{$\mathrm{IC}_{50}[95 \%$ confidence interval $](\mu \mathrm{M})$} \\
\cline { 2 - 3 } & MCF-7 & MDA-MB-231 \\
\hline $\mathbf{1}$ & 29.0 & $\sim 48.6$ \\
& {$[27.4-30.7]$} & $>100$ \\
\hline $\mathbf{1 2}$ & $>100$ & 30.6 \\
$\mathbf{1 3}$ & 20.8 & {$[28.0-33.4]$} \\
\hline $\mathbf{1 4}$ & {$[19.4-22.4]$} & 24.7 \\
& 15.5 & {$[23.2-26.2]$} \\
\hline
\end{tabular}

\subsubsection{Antitumor and efflux pump inhibitory activity on an MDR cancer cell model}

Based on the ABCB1 inhibitory activity of the oxidized morusin mixtures, neocyclomorusin (12), isolated from such a mixture, was tested on a mouse lymphoma cancer cell line pair, i.e. L5178 cells and their MDR counterpart L5178 $8_{\mathrm{B} 1}$ expressing the human $\mathrm{ABCB} 1$ transporter. Results are shown in Table 5.

Table 5. Antiproliferative, cytotoxic and $\mathrm{ABCB} 1$-inhibitory activities of morusin (1) and the two enantiomers of neocyclomorusin (12a and 12b) on L5178 cells and multi-drug resistant L5178 ${ }_{B 1}$ cells. C.I.: 95\% confidence interval, $n=4$. For ABCB1 inhibition, 20nM tariquidar was used as positive control (inh. 87.5\%). Cross-resistance: $\mathrm{CR}=\mathrm{IC}_{50}{ }^{\mathrm{MDR}} / \mathrm{IC}_{50}{ }^{\mathrm{PAR}}$

\begin{tabular}{|c|c|c|c|c|c|c|c|c|}
\hline & \multicolumn{3}{|c|}{ Antiproliferative } & \multicolumn{3}{|c|}{ Cytotoxicity } & \multirow{2}{*}{\multicolumn{2}{|c|}{$\begin{array}{c}\text { ABCB1 } \\
\text { inhibition }(\%)\end{array}$}} \\
\hline & $\mathrm{IC}_{50}[95 \%$ & C.I.] $(\mu \mathrm{M})$ & & $\mathrm{IC}_{50}[95 \%$ & C.I.] $(\mu \mathrm{M})$ & & & \\
\hline & L5178 & $\mathrm{L} 5178_{\mathrm{B} 1}$ & CR & L5178 & L5178 ${ }_{\mathrm{B} 1}$ & CR & $2 \mu \mathrm{M}$ & $20 \mu \mathrm{M}$ \\
\hline 1 & $\begin{array}{c}14.5 \\
{[12.6-16.6]}\end{array}$ & $\begin{array}{c}25.8 \\
{[22.7-29.2]}\end{array}$ & 1.8 & $\begin{array}{c}46.7 \\
{[40.4-53.9]}\end{array}$ & $\begin{array}{c}48.4 \\
{[44.4-52.6]}\end{array}$ & 1.0 & 0 & 8.6 \\
\hline 12a & $\begin{array}{c}6.5 \\
{[5.5-7.8]} \\
\end{array}$ & $\begin{array}{c}27.9 \\
{[24.1-32.2]}\end{array}$ & 4.3 & $\begin{array}{c}27.2 \\
{[24.6-30.2]}\end{array}$ & $\begin{array}{c}47.2 \\
{[38.8-57.5]}\end{array}$ & 1.8 & 0 & 55.3 \\
\hline $12 b$ & $\begin{array}{c}8.5 \\
{[7.3-9.9]}\end{array}$ & $\begin{array}{c}21.8 \\
{[19.9-23.8]}\end{array}$ & 2.6 & $\begin{array}{c}20.2 \\
{[17.5-23.3]}\end{array}$ & $\begin{array}{c}35.8 \\
{[31.3-41.0]}\end{array}$ & 1.8 & 0 & 48.8 \\
\hline
\end{tabular}

The two neocyclomorusin enantiomers (12a and 12b) exerted similar activities, indicating that the configuration of the newly formed stereocenter has little if any impact on their bioactivity. Further, they were more potent than their parent compound morusin against the L5178 lymphoma cells, both in terms of antiproliferative and cytotoxic activity. This was not the case on the MDR cells, in other words, the ABCB1 expressing MDR cells showed an increased cross-resistance to 12a and 12b as 
compared with that to morusin. This was particularly true in the antiproliferative assay's experimental setup. Further, as expected from the oxidized mixtures' activity, neocyclomorusin exerted a stronger effect as an inhibitor of ABCB1-mediated efflux, with a ca. $50 \%$ inhibition at $20 \mu \mathrm{M}$.

\section{DISCUSSION}

\subsection{Isolation of phenolic compounds}

Bioactive compounds from Morus nigra belong to various chemical groups of a wide polarity range [160]. Because of this, excessive percolation with the amphipolar methanol was selected to extract possibly all potential target compounds, but such extracts contain a wide range of contaminating compounds. The phenolics present in a methanol extract can be separated by solvent-solvent partition, so that the $n$-hexane layer contains mostly the lipids, and the targeted phenolic constituents concentrate in the ethyl acetate layer.

Preparative-scale classical adsorption chromatography on polyamide is also a valuable method in the preliminary purification. This stationary phase has a very high capacity that makes it economic in the separation of samples in larger amounts [161]

Polyamide is known to strongly bind compounds with phenolic hydroxyl groups through hydrogen bonding [162], and the retention of such compounds depends on the number and positions of the hydroxyl groups [163]. Further, polyamide is an especially versatile stationary phase since it can be used both in normal and reverse-phase mode depending on the mobile phase polarity, and this fundamentally influences retention mechanisms [164]. To exploit this, we performed a consecutive normal- and a reverse-phase separation step on the same stationary phase for most of our initial fractions at the beginning of our separation procedure.

After preliminary purification, a multistep procedure of combined chromatographic methods was performed for the isolation of bioactive phenolic compounds, following well established strategies for natural product isolation $[165,166]$, and each step was monitored by TLC. Other than providing an easy and convenient way to analyze chromatographic fingerprints of each fraction, TLC also served as a useful tool to assist choosing the chromatographic systems for each consecutive step. Our overall isolation strategy included an effort to maximize efficiency by a consecutive use of chromatographic techniques 
representing large differences in their selectivity. A general overview of our isolation strategy is shown in Fig. 11.

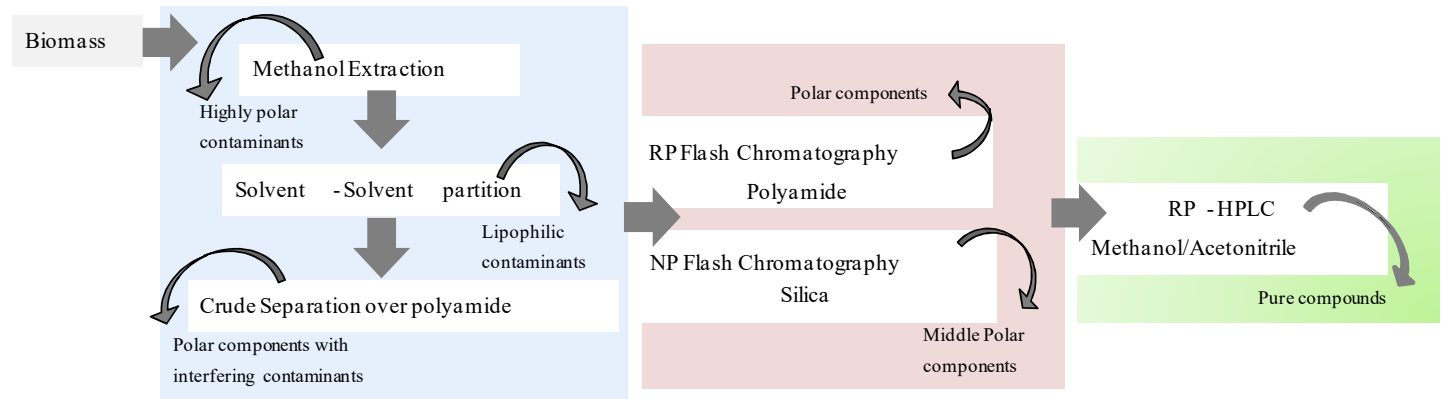

Figure 11. Scheme of the employed isolation strategy

Fractionation of the pre-purified extract was performed by extensive flash chromatography on silica with a range of solvents from hexane to methanol, or polyamide in reverse phase mode.

M. nigra contains a very high structural diversity of phenolic compounds many of which represent similar polarity [160], therefore a high chemical complexity of the fractions was frequently observed even at an advanced state of the purification procedure. For this reason, final purification was carried out by RP-HPLC with different isocratic programs. When selecting the stationary phase, most separations were developed starting with core-shell XB-C18 columns with acetonitrile-based mobile phases that typically showed an excellent performance in isolating our target compounds. In several cases, however, switching to phenyl-bonded (core-shell XB-biphenyl) columns became necessary; due to the fact that mechanism of retention for such columns includes $\pi$ $\pi$ interactions with the analytes [167], phenyl-bonded phases provide excellent alternatives to C18 columns when separating aromatic compounds of otherwise similar polarity. Concerning separations on phenyl-bonded columns, it is known that methanol enhances $\pi$ $\pi$ interactions as compared with acetonitrile that weakens them $[168,169]$, and since these interactions are the main reason for extra selectivity over C18 columns, we favored methanol-based mobile phases on the biphenyl columns. The extent of this mobile phase effect on the selectivity may be well illustrated by the challenging separation of Moracin $\mathrm{P}$ (4) and Moracin O (5) in our study (see Fig. 8 and Table 1). These compounds co-eluted from the biphenyl column as a single sharp peak $\left(t_{R}=18.9 \mathrm{~min}\right)$ when acetonitrile $(a q)$ was used but showed an excellent separation $\left(t_{R}=13.7\right.$ and $\left.17.0 \mathrm{~min}, \mathrm{R}_{\mathrm{s}}=2.5\right)$ on the same column when the solvent system was methanol $(\mathrm{aq})$. 
With combined chromatographic methods, eleven pure phenolic compounds were isolated among them two were isolated for the first time from the roots of this plant.

\subsection{Preparation of Semi-synthetic derivatives}

Morusin, a prenyl flavonoid isolated in higher amounts, was subjected to oxidation under various conditions, and reduction through catalytic hydrogenation to produce potentially bioactive semi-synthetic analogs.

Concerning oxidation, several oxidative conditions using transition metal catalysts were employed, and two hypervalent iodine reagents (PIFA and PIDA) that are known mild and selective phenolic oxidizing agents. PIFA and PIDA were also selected based on their ability to oxidize through single-electron transfer (SET) resulting in a cation radical, which upon deprotonation gives the same phenoxyl radical that is formed through hydrogen atom abstraction (HAT), a common mechanism in free radical scavenging by phenolic antioxidants. Therefore, these reactions led to the preparation of oxidized mixtures containing a wide range of potentially biorelevant metabolites.

Bioactivity screening of the obtained mixtures (not discussed here in detail) turned our attention to a compound whose presence in several mixtures seemed to coincide with an increased inhibitory activity on the ABCB1 efflux transporter. This compound, identified after isolation as neocyclomorusin (12), was a major product of PIDA-mediated oxidation in anhydrous acetonitrile. This solvent, possessing a high ionizing power with a low nucleophilicity, may not only stabilize the aromatic cation radical species but it is also favorable for the spontaneous elimination of iodobenzene from the reagent $[170,171]$.

Neocyclomorusin (12) has previosly been isolated from another Morus species, $M$. lhou [172]. According to a recent report, the palladium-catalyzed intramolecular oxidative cyclization of kuwanon $\mathrm{F}$ under $\mathrm{N}_{2}$ atmosphere afforded cyclomorusin as a major product and neocyclomorusin as the side product [134]. The oxidative cyclization of morusin using manganese dioxide afforded morusin hydroperoxide and neocyclomorusin in $35 \%$ and $2 \%$ yield respectively. In another study, the use of silver dioxide for the cyclization of morusin favored the production of morusin hydroperoxide with $85 \%$ yield [132]. The photooxidation of morusin by bright sunlight or a high-pressure mercury lamp also produced morusin hydroperoxide (ca. $80 \%$ yield) and this can be reduced by sodium borohydride to form neocyclomorusin [133]. In contrast, when we used PIDA, the reaction favored the production of 
neocyclomorusin with a fair, 25\% yield. Since we did not attempt any yield optimization, this reaction may serve as a starting point towards a one-step procedure to obtain neocyclomorusin from morusin in a more favorable manner as compared to the previous methods.

The hydrogenation of Morusin was catalyzed by palladium under $\mathrm{H}_{2}$ atmosphere that is a commonly used strategy to prepare saturated olefins. The geometry of a molecule plays an important part since contact with the catalyst is of high importance [173]. Based on the conjugation of the D-ring with the aromatic A-ring, it was expectable that hydrogenation should first take place at the 3-prenyl sidechain of morusin, whereas later both the D ring and the prenyl moiety were hydrogenated. In a related study, the hydrogenation of prenylflavonoids khonklonginol A and lupinifolinol (both of which containing an 8prenyl group and a 2,2-dimethyl-2H-pyran ring similar to the D-ring of morusin) was reported to take place both at the D-ring and the prenyl chain [174]. Here we also succeeded in obtaining the selectively hydrogenated product (13).

\subsection{Structure elucidation of the compounds obtained}

The phenolic compounds isolated from the roots of Morus nigra belong to several compound groups such as flavonoids, arylbenzofurans, stilbenes, and Dies-Alder type adducts. The isolated flavonoids contain terpenic side chains namely prenyl and geranyl substitutions. The biosynthesis of prenyl chains involves the membrane-bound proteins named as flavonoid prenyltransferases strictly specific to flavonoid substrates. Compound (1) Morusin a prenyl flavone, has the presence of both a 3-prenyl chain and 2'-hydroxyl group, which can further be cyclized to form cyclomorusin[7]. Kuwanon C (9) also known as mulberrin is a dehydro-prenylflavone, considered to form kuwanon $G$ through an enzymatic Diels-Alder reaction with a chalcone [175]. Kuwanon U (2) and Kuwanon E (3) are geranylflavanones, these side attachments of flavonoid compounds involve the action of the specific chain lengthening enzymes, geranyl pyrophosphate synthases [176]. Although no enzyme work has yet been reported, the enzymatic synthesis of these compounds may involve geranylation of the corresponding flavonoids, similarly to the prenylation. In addition, moracin $\mathrm{P}, \mathrm{O}$, and $\mathrm{M}(4,5$, and $\mathbf{1 0}$, respectively) contain furan ring that is often produced through cyclization of the terpenoid chains with an ortho-phenolic hydroxyl to yield various oxidized five-membered rings. Cyclization of the isoprenoid side chain seems to be catalyzed by prenyl cyclases [177]. Compound 8 was identified as the 
stilbene oxyresveratrol, an aglycone of mulberroside A [178]. Albanol A and B, and mulberofuran $\mathrm{C}(\mathbf{6}, 7$, and 11, respectively) were identified as Diels-Alder adducts from a prenylchalcone and a dehydroprenyl-2-arylbenzofuran [159]. Interestingly, not only these DielsAlder adducts but also their arylbenzofuran precursor fragments (i.e. kuwanon E, 2; moracin M, 11; and moracin $\mathrm{O}, 5$ ) were isolated in this work.

When comparing the NMR chemical shifts of compounds $\mathbf{4}$ and $\mathbf{5}$ with literature data, we found some contradictory spectral data concerning moracin $\mathrm{P}$ and two related arylbenzofurane derivatives, moracins $\mathrm{Q}$ and $\mathrm{R}$. In the paper reporting the first isolation of moracins Q and R [179] chemical shifts of the prenyl-originated dimethyl-dihydropirane ring of moracin $\mathrm{Q}$, i.e. the dimethoxy derivative of moracin $\mathrm{P}$, were assigned as nearly identical to those previously reported for the substituted dihydrofurane ring of moracin $\mathrm{O}$ [180]. Further, the same paper [179] reported chemical shifts of the prenyl side-chain of moracin $\mathrm{R}$ nearly identical to those previously published for the analogous prenyloriginated ring of moracin $\mathrm{P}$ [180].

First, we attempted to clarify this through HRESIMS, but both compounds $\mathbf{4}$ and $\mathbf{5}$ showed the same elemental compositions, i.e. $\mathrm{C}_{19} \mathrm{H}_{18} \mathrm{O}_{5}$. Considering that both moracins $\mathrm{P}$ and $\mathrm{O}$ may be formed from moracin $\mathrm{R}$ by a water elimination, this may still have meant that the molecular ion of moracin $\mathrm{R}$ could not be observed. It is worth noting that moracin $\mathrm{R}$ was reported with high-resolution mass spectral data referring to the $\left[\mathrm{M}-\mathrm{H}_{2} \mathrm{O}\right]^{+} \mathrm{m} / \mathrm{z}$ value [179]. Compound 4 was obtained as a brown amorphous powder. The molecular formula was determined as $\mathrm{C}_{19} \mathrm{H}_{18} \mathrm{O}_{5}$ by HRESIMS. Signal assignment of the ${ }^{1} \mathrm{H}$ NMR spectrum (Fig. S1) revealed the presence of a disubstituted 2-arylbenzofuran moiety, a trisubstituted 2,2dimethyldihydropyran ring, and a 1,3,5-trisubstituted benzene ring. The ${ }^{13} \mathrm{C}$ measurement showed 16 signals corresponding to 18 carbon atoms, including two methyls, one methylene, one $\mathrm{sp}^{3}$ oxymethyne and one $\mathrm{sp}^{3}$ quaternary carbon, and in the $\mathrm{sp}^{2}$ region further six methyne, three quaternary carbon and five oxyaryl carbon atoms. The HSQC experiment revealed the one-bond ${ }^{1} \mathrm{H} /{ }^{13} \mathrm{C}$ connections, while the $\mathrm{HMBC}$ measurement allowed the assignment of the quaternary carbon atoms through the ${ }^{2} J_{\mathrm{H}, \mathrm{C}}$ and ${ }^{3} J_{\mathrm{H}, \mathrm{C}}$ couplings. Based on the above spectroscopic evidence, compound 4 was unambiguously identified as moracin P. Therefore, previous assignment of the structure of this compound was correct [180], and this conclusion is also supported by reports on other moracin $\mathrm{P}$ derivatives [181-183]. 
The condensed dimethyldihydropyran ring of moracin P (4) appears in an equilibrium of two half-chair conformations where C-2" and C-3" are the atoms out of a plane. The unambiguous identification of the chemical shifts of the cis and trans located methyl/methine hydrogens was achieved utilizing the two-dimensional NOESY measurement $\left(\tau_{\text {mixing }}=300 \mathrm{~ms}\right)$. The $2.83 / 1.28$ cross-peak assigned that in the preferred conformation $\mathrm{H}-1{ }^{\prime \prime} / \mathrm{CH}_{3}(\delta=1.28)$ are cis and take the $1^{\prime \prime} / 3^{\prime \prime}$ diaxial position. The ${ }^{3} J\left(\mathrm{H}_{\text {trans }}{ }^{-}\right.$ $\left.1^{\prime \prime}, \mathrm{H}-2^{\prime \prime}\right)>{ }^{3} J\left(\mathrm{H}_{\mathrm{cis}}-1^{\prime \prime}, \mathrm{H}-2^{\prime \prime}\right)$ values $(7.6 \mathrm{~Hz} / 5.2 \mathrm{~Hz})$ supported preference of the depicted conformation.

Compound 5 was obtained as a brown amorphous powder. The molecular formula was determined also, in this case, to be $\mathrm{C}_{19} \mathrm{H}_{18} \mathrm{O}_{5}$ by HRESIMS. The ${ }^{1} \mathrm{H}$ and ${ }^{13} \mathrm{C}$ APT NMR spectra exhibited signals rather similar to those obtained for $\mathbf{4}$, indicating that they should be structural isomers. The spectra suggested the presence of a disubstituted 2arylbenzofuran moiety and a 1,3,5-trisubstituted benzene ring. Considering the HMBC correlations of the $\delta \mathrm{H}-2^{\prime \prime}(4.64 \mathrm{ppm})$ atom with the $\delta \mathrm{C}-5$ (125.2 ppm) and $\delta$ C-6 (160.0 ppm), the third ring of compound $\mathbf{5}$ is a condensed dihydrofuran ring substituted with a 2hydroxy-propyl group (HO-C( $\left(\mathrm{Me}_{2}\right)$-), suggesting that this compound should be moracin $\mathrm{O}$. The NMR signal assignment was also supported by the HSQC, HMBC and NOESY spectra. It needs to be stressed that NMR measurements taken in $\mathrm{CD}_{3} \mathrm{OD}$, or in other solvents where no separated $\mathrm{OH}$ signals can be observed, provide no information on the number of the $\mathrm{OH}$ groups. To overcome this uncertainty, we have taken the NMR investigations $\left({ }^{1} \mathrm{H},{ }^{13} \mathrm{C}\right.$, edited HSQC, HMBC) of compound 5 also in DMSO-D 6 .

Clear differentiation between moracin $\mathrm{O}$ and moracin $\mathrm{R}$ can be accomplished by detecting the $\mathrm{OH}$ signals in the ${ }^{1} \mathrm{H}$ NMR spectrum: moracin $\mathrm{R}$ contains five, whereas Moracin $\mathrm{O}$ only three $\mathrm{OH}$ groups. In the ${ }^{1} \mathrm{H}$ spectrum, two new singlets appeared at $\delta 9.43(2 \mathrm{H})$ and $4.63(1 \mathrm{H})$, and these did not give HSQC cross-peaks justifying the presence of three hydroxyl groups. Since the values of ${ }^{1} \mathrm{H}$ and ${ }^{13} \mathrm{C}$ chemical shifts have slightly changed in DMSO- $\mathrm{D}_{6}$ as compared to those observed in $\mathrm{CD}_{3} \mathrm{OD}$, HSQC and $\mathrm{HMBC}$ experiments were also performed to establish a complete ${ }^{1} \mathrm{H}$ and ${ }^{13} \mathrm{C}$ signal assignment. The limited resolution in the $\mathrm{F} 1$ dimension $\left({ }^{13} \mathrm{C}\right.$ ) of the routine $\mathrm{HMBC}$ experiment (optimized for $J_{C, H}=$ $8 \mathrm{~Hz}$ long-range couplings) did not allow the confident assignment of several quaternary ${ }^{13} \mathrm{C}$ signals. To achieve the required extremely high ${ }^{13} \mathrm{C}$ chemical shift resolution, the band selective HMBC experiment was the method of our choice. The 9.43/158.8 ppm cross-peak assigned the $3^{\prime}, 5^{\prime}-\mathrm{OH}$ positions, and the exact $\delta \mathrm{C}-3^{\prime}, 5^{\prime}$ chemical shifts, differentiating from 
the rather closely appearing C-6 $(\delta 158.3)$ peak. With the aid of the well-separated HMBC cross-peaks 6.66/154.1 and 7.34/154.2 ppm, respectively, the unambiguous assignment of the $\delta \mathrm{C}-2$ and $\delta \mathrm{C}-7 \mathrm{a}$ values became possible. Based on the above, compound 5 was clearly identified as moracin $\mathrm{O}$. As for the contradictory literature data, this also suggests that the compound previously reported as moracin $\mathrm{Q}$ is likely the dimethoxy derivative of moracin $\mathrm{O}$ instead of that of moracin P. Further, the chemical shifts reported for moracin R suggest a possible false assignment of the structure of this compound that was moracin $\mathrm{P}$ instead [179].

Concerning natural product isolation, it is a frequently arising question whether the isolated compounds are the ones present in the plant or is there a possibility for some of them to be formed during the process of isolation. Interestingly, several Diels-Alder type adducts isolated from the extract of the callus from $M$. nigra were different from those obtained from the root bark of the plant, not only for the cyclohexene ring substitution but also for the stereochemistry of the alicyclic ring (cis-trans in vitro in contrast with transtrans in vivo) [55]. However, in our current study, the HPLC chromatogram of the ethyl acetate layer of the pre-purified extract (that has not been affected by any adsorption chromatography) showed the presence of peaks corresponding to the isolated phenolic compounds, suggesting their presence in the (dried) roots before their isolation.

Many studies reported the isolation of moracin O (5) from M. nigra roots, whereas moracin P (4) was isolated by us for the first time from this herbal drug [60]. Both compounds have a very similar structure and they also share nearly similar UV absorption maxima at $217 \mathrm{~nm}$ and $319 \mathrm{~nm}(4)$, and $217 \mathrm{~nm}$ and $321 \mathrm{~nm}(5)$. According to the literature, albanol A, commonly known as mulberrofuran G, has been isolated from roots in many studies[55], however, a similar compound albanol B having a difference in benzene ring was not isolated so far. In our study, both compounds albanol A (6) and albanol B (7) were isolated in fair amounts, 75 and $85 \mathrm{mg}$, respectively.

\subsection{Biological activity of the isolated compounds}

\subsubsection{Antispasmodic activity of the isolated compounds}

Several prenylated phenolic compounds have previously been reported with vasorelaxant activity, but much higher concentrations were needed for a 50\% relaxation $[184,185]$. An extract of the prenylflavone-containing hops was reported to exert relaxant activity on rat ileum contractions ex vivo, but since the extracting solvent was water, it is unlikely that the 
active constituents were prenylated phenolics [186]. As the cases of bowel motility and bronchial asthmatic complaints are increasing $[187,188]$, the need to find new, potential, and natural drugs for the treatment of these disorders is growing.

Black mulberry preparations are also used as antispasmodic agents in folk medicine, but no related studies on this bioactivity of its isolated constituents have previously been available. In our study, seven phenolic compounds namely morusin, kuwanon U, kuwanon E, moracin P, moracin O, albanol A, and albanol B were tested. Based on our results, kuwanon $\mathrm{U}$, Moracin $\mathrm{O}$, and albanol $\mathrm{B}$ were identified as potential antispasmodic agents in both ileal and tracheal models, while kuwanon $\mathrm{E}$ that differs from kuwanon $\mathrm{U}$ only in a methoxy substitution was inactive. These compounds were further studied for their efficacy. Remarkably, the inhibition of ileal contractions revealed that kuwanon U, moracin $\mathrm{O}$, and albanol $\mathrm{B}$ were equipotent to papaverine, the well-known opium alkaloid and approved antispasmodic drug) concerning their $\mathrm{EC}_{50}$ values in both experimental models. Further, each of these compounds showed a tendency for higher $\mathrm{E}_{\max }$ value on ileal contraction than that of papaverine. With respect to the compounds' activity on the tracheal tone, similar results were obtained. The three studied compounds exerted their $50 \%$ activity at the same, low nanomolar concentration range as papaverine. This would warrant their further studies in intact animals. It is also remarkable that moracin $\mathrm{O}$ exerted a significantly stronger maximum decrease in the tracheal tone as compared to papaverine. Accordingly, this compound was identified as a new lead molecule, which may be further developed to a potent new gastrointestinal or tracheal relaxant, and/or may serve as a chemical starting point towards the development of a new class of spasmolytic drugs.

\subsubsection{SERCA activity of the isolated phenolic compounds}

Phenolic compounds are also known for their interaction with various proteins. According to previously published virtual screening and in vitro results, such compounds may also act on the transmembrane enzyme sarco/endoplasmic reticulum $\mathrm{Ca}^{2+}$-ATPase (SERCA) [189, 190]. SERCA transports $\mathrm{Ca}^{2+}$ into the ER and plays a key role in the maintenance of calcium homeostasis, and, through this, in cell death and survival [191]. Based on this, a growing body of evidence suggests that activating/restoring or inhibiting SERCA function may provide prospective strategies to combat various chronic diseases [191], e.g. SERCA inhibition may offer new ways against cancer stem cells [192]. In this study, we found that SERCA1 activity was effectively reduced by Albanols A and B, whereas Moracin P and O 
showed the weakest binding energy to SERCA1, without any inhibitory effects. This may be at least partially due to their lower octanol/water partition coefficients $(\log \mathrm{P})$, i.e. 2.8 and 2.5 for moracin $\mathrm{O}$ and $\mathrm{P}$, respectively, as compared to the other tested compounds (5.2-5.8). The compounds' effect on SERCA1 activity and the viability of insulinoma cells were observed in the same concentration range of treatment, which may support the significant role of SERCA in the regulation of these cells' viability.

While SERCA isoforms have distinct tissue specificity, they share functional similarities [193]. Therefore, the compounds were also tested for their effect on the expression of SERCA2b, a key regulator of the $\mathrm{Ca}^{2+}$ transport in pancreatic beta-cells [194]. Increased expression of SERCA2b was induced by the compounds with the strongest binding to SERCA1 (i.e. Albanol A and B), and a correlation was observed between the two effects, which suggests that the upregulation of SERCA2b may be an adaptation mechanism to SERCA1 inhibition. $\mathrm{Ca}^{2+}$-ATPases are involved in insulin response, and the compounds decreased the cells' ability to release insulin after glucose stimulation. This was in correlation with the compounds' SERCA1 inhibitory activity, and so was the ability of albanols and kuwanons to decrease beta-cell viability. Morusin exerted stronger effect in this regard as compared to that expected from its efficiency to inhibit SERCA1. This might be due to the capacity of morusin to decrease cell viability and induce apoptosis by other mechanisms, e.g. through the STAT3 signaling pathway [195]. Recent studies have reported a significant reduction of SERCA2b expression in pancreatic islets under diabetic conditions [191]. This can increase basal cytosolic $\mathrm{Ca}^{2+}$ levels, decrease insulin secretion and beta-cell proliferation along with an increase of beta-cell ER stress and death [196]. Understanding the molecular regulation of calcium homeostasis via SERCA and its impairment may be a novel therapeutic approach to treat diseases related to ER dysfunction.

\subsubsection{Anti-tumor activity of semi-synthetic morusin analogs}

Morusin has been thoroughly studied for its promising antitumor effects on various in vitro and in vivo models of tumor diseases including pancreas, cervical, breast, and colorectal cancer, and it also demonstrated potent activity against some cancer stem cell models [160]. Since this compound was isolated as a major constituent during our work, it was an 
ideal starting material to prepare semi-synthetic derivatives with possibly improved anticancer activity.

Neocyclomorusin was identified as an oxidized derivative that was able to inhibit $\left(\mathrm{IC}_{50} \mathrm{ca}\right.$. $20 \mu \mathrm{M})$ the ABCB1 multi-drug efflux transporter, unlike the practically inactive morusin. Acquired resistance due to the upregulation of this transporter represents a major problem in chemotherapy, and even though decades-long research efforts to develop selective and potent inhibitors have not resulted in a clinically applicable drug [197], it is still considered as a therapeutic target in fighting MDR cancer [198]. Several flavonoids have been reported to be able to inhibit this efflux pump, and prenylation at the A-ring (C-6 or C-8) is expected to increase the activity $[199,200]$. To the best of our knowledge, our study provides the first comparison of the activities of morusin and neocyclomorusin in this regard.

Dihydromorusin and tetrahydromorusin demonstrated superior cytotoxic activities against both MCF-7 and MDA-MB-231 cancer cell lines as compared with morusin. When searching the literature, we could not find any studies that would directly compare the in vitro cytotoxic activity of similar prenylflavones and their partially or fully hydrogenated derivatives. Nevertheless, this bioactivity increase might be connected to metabolic processes. Based on a study conducted with human liver microsomes, morusin is known to be metabolized mainly by the cytochrome P isoenzyme CYP3A4 to various hydroxylated products, and most of these metabolic steps take place on the prenyl side chain [201]. Several cancer cell lines including MCF-7 were shown to express high levels of CYP3A4 in connection with their resistance to chemotherapy [202]. Based on this, it seems a reasonable hypothesis that the observed bioactivity increase for hydrogenated compounds may be the result of their increased metabolic stability as compared with that of morusin. 


\section{SUMMARY}

Results of our study, aiming to prepare and evaluate bioactive phenolic compounds from Morus nigra root bark, can briefly be summarized according to the following.

Natural product isolation. The crude methanol extract was fractionated by a multistep separation procedure, including OCC, TLC, NP-FC, RP-FC, and RP-HPLC. The structures of the isolated compounds were elucidated using the spectroscopic method (NMR). Eleven phenolic compounds were isolated, and two of them, moracin P (4) and albanol B (7) were isolated for the first time from the roots of the plant. The isolated compounds belong to different groups namely geranyl and prenyl flavonoids, Diels-Alder type adducts, stilbene, and aryl benzofurans. Contradictory literature data on the moracin derivatives' NMR signal assignments, allowing misidentification, were clarified through the unambiguous assignment of compound $\mathbf{4}$ as moracin $\mathrm{P}$ and compound $\mathbf{5}$ as moracin $\mathrm{O}$.

Semi-synthesis. Morusin (1) was subjected to semi-synthetic transformations. A simple and effective method for the preparation of racemic neocyclomorusin (12) from morusin through a hypervalent iodine-catalyzed oxidation was developed, and the enantiomers 12a and 12b were also isolated by chiral HPLC to allow their bioactivity testing in enantiopure form. Further, two hydrogenated analogs of morusin were produced through catalytic hydrogenation.

Bioactivity testing - antispasmodic activity. Pharmacological analysis of the isolated compounds revealed that several compounds possess significant antispasmodic activity ex vivo. Kuwanon U (2), moracin O (5), and albanol B (7) exerted remarkably strong activity on rat ileal and tracheal smooth muscles. Kuwanon $U$ and albanol $B$ were found to be equipotent with the approved drug papaverine, whereas moracin $\mathrm{O}$ was proved to be superior to papaverine in both models.

Bioactivity testing - activity on SERCA. Several compounds were found efficient inhibitors of SERCA1, and their activity correlated with their in silico docking scores and with their effect on SERCA2b expression, and with their ability to modulate viability and apoptosis in a pancreatic beta cell model.

Bioactivity testing - antitumor activity. Both neocyclormorusin enantiomers showed stronger activity as $\mathrm{ABCB} 1$ inhibitors as compared with morusin, while, at the same time, over-expressed ABCB1 conferred stronger cross-resistance to them. Saturation of one or both non-aromatic olefins present in morusin led to a significantly increased cytotoxic 
activity on two breast cancer cell lines, and tetrahydromorusin was ca. twice as active in this regard than morusin.

Our results demonstrate that Morus nigra roots constitute a rich source of biologically active phenolic metabolites with great structural diversity. The investigated compounds, as well as the semi-synthetic analogs, can be regarded as promising starting materials in the search for new pharmaceutical discoveries in the future. In consequence, the elucidation of their mechanism of action can be a good basis for developing new effective agents against several pharmacological conditions. 


\section{REFERENCES}

1. Newman, D.J. and G.M. Cragg, Natural Products as Sources of New Drugs from 1981 to 2014. J Nat Prod, 2016. 79(3): p. 629-61.

2. Quideau, S., Flavonoids. Chemistry, Biochemistry and Applications. Edited by Øyvind M. Andersen and Kenneth R. Markham. 2006. 45(41): p. 6786-6787.

3. Hunyadi, A., The mechanism(s) of action of antioxidants: From scavenging reactive oxygen/nitrogen species to redox signaling and the generation of bioactive secondary metabolites. Med Res Rev, 2019. 39(6): p. 2505-2533.

4. Cheng, P.S., et al., Involvement of the antioxidative property of morusin in blocking phorbol ester-induced malignant transformation of JB6 $P(+)$ mouse epidermal cells. Chem Biol Interact, 2017. 264: p. 34-42.

5. Hadi, S.M., et al., Putative mechanism for anticancer and apoptosis-inducing properties of plant-derived polyphenolic compounds. IUBMB Life, 2000. 50(3): p. 167-71.

6. Manson, J.E., et al., Antioxidants and cardiovascular disease: a review. J Am Coll Nutr, 1993. 12(4): p. 426-32.

7. Barron, D. and R.K. Ibrahim, Isoprenylated flavonoids-a survey. Phytochemistry, 1996. 43(5): p. 921-982.

8. Botta, B., et al., Prenylated flavonoids: pharmacology and biotechnology. Curr Med Chem, 2005. 12(6): p. 717-39.

9. Chen, X., et al., A systematic review on biological activities of prenylated flavonoids. Pharm Biol, 2014. 52(5): p. 655-60.

10. Brezani, V., et al., Anti-inflammatory Natural Prenylated Phenolic Compounds - Potential Lead Substances. Curr Med Chem, 2018. 25(10): p. 1094-1159.

11. Prausova, N. and P. Kollar, Prenylated phenols with cytotoxic and antiproliferative activity isolated from Morus alba. Ceska Slov Farm, 2019. 68(2): p. 48-68.

12. Marin, M. and S. Manez, Recent trends in the pharmacological activity of isoprenyl phenolics. Curr Med Chem, 2013. 20(2): p. 272-9.

13. Marcucci, M.C., et al., Phenolic compounds from Brazilian propolis with pharmacological activities. J Ethnopharmacol, 2001. 74(2): p. 105-12.

14. Lewandowska, U., J. Fichna, and S. Gorlach, Enhancement of anticancer potential of polyphenols by covalent modifications. Biochem Pharmacol, 2016. 109: p. 1-13.

15. Mahapatra, D.K., et al., Perspectives of medicinally privileged chalcone based metal coordination compounds for biomedical applications. Eur J Med Chem, 2019. 174: p. 142158.

16. Ercisli, S. and E. Orhan, Chemical composition of white (Morus alba), red (Morus rubra) and black (Morus nigra) mulberry fruits. Food Chem, 2007. 103: p. 1380-1384.

17. Fazaeli, M., G. Hojjatpanah, and Z. Emam-Djomeh, Effects of heating method and conditions on the evaporation rate and quality attributes of black mulberry (Morus nigra) juice concentrate. J Food Sci Technol, 2013. 50(1): p. 35-43.

18. Bircher, A. and W. Bircher, Encyclopedia of fruit trees and edible flowering plants in Egypt and the subtropics. . 2000, Cairo, Egypt American University in Cairo Press

19. Hanelt, P., R. Buttner, and R. Mansfeld, Mansfeld's Encyclopedia of Agricultural and Horticultural Crops (except Ornamentals). 2001, Berlin, Germany: Springer.

20. Orwa, C., et al., Agroforestree Database: a tree reference and selection guide version 4.0. . 2009, World Agroforestry Centre.

21. HUXLEY, A. and W. TAYLOR, Flowers of Greece and the Aegean. 1989, London: Hogarth Press.

22. Ciaraldi, M., People and Plants in Ancient Pompeii : a New Approach to Urbanism from the Microscope Room: the Use of Plant Resources at Pompeii and in the Pompeian Area from 
the 6th century $B C$ to $A D$ 79. . 2007, University of London: London: Accordia Research Institute.

23. Veen, M.V.d., The botanical evidence. In D. Peacock \& V. Maxfield (Eds.), Survey and Excavations at Mons Claudianus 1987-1993 ii. The Excavations: Part 1 2001, egypt: Cairo: Institute Francais d'Archaeologie Orientale du Caire.

24. Vivarelli, L. and S. Alvisi, An historical note on the mulberry species M. nigra and M. alba. . Altalia Agricola,, 1934. 71: p. 187-193.

25. Grieve, M., A modern herbal. Vol. 2. 1931, London: Jonathan Cape

26. Lev, E., Reconstructed materia medica of the Medieval and Ottoman al-Sham. Journal of ethnopharmacology, 2002. 80(2-3): p. 167-179.

27. Venkatesh, K. and S. Chauhan, Mulberry: Life enhancer. J Med Plants, 2008. 2: p. 271-278.

28. Dillard, C.J. and J.B. German, Phytochemicals: nutraceuticals and human health. 2000. 80(12): p. 1744-1756.

29. Leonti, M., et al., From cumulative cultural transmission to evidence-based medicine: evolution of medicinal plant knowledge in Southern Italy. Front Pharmacol, 2015. 6: p. 207.

30. Elder, P.t., Delphi complete work of Pliny the Elder (Illustrated), version 1. . (2015) Delphi Classics.

31. Lev, E. and E. Dolev, Use of natural substances in the treatment of renal stones and other urinary disorders in the medieval Levant. Am J Nephrol, 2002. 22(2-3): p. 172-9.

32. Warrier, P., V. Nambiar, and C. Ramankutty, ndian Medicinal Plants, A Compendium of 500 species. Vol. 4. 1995, Kottakal, India Orient Longman.

33. Khare, C., Indian medicinal plants, an illustrated dictionary. 2010, Berlin: Springer.

34. Ahmed, J., A. Farooqui, and T. Siddiqui, Morus nigra Hamdard Medicines, 1985. 15: p. 7678.

35. H, P., Handbook on Ayurvedic Medicines with Formulae, Processes \& Their Uses. Vol. 2. 2013, New delhi: National Institute of Industrial Research

36. China, P.C.o.P.R., Pharmacopoeia of People's Republic of China. . 2010, Beijing: Chemical Industry Publishers.

37. Naderi, G.A., et al., Antioxidant activity of three extracts of Morus nigra. Phytother Res, 2004. 18(5): p. 365-9.

38. Abd El-Mawla, A.M., K.M. Mohamed, and A.M. Mostafa, Induction of Biologically Active Flavonoids in Cell Cultures of Morus nigra and Testing their Hypoglycemic Efficacy. Sci Pharm, 2011. 79(4): p. 951-61.

39. Oryan, S., et al., Hypoglycaemic effect of alcoholic extract of Morus nigra L. leaves in normal and diabetic rats \%J Journal of Medicinal Plants. 2003. 2(6): p. 27-32.

40. Padilha, M.M., et al., Antiinflammatory properties of Morus nigra leaves. Phytother Res, 2010. 24(10): p. 1496-500.

41. Ziaei, S.A., et al., Inhibitory Effects of Germinal Angiotensin Converting Enzyme by Medicinal Plants Used in Iranian Traditional Medicine as Antihypertensive \%J Journal of Kerman University of Medical Sciences. 2009. 16(2): p. 134-143.

42. Ribeiro, R.V., et al., Ethnobotanical study of medicinal plants used by Ribeirinhos in the North Araguaia microregion, Mato Grosso, Brazil. J Ethnopharmacol, 2017. 205: p. 69-102.

43. Shoja, M.M., et al., Herbal diuretics in medieval Persian and Arabic medicine. J Altern Complement Med, 2015. 21(6): p. 309-20.

44. Mohiuddin, E., et al., Morus nigra-L.A. . J Med Plants Res 2011. 5(20): p. 5197-5199.

45. Tag, H.M. Hepatoprotective effect of mulberry (Morus nigra) leaves extract against methotrexate induced hepatotoxicity in male albino rat. BMC complementary and alternative medicine, 2015. 15, 252 DOI: 10.1186/s12906-015-0744-y. 
46. Akhlaq, A., et al., The Prokinetic, Laxative, and Antidiarrheal Effects of Morus nigra: Possible Muscarinic, $\mathrm{Ca}(2+)$ Channel Blocking, and Antimuscarinic Mechanisms. Phytother Res, 2016. 30(8): p. 1362-76.

47. Lim, T., Edible medicinal and non-medicinal plants, fruits. Vol. 3. 2012, Dordrecht: Springer.

48. Nomura, T., Phenolic compounds of the mulberry tree and related plants. Fortschr Chem Org Naturst, 1988. 53: p. 87-201.

49. Nomura, T. and Y. Hano, Isoprenoid-substituted phenolic compounds of moraceous plants. Natural Product Reports, 1994. 11(0): p. 205-218.

50. Arfan, M., et al., Antioxidant activity of mulberry fruit extracts. Int J Mol Sci, 2012. 13(2): p. 2472-80.

51. Ercisli, S., et al., Phytochemical Content of Some Black (Morus nigra L.) and Purple (Morus rubra L.) Mulberry Genotypes. Food Technol Biotechnol, 2009. 48(1): p. 102-106.

52. Wang, L., H.Q. Wang, and R.Y. Chen, [Studies on chemical constituents from bark of Morus nigra]. Zhongguo Zhong Yao Za Zhi, 2007. 32(23): p. 2497-9.

53. Jiang, Y. and W.J. Nie, Chemical properties in fruits of mulberry species from the Xinjiang province of China. Food Chem, 2015. 174: p. 460-6.

54. de Souza, M.M., et al., Antinociceptive properties of morusin, a prenylflavonoid isolated from Morus nigra root bark. Z Naturforsch C, 2000. 55(3-4): p. 256-60.

55. Ferrari, F., B. Monacelli, and I. Messana, Comparison Between in Vivo and in Vitro Metabolite Production of Morus nigra. Planta Med, 1999. 65(1): p. 85-7.

56. Simonetti, G., et al., Prenylated flavonoids and total extracts from Morus nigra L. root bark inhibit in vitro growth of plant pathogenic fungi. Plant Biosystems - An International Journal Dealing with all Aspects of Plant Biology, 2017. 151(5): p. 783-787.

57. Wang, L., et al., Three new compounds from the barks of Morus nigra. Journal of Asian Natural Products Research, 2008. 10(9): p. 897-902.

58. Wang, L., T. Gong, and R.Y. Chen, Two new prenylflavonoids from Morus nigra L. Chinese Chemical Letters, 2009. 20(12): p. 1469-1471.

59. Zelová, H., et al., Evaluation of Anti-Inflammatory Activity of Prenylated Substances Isolated from Morus alba and Morus nigra. Journal of Natural Products, 2014. 77(6): p. 1297-1303.

60. Zheng, Z.P., et al., Tyrosinase inhibitory constituents from the roots of Morus nigra: a structure-activity relationship study. J Agric Food Chem, 2010. 58(9): p. 5368-73.

61. Botta, B., et al., Prenylated Flavonoids: Pharmacology and Biotechnology. Current medicinal chemistry, 2005. 12: p. 717-39.

62. Chen, X., et al., A systematic review on biological activities of prenylated flavonoids. Pharmaceutical Biology, 2014. 52(5): p. 655-660.

63. Yang, Y., et al., The latest review on the polyphenols and their bioactivities of Chinese Morus plants. Journal of Asian Natural Products Research, 2014. 16(6): p. 690-702.

64. Nguyen, H.T., et al., Antitumor Psoropermum Xanthones and Sarcomelicope Acridones: Privileged Structures Implied in DNA Alkylation. Journal of Natural Products, 2009. 72(3): p. 527-539.

65. Fukai, T., K. Kaitou, and S. Terada, Antimicrobial activity of 2-arylbenzofurans from Morus species against methicillin-resistant Staphylococcus aureus. Fitoterapia, 2005. 76(7-8): p. 708-11.

66. Kone, W.M., et al., Traditional medicine in north Cote-d'Ivoire: screening of 50 medicinal plants for antibacterial activity. J Ethnopharmacol, 2004. 93(1): p. 43-9.

67. Pandey, K.B. and S.I. Rizvi, Plant polyphenols as dietary antioxidants in human health and disease. Oxid Med Cell Longev, 2009. 2(5): p. 270-8. 
68. Pérez-Gregorio, M.R., et al., Influence of alcoholic fermentation process on antioxidant activity and phenolic levels from mulberries (Morus nigra L.). LWT - Food Science and Technology, 2011. 44(8): p. 1793-1801.

69. Imran, M., et al., Chemical composition and antioxidant activity of certain Morus species. J Zhejiang Univ Sci B, 2010. 11(12): p. 973-80.

70. Radojkovic, M., et al., Biological activities and chemical composition of Morus leaves extracts obtained by maceration and supercritical fluid extraction. Journal of Supercritical Fluids, 2016. 117: p. 50-58.

71. Ko, H.-H., et al., Chemistry and biological activities of constituents from Morus australis. Biochimica et Biophysica Acta (BBA) - General Subjects, 1999. 1428(2): p. 293-299.

72. Sharma, R., et al., Mulberry moracins: scavengers of UV stress-generated free radicals. Biosci Biotechnol Biochem, 2001. 65(6): p. 1402-5.

73. Tan, Y.-X., C. Liu, and R.-Y. Chen, [2-Arylbenzofuran derivatives from Morus wittiorum]. Yao xue xue bao = Acta pharmaceutica Sinica, 2008. 43(11): p. 1119-1122.

74. Oh, H., et al., Hepatoprotective and free radical scavenging activities of prenylflavonoids, coumarin, and stilbene from Morus alba. Planta Med, 2002. 68(10): p. 932-4.

75. Cui, L., et al., Protein tyrosine phosphatase $1 B$ inhibitors from Morus root bark. Bioorg Med Chem Lett, 2006. 16(5): p. 1426-9.

76. Fu, W., et al., A new alkylene dihydrofuran glycoside with antioxidation activity from the root bark of Morus alba L. Chinese Chemical Letters, 2010. 21(7): p. 821-823.

77. Mazimba, O., et al., Antioxidant and antibacterial constituents from Morus nigra. . Afr J Pharm Pharmacol 2011. 5(6): p. 751-754.

78. Feng, R.Z., et al., Extraction and antioxidant activity of flavonoids of Morus nigra. Int J Clin Exp Med, 2015. 8(12): p. 22328-36.

79. Volpato, G.T., et al., Effect of Morus nigra aqueous extract treatment on the maternalfetal outcome, oxidative stress status and lipid profile of streptozotocin-induced diabetic rats. J Ethnopharmacol, 2011. 138(3): p. 691-6.

80. Heo, S.I., et al., Antidiabetic properties of 2,5-dihydroxy-4,3'-di(beta-D-glucopyranosyloxy)trans-stilbene from mulberry (Morus bombycis koidzumi) root in streptozotocin-induced diabetic rats. J Med Food, 2007. 10(4): p. 602-7.

81. Jin, Y.S., et al., Antioxidant effects and hepatoprotective activity of 2,5-dihydroxy-4,3'di(beta-d-glucopyranosyloxy)-trans-stilbene from Morus bombycis Koidzumi roots on CCl4induced liver damage. Free Radic Res, 2006. 40(9): p. 986-92.

82. Jin, Y.-S., et al., Identification and properties of 2,5-Dihydroxy-4,3'-di(6-dglucopyranosyloxy)-trans-stilbene from Morus bombycis Koidzumi roots. 2007. 21(7): p. 605-608.

83. Wang, L., et al., Three new compounds from Morus nigra L. Journal of Asian Natural Products Research, 2010. 12(6): p. 431-437.

84. Kimura, Y., et al., Effects of Phenolic Constituents from the Mulberry Tree on Arachidonate Metabolism in Rat Platelets. Journal of Natural Products, 1986. 49(4): p. 639-644.

85. Kimura, Y., et al., Effects of Flavonoids and Related Compounds from Mulberry Tree on Arachidonate Metabolism in Rat Platelet Homogenates. CHEMICAL \& PHARMACEUTICAL BULLETIN, 1986. 34(3): p. 1223-1227.

86. Chi, Y.S., et al., Effects of naturally occurring prenylated flavonoids on enzymes metabolizing arachidonic acid: Cyclooxygenases and lipoxygenases11Abbreviations: $A A$, arachidonic acid; COX, cyclooxygenase; LOX, lipoxygenase; PG, prostaglandin; $T X$, thromboxane; HETE, hydroxyeicosatetraenoic acid; NDGA, nordihydroguaiaretic acid; MTT, 3-(4,5-dimethylthiazol-2-yl)-2,5-diphenyltetrazolium bromide; LPS, lipopolysaccharide; DMEM, Dulbecco's modified Eagle's medium; FBS, fetal bovine serum; 
and PMN, polymorphonuclear leukocyte. Biochemical Pharmacology, 2001. 62(9): p. 11851191.

87. Rollinger, J.M., et al., Venturia inaequalis-Inhibiting Diels-Alder Adducts from Morus Root Bark. Journal of Agricultural and Food Chemistry, 2006. 54(22): p. 8432-8436.

88. Chung, K.O., et al., In-vitro and in-vivo anti-inflammatory effect of oxyresveratrol from Morus alba L. J Pharm Pharmacol, 2003. 55(12): p. 1695-700.

89. Qin, J., et al., New cytotoxic and anti-inflammatory compounds isolated from Morus alba L. Natural Product Research, 2015. 29(18): p. 1711-1718.

90. Yang, Z.-G., et al., Inhibitory Effects of Constituents from Morus alba var. multicaulis on Differentiation of 3T3-L1 Cells and Nitric Oxide Production in RAW264.7 Cells. 2011. 16(7): p. 6010.

91. Phung, T.X.B., et al., Chalcone-derived Diels-Alder adducts as NF-KB inhibitors from Morus alba. Journal of Asian Natural Products Research, 2012. 14(6): p. 596-600.

92. Hošek, J., et al., Natural Compound Cudraflavone B Shows Promising Anti-inflammatory Properties in Vitro. Journal of Natural Products, 2011. 74(4): p. 614-619.

93. Kollar, P., et al., Prenylated Flavonoids from Morus alba L. Cause Inhibition of G1/S Transition in THP-1 Human Leukemia Cells and Prevent the Lipopolysaccharide-Induced Inflammatory Response. Evid Based Complement Alternat Med, 2013. 2013: p. 350519.

94. Lim, H.J., et al., The root barks of Morus alba and the flavonoid constituents inhibit airway inflammation. Journal of Ethnopharmacology, 2013. 149(1): p. 169-175.

95. Ahangarpour, A., et al., Effects of Morus Nigra Leaves Extract on Insulin Secretion from Isolated Islets of Langerhans in Male Mouse. Indian J Physiol Pharmacol 2016. 60(4): p. 386-391.

96. \#xfa, et al., Brazilian Morus nigra Attenuated Hyperglycemia, Dyslipidemia, and Prooxidant Status in Alloxan-Induced Diabetic Rats \%J The Scientific World Journal. 2017. 2017: p. 10.

97. Hassanalilou, T., et al., The protective effects of Morus nigra L. leaves on the kidney function tests and histological structures in streptozotocin-induced diabetic rats. Biomedical Research (0970-938X), 2017. 28(14): p. 6113-6118.

98. Hoang, D.M., et al., Protein tyrosine phosphatase $1 B$ inhibitors isolated from Morus bombycis. Bioorg Med Chem Lett, 2009. 19(23): p. 6759-61.

99. Jo, S.-P., J.-K. Kim, and Y.-H. Lim, Antihyperlipidemic effects of stilbenoids isolated from Morus alba in rats fed a high-cholesterol diet. Food and Chemical Toxicology, 2014. 65: p. 213-218.

100. Turan, I., et al., Antiproliferative and apoptotic effect of Morus nigra extract on human prostate cancer cells. Saudi Pharm J, 2017. 25(2): p. 241-248.

101. Qadir, M.I., M. Ali, and Z. Ibrahim, Anticancer activity of Morus nigra leaves extract. 2014, 2014. 9(4): p. 2 \%J Bangladesh Journal of Pharmacology.

102. Kim, C., et al., Blockage of STAT3 Signaling Pathway by Morusin Induces Apoptosis and Inhibits Invasion in Human Pancreatic Tumor Cells. Pancreas, 2016. 45(3): p. 409-19.

103. Lee, J.C., et al., Morusin induces apoptosis and suppresses NF-kappaB activity in human colorectal cancer HT-29 cells. Biochem Biophys Res Commun, 2008. 372(1): p. 236-42.

104. Wang, C.P., et al., Mulberroside A protects against ischemic impairment in primary culture of rat cortical neurons after oxygen-glucose deprivation followed by reperfusion. J Neurosci Res, 2014. 92(7): p. 944-54.

105. Lin, W.L., et al., Antitumor progression potential of morusin suppressing STAT3 and NFkappaB in human hepatoma SK-Hep1 cells. Toxicol Lett, 2015. 232(2): p. 490-8.

106. Kang, S., et al., Morusin induces apoptosis by regulating expression of Bax and Survivin in human breast cancer cells. Oncol Lett, 2017. 13(6): p. 4558-4562. 
107. Cho, S.W., et al., Autophagy inhibits cell death induced by the anti-cancer drug morusin. Am J Cancer Res, 2017. 7(3): p. 518-530.

108. Wan, L.-Z., B. Ma, and Y.-Q. Zhang, Preparation of morusin from Ramulus mori and its effects on mice with transplanted H22 hepatocarcinoma. BioFactors (Oxford, England), 2014. 40(6): p. 636-645.

109. Gao, L., et al., Morusin shows potent antitumor activity for human hepatocellular carcinoma in vitro and in vivo through apoptosis induction and angiogenesis inhibition. Drug Des Devel Ther, 2017. 11: p. 1789-1802.

110. Li, H., et al., Morusin suppresses breast cancer cell growth in vitro and in vivo through C/EBPbeta and PPARgamma mediated lipoapoptosis. J Exp Clin Cancer Res, 2015. 34: p. 137.

111. Wang, F., et al., Morusin inhibits cell proliferation and tumor growth by down-regulating cMyc in human gastric cancer. Oncotarget, 2017. 8(34): p. 57187-57200.

112. Wicha, M.S., S. Liu, and G. Dontu, Cancer stem cells: an old idea--a paradigm shift. Cancer Res, 2006. 66(4): p. 1883-90; discussion 1895-6.

113. Wang, L., et al., Morusin inhibits human cervical cancer stem cell growth and migration through attenuation of NF-kappaB activity and apoptosis induction. Mol Cell Biochem, 2013. 379(1-2): p. 7-18.

114. Guo, H., et al., Morusin inhibits glioblastoma stem cell growth in vitro and in vivo through stemness attenuation, adipocyte transdifferentiation, and apoptosis induction. Mol Carcinog, 2016. 55(1): p. 77-89.

115. Mihara, S., et al., Non-peptide bombesin receptor antagonists, kuwanon $G$ and $H$, isolated from mulberry. Biochemical and Biophysical Research Communications, 1995. 213(2): p. 594-599.

116. Hu, C., et al., Inhibition of protein kinase $C$ by stilbene derivatives from Monus alba $L$. Natural Product Research and Development, 1996. 8(2): p. 13-16.

117. Huang, $\mathrm{H}$., et al., Sanggenon $\mathrm{C}$ decreases tumor cell viability associated with proteasome inhibition. Front Biosci (Elite Ed), 2011. 3: p. 1315-25.

118. Dat, N.T., et al., Cytotoxic prenylated flavonoids from Morus alba. Fitoterapia, 2010. 81(8): p. 1224-1227.

119. Kikuchi, T., et al., Albanol A from the root bark of Morus alba L. induces apoptotic cell death in HL60 human leukemia cell line. Chem Pharm Bull (Tokyo), 2010. 58(4): p. 568-71.

120. Lin, C.N., et al., Antiplatelet activity of some prenylflavonoids. Biochem Pharmacol, 1993. 45(2): p. 509-12.

121. Ko, H.-H., et al., Bioactive Constituents of Morus australis and Broussonetia papyrifera. Journal of Natural Products, 1997. 60(10): p. 1008-1011.

122. Li, Y., et al., Down-regulation of P-gp expression and function after Mulberroside $A$ treatment: Potential role of protein kinase $C$ and NF-kappa B. Chemico-Biological Interactions, 2014. 213: p. 44-50.

123. Kim, H.J., et al., HPLC-based Activity Profiling - Discovery of Sanggenons as GABAA Receptor Modulators in the Traditional Chinese Drug Sang bai pi (Morus alba Root Bark). Planta Med, 2012. 78(05): p. 440-447.

124. Kim, H.J., et al., Cortex Mori Radicis extract exerts antiasthmatic effects via enhancement of CD4(+)CD25(+)Foxp3(+) regulatory $T$ cells and inhibition of Th2 cytokines in a mouse asthma model. J Ethnopharmacol, 2011. 138(1): p. 40-6.

125. Chen, H.-D., et al., Morusalbanol A, a neuro-protective Diels-Alder adduct with an unprecedented architecture from Morus alba. Tetrahedron, 2012. 68(30): p. 6054-6058.

126. Jung, J.-W., et al., Isoprenylated flavonoids from the root bark of Morus alba and their hepatoprotective and neuroprotective activities. 2015. 38(11): p. 2066-2075.

127. Lee, N.K., et al., Prenylated flavonoids as tyrosinase inhibitors. 2004. 27(11): p. 1132-1135. 
128. Kim, J.-K., et al., Evaluation of the inhibition of mushroom tyrosinase and cellular tyrosinase activities of oxyresveratrol: comparison with mulberroside A. Journal of Enzyme Inhibition and Medicinal Chemistry, 2012. 27(4): p. 495-503.

129. Kim, J.-K., et al., Biotransformation of mulberroside $A$ from Morus alba results in enhancement of tyrosinase inhibition. Journal of industrial microbiology \& biotechnology, 2010. 37(6): p. 631-637.

130. Zheng, Z.-P., H.-Y. Tan, and M. Wang, Tyrosinase inhibition constituents from the roots of Morus australis. Fitoterapia, 2012. 83(6): p. 1008-1013.

131. Lee, Y.-j., et al., The First Total Synthesis Of Morusin And Himanimide D As Arachidonate 5lipoxygenase Inhibitor In Automated Docking. Biophysical Journal - BIOPHYS J, 2009. 96.

132. Nomura, T., Fukai, T, and Matsumoto J, , Oxidative cyclization of Morusin (1,2). J Heterocyclic Chem, 1980. 17: p. 641

133. Nomura, T., et al., Photo-oxidative Cyclization of Morusin. 1977. 25: p. 1155-1156.

134. Guo, Y.Q., et al., Prenylated flavonoids as potent phosphodiesterase-4 inhibitors from Morus alba: Isolation, modification, and structure-activity relationship study. Eur J Med Chem, 2018. 144: p. 758-766.

135. Kaur, A. and A. Ariafard, Mechanistic investigation into phenol oxidation by IBX elucidated by DFT calculations. 2020. 18(6): p. 1117-1129.

136. Awouafack, M.D., et al., Eriosema (Fabaceae) Species Represent a Rich Source of Flavonoids with Interesting Pharmacological Activities. Natural product communications, 2015. 10: p. 1325-1330.

137. Mahato, N., et al., Modern Extraction and Purification Techniques for Obtaining High Purity Food-Grade Bioactive Compounds and Value-Added Co-Products from Citrus Wastes. Foods, 2019. 8(11).

138. Mosic, M., et al., Extraction as a Critical Step in Phytochemical Analysis. J AOAC Int, 2019.

139. Ahmad Dar, A., P.L. Sangwan, and A. Kumar, Chromatography: An important tool for drug discovery. J Sep Sci, 2020. 43(1): p. 105-119.

140. Wang, Z., et al., Review of Distribution, Extraction Methods, and Health Benefits of Bound Phenolics in Food Plants. 2020. 68(11): p. 3330-3343.

141. Hunyadi, A., et al., Preparative-Scale Chromatography of Ecdysteroids of Serratula wolffii Andrae. Journal of Chromatographic Science, 2007. 45(2): p. 76-86.

142. Poulios, E., C. Giaginis, and G.K. Vasios, Current Advances on the Extraction and Identification of Bioactive Components of Sage (Salvia spp.). Curr Pharm Biotechnol, 2019. 20(10): p. 845-857.

143. Pretsch, E., et al., Computer-aided structure elucidation: spectra interpretation and structure generation. 2002, Weinheim, Germany: Wiley-VCH. 279.

144. Duddeck, H., W. Dietrich, and G.b. Tóth, Structure elucidation by modern NMR : a workbook. 3rd, rev. and updated ed. 1998, Darmstadt Heidelberg: Steinkopff Verlag ; Springer. $211 \mathrm{p}$.

145. Warren, G.B., et al., Reconstitution of a calcium pump using defined membrane components. Proc Natl Acad Sci U S A, 1974. 71(3): p. 622-6.

146. Vilar, S., G. Cozza, and S. Moro, Medicinal Chemistry and the Molecular Operating Environment (MOE): Application of QSAR and Molecular Docking to Drug Discovery. Current topics in medicinal chemistry, 2008. 8: p. 1555-72.

147. Krieger, E. and G. Vriend, YASARA View-molecular graphics for all devices-from smartphones to workstations. Bioinformatics (Oxford, England), 2014. 30.

148. Stefkó, D., et al., Phenanthrenes from Juncus atratus with antiproliferative activity. Tetrahedron, 2019. 75(1): p. 116-120. 
149. Szabó, J., et al., Synthesis and in Vitro Antiproliferative Evaluation of C-13 Epimers of

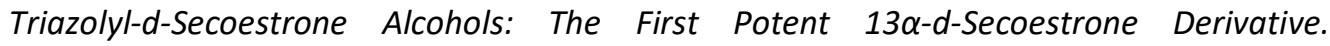
Molecules, 2016. 21: p. 611.

150. Nomura, T., et al., Phenolic Constituents of the Cultivated Mulberry Tree (Morus alba L.). CHEMICAL \& PHARMACEUTICAL BULLETIN, 1976. 24(11): p. 2898-2900.

151. L.F. Alves, A.C., M.J. Milewska, Nomura T Fortschritte der chemie organischer naturstoffe/ progress in the chemistry of organic natural products. . Phenolic compounds of the mulberry tree and related plants. Vol. 53. 1988, New york Springer-verlag.

152. Nomura, T. and T. Fukai, Constituents of the cultivated mulberry tree. Planta Med, 1981. 42(1): p. 79-88.

153. Structures of two natural hypotensive diels alder type adducts mulberrofurans $f$ and $g$ from the cultivated mulberry tree morus Ihou. Chemical \& Pharmaceutical Bulletin, 1985. 33(8): p. 3195-3204.

154. Duangdee, N., et al., Quantitative 1HNMR spectroscopy for the determination of oxyresveratrol in Artocarpus lacucha heartwood. Phytochemical Analysis, 2019. 30(6): p. 617-622.

155. Nomura, T., T. Fukai, and M. Katayanagi, Kuwanon A, B, C and oxydihydromorusin, four new flavones from the root bark of the cultivated mulberry tree (Morus alba L.). CHEMICAL \& PHARMACEUTICAL BULLETIN, 1977. 25: p. 529-532.

156. Nomura, T., et al., Constituents of the Cultivated Mulberry Tree. Planta Med, 1982. 46(09): p. 28-32.

157. 門田, 重., et al., Two New 2-Arylbenzofuran Derivatives from Hypoglycemic ActivityBearing Fractions of Morus insignis. CHEMICAL \& PHARMACEUTICAL BULLETIN, 1993. 41(7): p. 1238-1243.

158. Oke-Altuntas, F., et al., Bioactivity evaluation of cudraxanthone I, neocyclomorusin and (98h)-36-acetoxylanosta-7,24-diene isolated from Milicia excelsa Welw. C. C. Berg (Moraceae). Medicinal Chemistry Research, 2016. 25.

159. Mitsuo, T., et al., CHALCOMORACIN, A NATURAL DIELS-ALDER ADDUCT FROM DISEASED MULBERRY. Chemistry Letters, 1980. 9(12): p. 1573-1576.

160. Zoofishan, Z., J. Hohmann, and A. Hunyadi, Phenolic antioxidants of Morus nigra roots, and antitumor potential of morusin. Phytochemistry Reviews, 2018.

161. Hunyadi, A., et al., Preparative-scale chromatography of ecdysteroids of Serratula wolffli andrae. J Chromatogr Sci, 2007. 45(2): p. 76-86.

162. Routray, W. and V. Orsat, Preparative Extraction and Separation of Phenolic Compounds, in Natural Products: Phytochemistry, Botany and Metabolism of Alkaloids, Phenolics and Terpenes, K.G. Ramawat and J.-M. Mérillon, Editors. 2013, Springer Berlin Heidelberg: Berlin, Heidelberg. p. 2013-2045.

163. Gao, M., et al., Separation of polyphenols using porous polyamide resin and assessment of mechanism of retention. Journal of Separation Science, 2011. 34(15): p. 1853-1858.

164. Zhang, Q.-W., L.-G. Lin, and W.-C. Ye Techniques for extraction and isolation of natural products: a comprehensive review. Chinese medicine, 2018. 13, 20 DOI: 10.1186/s13020018-0177-x.

165. Sticher, O., Natural product isolation. Natural Product Reports, 2008. 25(3): p. 517-554.

166. Bucar, F., A. Wube, and M. Schmid, Natural product isolation - how to get from biological material to pure compounds. Natural Product Reports, 2013. 30(4): p. 525-545.

167. Atapattu, S.N., C.F. Poole, and M.B. Praseuth, Insights into the Retention Mechanism for Small Neutral Compounds on Silica-Based Phenyl Phases in Reversed-Phase Liquid Chromatography. Chromatographia, 2018. 81(2): p. 225-238.

168. Marchand, D.H., et al., Column selectivity in reversed-phase liquid chromatography. VIII. Phenylalkyl and fluoro-substituted columns. J Chromatogr A, 2005. 1062(1): p. 65-78. 
169. Yang, M., et al., Impact of methanol and acetonitrile on separations based on $\pi-\pi$ interactions with a reversed-phase phenyl column. Journal of Chromatography A, 2005. 1097(1): p. 124-129.

170. Minegishi, S., S. Kobayashi, and H. Mayr, Solvent Nucleophilicity. Journal of the American Chemical Society, 2004. 126(16): p. 5174-5181.

171. Kita, Y. and T. Dohi, Pioneering Metal-Free Oxidative Coupling Strategy of Aromatic Compounds Using Hypervalent lodine Reagents. The Chemical Record, 2015. 15(5): p. 886906.

172. Kim, J.Y., et al., Isolation of cholinesterase-inhibiting flavonoids from Morus Ihou. J Agric Food Chem, 2011. 59(9): p. 4589-96.

173. Freifelder, M., FACTORS IN HYDROGENATION. Annals of the New York Academy of Sciences, 1967. 145(1): p. 5-18.

174. Awouafack, M.D., et al., Eriosema (Fabaceae) species represent a rich source of flavonoids with interesting pharmacological activities. Natural product communications, 2015. 10(7): p. $1934578 \times 1501000749$.

175. Nomura, T., Y. Hano, and T. Fukai, Chemistry and biosynthesis of isoprenylated flavonoids from Japanese mulberry tree. Proc Jpn Acad Ser B Phys Biol Sci, 2009. 85(9): p. 391-408.

176. Pennock, J.F., [35] Biosynthesis of plastoquinone, in Methods in Enzymology. 1985, Academic Press. p. 313-319.

177. Welle, R. and H. Grisebach, Induction of phytoalexin synthesis in soybean: enzymatic cyclization of prenylated pterocarpans to glyceollin isomers. Arch Biochem Biophys, 1988. 263(1): p. 191-8.

178. Lim, Y.-H., K.-H. Kim, and J.-K. Kim, Source, Biosynthesis, Biological Activities and Pharmacokinetics of Oxyresveratrol. Korean Journal of Food Science and Technology, 2015. 47: p. 545-555.

179. Kapche, G.D.W.F., et al., Prenylated arylbenzofuran derivatives from Morus mesozygia with antioxidant activity. Phytochemistry, 2009. 70(2): p. 216-221.

180. Lee, H.J., et al., Inhibitory effect of 2-arylbenzofurans from the Mori Cortex Radicis (Moraceae) on oxygen glucose deprivation (OGD)-induced cell death of SH-SY5Y cells. Arch Pharm Res, 2011. 34(8): p. 1373-80.

181. Hirakura, K., et al., Two Phenolic Glycosides from the Root Bark of the Cultivated Mulberry Tree (Morus Ihou). Journal of Natural Products, 1986. 49(2): p. 218-224.

182. Wang, Y.-N., et al., Bioactive Benzofuran Derivatives from Cortex Mori Radicis, and Their Neuroprotective and Analgesic Activities Mediated by $m G l u R_{1}$. Molecules (Basel, Switzerland), 2017. 22(2): p. 236.

183. Zheng, X.K., et al., Phenolic constituents from the root bark of Morus alba L. and their cardioprotective activity in vitro. Phytochemistry, 2017. 135: p. 128-134.

184. Dong, X., et al., Synthesis, biological evaluation of prenylflavonoids as vasorelaxant and neuroprotective agents. Bioorg Med Chem Lett, 2009. 19(12): p. 3196-8.

185. Kim, C.Y., et al., Vasorelaxant prenylated flavonoids from the roots of Sophora flavescens. Biosci Biotechnol Biochem, 2013. 77(2): p. 395-7.

186. Hejazian, S.H., S.M. Bagheri, and M.H. Dashti-R, Relaxant effect of Humulus lupulus extracts on isotonic rat's ileum contractions. Avicenna journal of phytomedicine, 2014. 4(1): p. 53-58.

187. Peery, A.F., et al., Burden of Gastrointestinal, Liver, and Pancreatic Diseases in the United States. Gastroenterology, 2015. 149(7): p. 1731-1741.e3.

188. Kuenzig, M.E., et al., Co-occurrence of Asthma and the Inflammatory Bowel Diseases: $A$ Systematic Review and Meta-analysis. Clinical and translational gastroenterology, 2018. 9(9): p. 188-188. 
189. Ogunbayo, O.A., et al., Inhibition of the sarcoplasmic/endoplasmic reticulum Ca2+-ATPase by flavonoids: a quantitative structure-activity relationship study. IUBMB Life, 2008. 60(12): p. 853-8.

190. Elam, C., et al., Discovery of novel SERCA inhibitors by virtual screening of a large compound library. European journal of medicinal chemistry, 2011. 46(5): p. 1512-1523.

191. Chemaly, E.R., L. Troncone, and D. Lebeche, SERCA control of cell death and survival. Cell calcium, 2018. 69: p. 46-61.

192. Park, K.C., et al., Survival of Cancer Stem-Like Cells Under Metabolic Stress via CaMK2 $\alpha$ mediated Upregulation of Sarco/Endoplasmic Reticulum Calcium ATPase Expression. Clin Cancer Res, 2018. 24(7): p. 1677-1690.

193. Lytton, J., et al., Functional comparisons between isoforms of the sarcoplasmic or endoplasmic reticulum family of calcium pumps. Journal of Biological Chemistry, 1992. 267(20): p. 14483-14489.

194. Kono, T., et al., PPAR-gamma activation restores pancreatic islet SERCA2 levels and prevents beta-cell dysfunction under conditions of hyperglycemic and cytokine stress. Mol Endocrinol, 2012. 26(2): p. 257-71.

195. Lim, S.L., et al., Morusin induces cell death through inactivating STAT3 signaling in prostate cancer cells. Am J Cancer Res, 2015. 5(1): p. 289-99.

196. Tong, X., et al., SERCA2 Deficiency Impairs Pancreatic beta-Cell Function in Response to Diet-Induced Obesity. Diabetes, 2016. 65(10): p. 3039-52.

197. Callaghan, R., F. Luk, and M. Bebawy, Inhibition of the multidrug resistance P-glycoprotein: time for a change of strategy? Drug metabolism and disposition: the biological fate of chemicals, 2014. 42(4): p. 623-631.

198. Nanayakkara, A.K., et al., Targeted inhibitors of P-glycoprotein increase chemotherapeuticinduced mortality of multidrug resistant tumor cells. Scientific Reports, 2018. 8(1): p. 967.

199. Di Pietro, A., et al., Modulation by flavonoids of cell multidrug resistance mediated by $P$ glycoprotein and related ABC transporters. Cell Mol Life Sci, 2002. 59(2): p. 307-22.

200. Jiahua, C., L. Xiaoyang, and M.C.C. Larry, Flavonoids as P-gp Inhibitors: A Systematic Review of SARs. Current Medicinal Chemistry, 2019. 26(25): p. 4799-4831.

201. Shi, X., et al., Identification of the Metabolic Enzyme Involved Morusin Metabolism and Characterization of Its Metabolites by Ultraperformance Liquid Chromatography Quadrupole Time-of-Flight Mass Spectrometry (UPLC/Q-TOF-MS/MS). Evidence-Based Complementary and Alternative Medicine, 2016. 2016: p. 9240103.

202. van Eijk, M., et al., Cytochrome P450 3A4, 3A5, and 2C8 expression in breast, prostate, lung, endometrial, and ovarian tumors: relevance for resistance to taxanes. Cancer Chemotherapy and Pharmacology, 2019. 84(3): p. 487-499. 


\section{ACKNOWLEDGEMENTS}

I would like to express my sincere gratitude to my advisor Dr. Attila Hunyadi, for the continuous support of my Ph.D. study with his invaluable professional knowledge. I am deeply indebted for his guidance and encouragement.

I am very grateful to Prof. Dr. Judit Hohmann, Head of the department of pharmacognosy, for the support of my work and the possibility to study in her department.

I am also grateful to Dr. Norbert Kúsz, and Prof. Dr. Gábor Tóth, for the NMR investigations and for their invaluable help in the structure elucidation. I am thankful to $D r$. Kornél Szőri for his help during chemistry experiments. I owe special thanks to Ibolya Hevérné Herke for her selfless help during my research work. Her laboratory work knowledge and suggestions helped me essentially during my Ph.D. work.

I owe special thanks to Dr. Róbert Gáspár. Dr. Lubica Horakova, Dr. István Zupkó, and $D r$. Gabriella Spengler for supervising the pharmacological studies.

My special appreciation to my co-authors and collaborators Vladimir Heger (SERCA studies), Judit Hajagos-Tóth and Anna Kothencz (antispasmodic assays), and Ahmed D. Latif and Márta Nové (in vitro antitumor assays) for performing the pharmacological experiments. Without them, it would not have been possible to conduct this research.

My thanks are likewise due to all my colleagues in the Department of Pharmacognosy for providing the most wonderful and supportive atmosphere. I thank my fellow labmates for all the help they gave.

I would like to extend my special thanks to my family and friends. I could not have carried out this work without their support and love.

Financial support to this work was provided by the National Research, Development and Innovation Office, Hungary (NKFIH; K119770), and by the EU-funded Hungarian grant EFOP-3.6.1-16-2016-00008. 
